\title{
COMMON INTEREST TRAGEDIES
}

\section{Lee Anne Fennell*}

\section{INTRODUCTION}

No one working in property theory can ignore the anticommons. This upstart doppelgänger of the commons began its intellectual life as an imaginary regime in which everyone had the power to prevent everyone else from using a particular resource. ${ }^{1}$ Michael Heller's subsequent construction of a recognizable category of "anticommons property" corresponding to situations in lived experience ${ }^{2}$ represented an important advance in the property lexicon that sparked a surge of scholarly interest. ${ }^{3}$ Over a half-dozen years, ${ }^{4}$ the term "anticommons" has moved from near-

* Assistant Professor, University of Texas School of Law; Associate Professor, University of Illinois College of Law (beginning fall 2004). I would like to thank Richard Briffault, Daniel Cole, Reza Dibadj, Cynthia Estlund, Christopher Fennell, Eric Freyfogle, Mark Gergen, Victor Goldberg, Jeffrey Gordon, Michael Heller, Harold Hochman, Douglas Laycock, Lydia Loren, Geoffrey Manne, Thomas Merrill, Edward Morrison, Jonathan Nash, Catherine Sharkey, and Jay Weiser for helpful comments and conversation on earlier drafts, the participants in colloquia at Columbia Law School and Lewis \& Clark Law School for insightful ideas and questions, and Rebecca Heinemann for valuable research assistance. All errors are mine.

1 The notion of an anticommons originated in Frank I. Michelman, Ethics, Economics and the Law of Property, in Nomos XXIV: ETHICs, Economics AND THE LAW 3, 6, 9 (1982); see Robert C. Ellickson, Property in Land, 102 YALE L.J. 1315, 1322 n.22 (1993) (describing the anticommons problem and attributing the roots of the idea to a hypothetical regulatory regime developed in Michelman, supra).

2 Michael Heller, The Tragedy of the Anticommons: Property in the Transition from Marx to Markets, 111 HARV. L. REV. 621 (1998). Heller's principal example involved empty storefronts in Moscow, which he posited were the result of a regime in which multiple permissions to use the resource had to be assembled from various parties.

3 E.g., Abraham Bell \& Gideon Parchomovsky, Of Property and Anti-Property, 102 Mich. L. REV. (forthcoming); James M. Buchanan \& Yong J. Yoon, Symmetric Tragedies: Commons and Anticommons, 43 J.L. \& ECON. 1 (2000); Reza Dibadj, Regulatory Givings and the Anticommons, 64 OHIO ST. L.J. 1041 (2003); Michael A. Heller \& Rebecca S. Eisenberg, Can Patents Deter Innovation? The Anticommons in Biomedical Research, 280 SCIENCE 698 (1998); Shi-Ling Hsu, A Two-Dimensional Framework for Analyzing Property Rights Regimes, 36 U.C. DAVIS L. REV. 813 (2003); Dan Hunter, Cyberspace as Place, and the Tragedy of the Digital Anticommons, 91 CAL. L. REV. 439, 509-14 (2003); Francesco Parisi et al., Duality in Property: Commons and Anticommons, INT'L REV. L. \& ECON. (forthcoming), available at http://ssrn.com/abstract=224844 [hereinafter Parisi et al., Duality]; Francesco Parisi et al., Simultaneous and Sequential Anticommons, 17 EUR. J.L. \& ECON. 175 (2004).

${ }^{4}$ Heller's reformulation of the anticommons, Heller, supra note 2, was cited in draft and forthcoming form before it was published; hence, the impact of the article predated its publication somewhat. E.g., JeSSE DUKEMINIER \& JAMES E. KRIER, PROPERTY 56-57 (4th ed. 1998); Mark A. Lemley, The Economics of Improvement in Intellectual Property Law, 75 TEX. L. REV. 989, 1063 n.332 (1997). 
obscurity to general use; ${ }^{5}$ it now flows easily from the lips and pens of nearly every property teacher and scholar in the land. ${ }^{6}$

The recent concentration of attention on the anticommons has been constructive and revitalizing. Resources under common or interdependent control-from fisheries and grazing lands to metropolitan spatial configurations and scientific knowledge - present a daunting array of problems that profoundly affect large populations. ${ }^{7}$ While a rich body of literature on the commons has evolved in response to these concerns, ${ }^{8}$ the anticommons notion provides a fresh and critical perspective on this set of issues. Already, it has yielded important insights into a number of discrete, applied problems associated with multi-player resource dilemmas. ${ }^{9}$ The anticommons idea

${ }^{5}$ See Carol M. Rose, Left Brain, Right Brain, and History in the New Law and Economics of Property, 79 OR. L. REV. 479, 480 n.2 (2000) (noting the rapid and widespread acceptance and use of the term "anticommons" in the wake of Heller's article). Rose found sixty-six law review articles (not counting Heller's original article) using the word "anticommons" in the LEXIS database since the publication of Heller's 1998 article; now the count exceeds 300 (Mar. 30, 2004 search, LEXIS database of U.S. and Canadian Law Reviews, combined).

${ }^{6}$ A discussion of the anticommons in the first chapter of the best-selling property casebook in the country has not only ensured the transmission of the concept to the next generation of law students, but has also assisted the spread of the idea among teachers of property law. See DUKEMINIER \& KRIER, supra note 4, at 56-57; JESSE DUKEMINIER \& JAMES E. KRIER, PROPERTY 56-57 (5th ed. 2002) [hereinafter DUKEMINIER \& KRIER 5TH]; see also Peter T. Wendel, The Perfect Blend of Methodology, Doctrine, and Theory, 22 SeattLe U. L. ReV. 1031, 1031 n.1 (1999) (identifying the 4th edition of Dukeminier \& Krier's Property as "the most widely adopted property casebook" and listing about 120 law schools at which it had been adopted by at least one professor).

7 See, e.g., Elinor Ostrom, Governing the COMmons: THE EvOlution of InSTITUTions for Collective ACtion 3 (1990) (observing that "[m]uch of the world is dependent on resources that are subject to the possibility of a tragedy of the commons").

8 A crucial catalyst to work in this field was Garrett Hardin, The Tragedy of the Commons, 162 SCIENCE 1243 (1968) [hereinafter Hardin, Tragedy]. Recent collections on the commons include, for example, The Commons In THE New Millennium: Challenges AND AdAPTATIONS (Nives Dolak \& Elinor Ostrom eds., 2003); THE DRAMA OF THE COMMONS (Elinor Ostrom et al. eds., 2002); MANAGING THE Commons (John A. Baden \& Douglas S. Noonan eds., 2d ed. 1998); and Symposium, The Public Domain, 66 LAW \& CONTEMP. ProBs. (James Boyle ed., 2003) (addressing various aspects of the information commons). Many closely related bodies of work bear on the problems of the commons, including scholarship on collective action, see, e.g., RUSSELl HARDIN, COLLECTIVE ACTION (1982) [hereinafter Hardin, Collective Action]; Mancur Olson, The Logic of Collective Action (1965), game theory, see, e.g., Douglas G. BAIRD ET AL., GAME THEORY AND THE LAW (1994); ERIC RASMUSEN, GAMES AND INFORMATION: AN INTRODUCTION TO GAME THEORY (1989), public and club goods, see, e.g., RICHARD CORNES \& TODD SANDLER, THE THEORY OF EXTERNALITIES, PUBLIC GOODS, AND Club Goods (1986); James M. Buchanan, An Economic Theory of Clubs, 32 EconomicA 1 (Feb. 1965), and norms, see, e.g., Robert C. Ellickson, Order Without LAW: How Neighbors Settle Disputes (1991); EDNA UllmanN-MARGALiT, THE EMERGENCE OF NORMS (1977).

9 The anticommons idea has been applied in settings as diverse as biotechnology and land use. See, e.g., Dibadj, supra note 3 (arguing that anticommons problems can be created by regulatory "givings"); Heller \& Eisenberg, supra note 3 (applying anticommons analysis to the biomedical field); Hunter, supra note 3, at 509-14 (discussing dangers of a "digital anticommons"); Lydia Pallas Loren, Untangling the Web of Music Copyrights, 53 CASE W. RES. L. REV. 673, 700 \& n.130 (2003) (citing Heller's work on the anticommons in discussing the difficulties downstream users of copyrighted music face in obtaining multiple clearances); Bell \& Parchomovsky, supra note 3 (assessing positive potential of anticom- 
has thrown into bold relief theoretical and practical problems that had previously languished unnoticed in the background, and has generated renewed attention and excitement for addressing difficult problems involving the allocation of resources.

Despite its success, the emerging concept of the anticommons requires further clarification and refinement if it is to serve the diverse array of purposes for which it is now being deployed. This Article begins with a quite basic question that has not received a satisfactory answer in the literature: What distinguishes the problems associated with the anticommons from those associated with the old-fashioned tragedy of the commons? Significantly, some of the key criteria scholars have offered for identifying an anticommons and distinguishing it from an ordinary commons collapse upon scrutiny, as soon as one moves from the pure or prototypical versions of these forms of property to applied incarnations of them. The fragility of the boundaries between commons and anticommons suggests a deeper conceptual blurring that is likely both to impede the development of meaningful theoretical approaches and to hamper efforts to devise appropriate legal responses to realworld resource-allocation problems. Pushing a bit on the anticommons idea, then, leads to a broader rethinking of the nature of commons dilemmas and the prospects for their solution. These efforts open up the larger question that takes center stage here: How might the universe of common and interdependent resource problems be most usefully carved up?

In addressing that question, this Article makes three significant contributions. First, it develops and applies a new functional taxonomy capable of providing greater traction on problems involving the allocation of common resources. This taxonomy installs the fledgling anticommons concept more usefully and securely within the family of common resource dilemmas. My analysis, which both builds on and challenges existing approaches, emphasizes underappreciated structural connections between the commons and anticommons problems, and clarifies the nature of each dilemma. Far from being diametric opposites, the tragedies of the commons and the anticommons actually converge when taken to their logical conclusions. ${ }^{10}$ Moreover, they often appear together or in sequence. Indeed, a potential anticommons problem stands between every garden-variety commons tragedy and its solution.

The Article makes a second contribution by emphasizing that we often must choose between potential tragedies in contexts involving common re-

mons dynamic in land use settings). I take no position here on the degree of empirical fit between the anticommons story and the various real-world phenomena to which it has been applied. However, to the extent that the anticommons notion helps illuminate problems that either already exist at some level, or that could potentially exist under some set of plausibly imaginable circumstances, it is a useful notion to have around.

10 Their structural symmetry has already been recognized. See Buchanan \& Yoon, supra note 3. However, the ways in which they merge into each other upon close examination have not, to my knowledge, yet been studied. 
sources. ${ }^{11}$ Commentators have observed that an anticommons can result from overly "propertized" or "privatized" responses to commons dilemmas, so that efforts to solve one tragedy may introduce another. ${ }^{12}$ However, too little attention has been given to the factors creating this tension, ${ }^{13}$ or to the fact that an anticommons-like dynamic also underlies unaddressed commons dilemmas. ${ }^{14}$ Understanding these additional points requires an appreciation of the nature and significance of property interest fragmentation-a phenomenon that is more pervasive and less avoidable than the literature on the anticommons problem might suggest. ${ }^{15}$ In complex, interdependent settings such as neighborhoods, the apparently unified property interests that we enjoy are made possible only by fracturing other interests that could have been bundled together instead. ${ }^{16}$ The key question, then, is not

11 Cf. Guido Calabresi \& Philip BobBitt, Tragic Choices (1978) (discussing the inevitability of tragedy under conditions of scarcity). In this Article, I use the term "tragedy" in a somewhat specialized sense, to reference inefficient outcomes. Hence, a tragedy occurs when individual decisions fail to maximize the "pie" (the total value capable of being derived from a resource system) available for the parties to divide among themselves. Purely distributive changes do not constitute tragedies, on this definition. This fits with the standard usage of the term "tragedy" in the commons and anticommons literature, and with the recognition that there is little societal consensus about how one would begin to compare wins and losses that affect various parties in common resource settings. Distributive considerations remain important to my analysis, however, and will be referenced throughout the Article.

12 See Michael A. Heller, The Dynamic Analytics of Property Law, in 2 THEORETICAL INQUIRIES INTO LAW 79, 89 (2001) ("Constructing the anticommons ideal type helps to show why privatization must be more carefully deployed."); Heller \& Eisenberg, supra note 3, at 698 (arguing that "[p]rivatization can solve one tragedy but cause another"); Norbert Schulz et al., Fragmentation in Property: Towards a General Model, 158 J. Institutional \& THEORETICAL ECON. 594, 608 (2002) (explaining that "'propertization' may be a good antidote for offsetting commons deadweight losses, but, if carried out to excess, may lead to yet greater losses from anticommons problems").

13 As will be explained, the tension is primarily driven by the inverse relationship between holdout problems and externalities - a relationship identified and lucidly explained by Richard Epstein some years ago. Richard Epstein, Holdouts, Externalities, and the Single Owner: One More Salute to Ronald Coase, 36 J.L. \& ECON. 553 (1993); see infra Part II.B (drawing functional distinctions between commons and anticommons problems based on whether the primary impediment to an efficient outcome relates to externalities or holdout problems); infra Part III.D (discussing tradeoffs between these problems).

14 The intuition behind this point was articulated by Harold Demsetz three decades before the word "anticommons" came into common usage. See Harold Demsetz, Toward a Theory of Property Rights, 57 AM. ECON. REV. 347, 354-55 (1967) (explaining that an effort to solve a commons problem by mutual agreement may be blocked by a "hold-out" who, in the meantime, retains "the right to work the land as fast as he pleases"); see also James E. Krier, The Tragedy of the Commons, Part Two, 15 HARV. J.L. \& PUB. POL'Y 325, 335-36 (1992) (presenting an example that illustrates Demsetz's recognition of the problem of assembling the entitlements necessary to overcome the commons tragedy). A recent articulation of a similar point is found in Robert H. Nelson, Private Neighborhoods, ch. 12, at $11 \mathrm{n}$.* (unpublished book manuscript, on file with author). Nelson observes that a commons can lead to resource depletion that presents the potential for restoration, but that this restoration may be blocked by an anticommons dynamic. Id.

${ }^{15}$ See infra Part III.B (discussing property interest fragmentation).

${ }^{16}$ It is certainly true that, over the course of history, property has become less cohesively bound up in particular "things" and has become pervasively splintered along conceptual, temporal, and physical dimensions. See, e.g., Thomas C. Grey, The Disintegration of Property, in NoMOS XXII: ProperTY (J. 
whether one arrangement is more or less fragmented, but whether it tends to generate collective action problems that are more costly or harder to solve than those presented by some other arrangement.

The Article's third contribution involves an exploration of functionally relevant heterogeneities among tragedies. I first break tragedies into categories at the macro level based on the pattern of strategic interaction they embody. Doing this illuminates choices among ways of assigning and protecting entitlements. For example, it facilitates application of insights regarding the relative advantages of property rules and liability rules. ${ }^{17} \mathrm{I}$ then differentiate among tragedies at the micro level based on the shape of the production function for the deficit (or forgone surplus) that each generates. ${ }^{18}$ This focus on production functions provides guidance in choosing the lesser of two tragedies.

The analysis proceeds in three Parts. The first Part lays the groundwork for dividing up the universe of common interest tragedies functionally. To do this, I carefully parse the tragedies of the commons and anticommons, as these terms have been used to date. In each case, I separate out purely distributive questions from efficiency questions.

In Part II, I consider how the universe of "common interest tragedies"- my umbrella term for tragedies of the commons and anticommonsmight best be divided up for analytic purposes. I begin by critiquing attempts to draw a line between commons and anticommons tragedies based

Roland Pennock \& John W. Chapman eds., 1980) (making this observation). Nevertheless, even a "thing-bound" property system necessarily splinters other interests, although these other interests may have little importance during historical periods featuring low population densities, few interdependencies, and a low incidence of conflicts over property use.

17 The article that launched this field of study is Guido Calabresi \& Douglas Melamed, Property Rules, Liability Rules, and Inalienability: One View of the Cathedral, 85 HARV. L. REV. 1089 (1972). Literature analyzing and building upon Calabresi \& Melamed's taxonomy includes, for example: Ian Ayres \& Paul M. Goldbart, Optimal Delegation and Decoupling in the Design of Liability Rules, 100 Mich. L. REV. 1 (2001); Ian Ayres \& Eric Talley, Solomonic Bargaining: Dividing a Legal Entitlement To Facilitate Coasean Trade, 104 YALE L.J. 1027 (1995); Louis Kaplow \& Steven Shavell, Property Rules Versus Liability Rules: An Economic Analysis, 109 HARV. L. REV. 713 (1996); James Krier \& Stewart J. Schwab, Property Rules and Liability Rules: The Cathedral in Another Light, 70 N.Y.U. L. REV. 440 (1995); Daphna Lewinsohn-Zamir, The Choice Between Property Rules and Liability Rules Revisited: Critical Observations from Behavioral Studies, 80 TEX. L. REV. 219 (2001); Madeline Morris, The Structure of Entitlements, 78 CORNELL L. REV. 822 (1993); A. Mitchell Polinsky, Controlling Externalities and Protecting Entitlements: Property Right, Liability Rule, and Tax-Subsidy Approaches, 8 J. Legal StUd. 1 (1979); A. Mitchell Polinsky, Resolving Nuisance Disputes: The Simple Economics of Injunctive and Damage Remedies, 32 StAN. L. REV. 1075 (1980); Symposium, Property Rules, Liability Rules, and Inalienability: Twenty-Five Year Retrospective, 106 YALE L.J. 2083 (1997); Ronen Avraham, Modular Liability Rules, INT'L REV. L. \& ECON. (forthcoming 2005).

18 For example, some tragedies are "lumpier" than others. See, e.g., GERALD MARWELl \& PAMELA Oliver, The Critical Mass in Collective ACtion: A Micro-Social Theory 23 (1993) (distinguishing goods that are available "in (almost) continuously divisible increments" from those that "are available only in large, 'lumpy' units"); Michael Taylor \& Hugh Ward, Chickens, Whales, and Lumpy Goods: Alternative Models of Public-Goods Provision, 30 POL. STUD. 350, 353 (1982) (discussing goods that do not smoothly increase in a linear relationship with inputs). 
on whether resource "overuse" or "underuse" results, or based on whether a "privilege of use" or a "right to exclude" was granted to group members. I then suggest that resource problems can be more usefully divided up based on the strategic interaction that is most likely to block the efficient allocation of entitlements. Dividing up common interest tragedies functionally paves the way for addressing the strategic dilemmas directly through legal or nonlegal means.

In Part III, I demonstrate the payoff of this approach. I begin by showing how the functional taxonomy I have presented facilitates use of the large and intricate body of literature on choices about the assignment and protection of legal entitlements to engineer better solutions to resourceallocation problems. ${ }^{19}$ This corpus of scholarship has particular traction in interdependent resource settings in which policymakers must steer a careful course between the Scylla of the commons and the Charybdis of the anticommons. Using a stylized example, I examine how heterogeneity in the production functions of common interest tragedies provides a reasoned basis for choosing between potential tragedies, and show the implications of this analysis for entitlements and their protection.

\section{THE COMMONS AND THE ANTICOMMONS}

In this Part, I lay the groundwork for what follows by closely scrutinizing the tragic tendencies that can emerge in multi-party resource contexts. In subpart A, I focus on those tendencies toward tragedy that are usually placed under the rubric of "tragedies of the commons" and in subpart B on those associated with "tragedies of the anticommons." 20 In each case, I distinguish problems that affect only distribution from those that affect efficiency.

Before I begin parsing the tragedies, one point deserves emphasis: While certain resource arrangements seem to set the stage for tragic tendencies to manifest themselves, tragedy is not the inevitable result. ${ }^{21}$ Tragedy

19 See supra note 17.

20 The terms "commons" and "anticommons" are not always given consistent meanings in the literature, and there are a variety of things that people may mean when they speak of the tragedies associated with these property regimes. See, e.g., Heller, supra note 2, at 667-69 (describing the difference between his definition of an anticommons and the earlier meanings given the term); Charlotte Hess \& Elinor Ostrom, Ideas, Artifacts, and Facilities: Information as a Common-Pool Resource, 66 LAW \& CONTEMP. PROBS. 111, 114-28 (2003) (discussing differing uses of the term "the commons" and detailing some sources of confusion).

21 Many scholars have challenged or qualified the view that that a commons ineluctably leads to tragic consequences. See, e.g., OsTROM, supra note 7, at 35-37, 88-89, 205-07 (stressing the role of norms in managing common pool resources); Hanoch Dagan \& Michael A. Heller, The Liberal Commons, 110 YALE L.J. 549 (2001) (presenting a model of a "liberal commons" designed to foster cooperative interactions while preserving to each member autonomy and a right to exit); Carol Rose, The Comedy of the Commons: Custom, Commerce, and Inherently Public Property, 53 U. CHI. L. REV. 711 , 770 (1986) (suggesting that "doctrines of custom" explain "why certain kinds of property-particularly those necessary to commerce-were presumed to be more valuable if access were open to all”). 
can be averted not only through legal rules and state regulation, but also through de facto arrangements that mimic formal legal entitlements, ${ }^{22}$ norms or other social factors that alter the payoffs group members face and thereby induce cooperation, ${ }^{23}$ and related constraints on behavior that arise when part of what group members seek in a common resource context is a satisfying social interaction. ${ }^{24}$ Hence, the tragic tendencies described here may be absent or blunted in many real-world settings, without the intervention of law. This Article does not seek to add to the extensive literature on these informal, nonlegal solutions; instead, it concentrates on understanding and categorizing the impediments to efficient outcomes. ${ }^{25}$

\section{A. Tragedies of the Commons}

Scholarship about the commons often distinguishes a "limited-access" commons to which a limited number of people have access, from an "openaccess" regime that is open to "everyone." 26 As a matter of historical fact, limited-access commons, such as common grazing lands, have often operated pursuant to a set of explicit or implicit usage and membership constraints that avoid or limit tragic outcomes. ${ }^{27}$ Given my focus in this

${ }^{22}$ See, e.g., Edella Schlager \& Elinor Ostrom, Property-Rights Regimes and Coastal Fisheries: An Empirical Analysis, in THE POLITICAl ECONOMY OF Customs AND Culture: InFormal Solutions TO THE Commons Problem 13, 19-21 (Terry L. Anderson \& Randy T. Simmons eds., 1993) (discussing de jure and de facto rights to common property).

23 See, e.g., UlLmANN-MARGALit, supra note 8, at 37 (describing how factors like esteem and dishonor alter payoffs for soldiers confronting a strategic dilemma).

24 See Dagan \& Heller, supra note 21, at 552 (discussing importance of a framework that takes into account contexts in which "the social gains from cooperation are not just fringe benefits, but instead are a major part of what people seek").

${ }^{25}$ When considering how legal entitlements might best be structured to minimize the fallout from such tragic tendencies, the prospects for informal solutions under various alternatives must be taken into account, along with a number of other factors. See infra text accompanying notes 281-85.

26 See, e.g., OSTROM, supra note 7, at 48 (distinguishing limited-access from open-access common pool resources); Dagan \& Heller, supra note 21, at 557 (distinguishing open-access from commons property on the basis that the latter is open to only a limited number of people); Ellickson, supra note 1, at 1322 (distinguishing an open-access regime from ownership by a close-knit group or a larger "horde"). Because a limited-access commons endows the group of insiders with the power to exclude outsiders from the common pool resource, it looks like ordinary private property from the outside. Carol M. Rose, The Several Futures of Property: Of Cyberspace and Folk Tales, Emission Trades and Ecosystems, 83 MINN. L. REV. 129, 155 (1998). This power to exclude outsiders may be de facto (as where a group of local surfers protects "its" waves) or de jure (as where the law protects a tenancy in common or other collective ownership form). See Schlager \& Ostrom, supra note 22, at 19-21.

27 See, e.g., Yoram BARZEL, ECONOMIC ANALYSIS OF PROPERTY RIGHTS 99-100 (2d ed. 1997) (citing and discussing the descriptions of English villagers' use of commons contained in CARL J. DAHLMAN, The OPEN Field System AND BEyOND: A PROPERTy Rights ANALYSIS OF AN ECONOMIC Institution (1980)); Eric T. Freyfogle, The Land We Share: Private Property and the COMMON GOOD 160 (2003) (noting scholarship that indicates grazing lands have empirically operated pursuant to constraints and have not resembled the tragedy-prone open-access commons described by Garrett Hardin); Ellickson, supra note 1, at 1390-91 \& nn. 380-82 (discussing scholarship on this point). 
subpart on simply understanding and classifying potential impediments to efficient outcomes, I will discuss tragic tendencies in the commons without explicitly noting where on the spectrum of limited to open access a particular common resource system falls. ${ }^{28}$

1. Two Tragic Tendencies.-Tragedies of the commons stem from two tendencies that are usually denominated "overuse" and "underinvestment." ${ }^{29}$ Although these terms turn out to be more malleable than they appear at first, they are helpful in gaining an intuitive understanding of commons tragedies. The tendency towards overuse is typified by Garrett Hardin's example of grazing cattle; ${ }^{30}$ hence it is sometimes also termed an "overgrazing" problem. The basic idea is that grass is a replenishing resource that only can flourish when it is not constantly being trampled and eaten by cattle. Add too many cattle to a grazing field, and eventually the total amount of grass available for the entire group of cattle becomes depleted. Each additional head of cattle generates benefits that are wholly internalized by the animal's owner, but the owner internalizes only a fraction of the costs that the animal imposes on the grazing lands. Hence, the tendency is to add too many cattle. ${ }^{31}$

The same analysis applies to fishing from a common pool, harvesting fur-bearing creatures from a woodlands, drawing oil or water from the earth, ${ }^{32}$ or sending spam through the internet. Whether the situation in-

${ }^{28}$ When choosing between structural arrangements, however, it becomes important to know when tragic tendencies are likely to be self-limiting or self-correcting, and when they are likely to spin out of control. See infra Part III. That question depends on many factors, including some that track the "limited-access" versus "open-access" distinction, such as the stability, size, and homogeneity of the group. See, e.g., OSTROM, supra note 7, at 88-102 (discussing the features shared by successful self-governing common pool resource institutions).

${ }^{29}$ Dagan and Heller have characterized "wasteful struggles regarding the fruits and revenues that a commons may produce" as a third potential source of inefficiency in a commons. Dagan \& Heller, supra note 21, at 582. However, as I will explain, that source of inefficiency can be understood as the overuse of (or underinvestment in) a different "commons"- that of the resource-gathering environment (as opposed to the resource itself).

${ }^{30}$ Hardin, Tragedy, supra note 8, at 1244.

31 Adding "too many" cattle in this context does not mean that the person has added more than "their share" of cattle (based on some notion of distributive justice), but rather that cattle are added beyond the point that they produce marginal benefits for anyone - that is, they are added to the point that they decrease the overall benefit ("shrink the pie") available for the group as a whole. See infra Part I.A.2 (distinguishing distributive problems from a true tragedy of the commons).

32 Oil presents a tragedy of the commons to the extent that the total amount of oil available for anyone's use diminishes with overly-speedy extraction, or to the extent such rapid extraction ushers in other inefficiencies that reduce the total benefits to be gleaned from the resource (such as private storage costs). See, e.g., Gary D. Libecap \& James L. Smith, The Economic Evolution of Petroleum Property Rights in the United States, 31 J. LEGAL STUD. 589 (2002) (detailing some of the costs historically associated with "extractive anarchy" in oil, including fires associated with surface storage, and excessive drilling that decreased pressure and made extraction more difficult or that permitted water or gas to enter and trap oil). Similar problems attend excessive withdrawal of groundwater. See, e.g., Barton H. Thompson, Jr., Tragically Difficult: The Obstacles To Governing the Commons, 30 ENVTL. L. 241, 250 
volves "taking out" valuable resource units from the system ${ }^{33}$ (e.g., fish, oil, water, beavers), or "putting in" something that is harmful (e.g., grazing cattle, spam, litter, pollution), the individual making the decision about resource use enjoys all of the benefits of that use but does not bear all of the costs. $^{34}$ Put differently, these represent cases of negative externalities associated with resource use. ${ }^{35}$ Because the resource-appropriator is not taking all the costs of her appropriation into account, she is likely to do too much of it from the standpoint of allocative efficiency. ${ }^{36}$

The second tragic tendency associated with a commonsunderinvestment - is typified by shirking on a communal farm; hence, we might also term this problem "undercultivation." Here, the problem is a function of positive externalities, not negative externalities. ${ }^{37}$ The person who cultivates a garden, for example, internalizes all of the costs but (in a setting where the produce is open to the group as a whole) does not internalize all of the benefits. Therefore, she will invest too little time and effort

(2000) (explaining how "overdrafting" of aquifers can lead to more costly pumping, contamination from salt water (in the case of coastal aquifers), and degradation of the surface).

33 See Hess \& Ostrom, supra note 20, at 121 (distinguishing between a "resource system" such as a fishery, and "resource units" that can be extracted from that system, such as individual fish); Dean Lueck, First Possession as the Basis of Property, in PROPERTY RIGHTS: COOPERATION, CONFLICT, AND LAW 200, 202 (Terry L. Anderson \& Fred S. McChesney eds., 2003) (distinguishing between resource "stocks" and "flows").

34 There may be other differences between the "taking out" and "putting in" situations, however, that call for different management strategies. See Carol M. Rose, Common Property, Regulatory Property, and Environmental Protection: Comparing Community-Based Management to Tradable Environmental Allowances, in THE DRAMA OF THE COMMONS, supra note 8, at 233, 245-47 (distinguishing between "'taking-out' or extractive issues" and "putting-in" issues, and discussing possible differences, such as ease of monitoring, between these two classes of problems).

35 See Robert A. Mundell, Man AND ECONOMics 185 (1968) (defining externalities as "those benefits or costs of decisions not accruing to the choice unit in question, but rather received or paid by others").

36 See id. at 182 (explaining that "those industries producing harmful by-products causing damage or creating costs for others, would tend to produce too much for the good of society"). The mere fact that appropriation generates externalities does not establish that inefficiency will necessarily result. See DUKEMINIER \& KRIER 5TH, supra note 6, at 51-52 (explaining how externalities foster inefficiency, but do not guarantee that it will occur); infra Part II.B.1 (distinguishing Pareto-relevant from Paretoirrelevant externalities).

37 Some treatments of commons tragedies have focused exclusively on the negative externalities associated with overuse. See, e.g., Parisi et al., Duality, supra note 3, at 9 (suggesting that "the problem of the commons is related to a negative externality of use rights"). However, the problem of underinvestment turns up ubiquitously in the commons literature. See, e.g., Thráinn Eggertsson, Open Access Versus Common Property, in PROPERTY Rights: COOPERATION, CONFLICT, AND LAW, supra note 33, at 73, 77 (explaining that the economic consequences of an open access regime include "supply side" effects, such as the disincentive to invest, as well as "demand side" effects on appropriation behavior); Elinor Ostrom et Al., Rules, Games, And COMmon-PoOl Resources 14-15 (1994) (discussing problems of underprovision, as well as problems of overuse). Moreover, it is often possible to couch a particular decision as either creating negative externalities (e.g., "shirking") or failing to produce positive externalities (e.g., "not working"). See infra note 45 and accompanying text. 
into cultivation, because she will not receive the benefits of her work. ${ }^{38} \mathrm{~A}$ similar dynamic obtains when initial work is necessary to sever a resource unit from the common pool, but another party has the ability to swoop in and take the resource after these initial investments have been made. This is the familiar problem presented by the case of Pierson v. Post. ${ }^{39}$ Underinvestment can thus lead to underuse of the resource in question, rather than overuse. ${ }^{40}$

Both tragic tendencies depend on the existence of private property rights in the resource that one harvests from, or fails to contribute to, the collectivity. ${ }^{41}$ A moment's reflection establishes that the overgrazing example only works if the rancher "owns" the meat that results from grazing cattle on the common land; that is, if we have some coherent idea of what is meant by "his cattle" that affords him the benefit of the product of the animal and the grass that it eats. ${ }^{42}$ In other words, even though the resource system in question is under common ownership, individuals have a right to capture and own specific resource units. ${ }^{43}$ Likewise, an individual's failure to contribute labor to the collective farming enterprise only makes sense if the individual otherwise owns her human capital and can glean the benefits of using it in other ways (whether for leisure or money-making endeavors).

Thus, the tragedy of the commons boils down to this: inefficient decisions regarding the allocation of property interests between the collectivity and one's personal stock. In a commons situation, each group member has the unilateral ability to transfer commons resources to herself and to transfer her own resources to the collectivity. We would expect to see too much of the former and not enough of the latter. This can be understood as a pricing flaw. Transferring commons resources to oneself comes "too cheaply"

\footnotetext{
38 See, e.g., Ellickson, supra note 1, at 1326 (discussing incentive to shirk when land is commonly owned).

393 Cai. R. 175 (N.Y. Sup. Ct. 1805). In Pierson, one hunter (Post) had begun pursuit of a fox with his hounds and was on the verge of capturing it when another hunter (Pierson) arrived on the scene and nabbed the fox. The majority held that Post had no claim to the fox because he had not yet "deprived him of his natural liberty, and brought him within his certain control." Id. at 178. However, the dissent worried that this rule would remove the incentive to invest in foxhunting. What person, asked the dissent, would invest in hounds, rise at the break of day, and spend hours chasing "the windings of this wily quadraped, if . . . a saucy intruder, who had not shared in the honours or labours of the chase, were permitted to come in at the death, and bear away in triumph the object of pursuit?" Id. at 181 (Livingston, J., dissenting).

40 See Heller, supra note 2, at 675 (presenting example of "Poach Pond"-a communal fish pond in which no person owns a fish until the moment of consumption). Heller's "Poach Pond" will be underused because the entitlement structure creates a disincentive to invest in catching fish; one can instead sit on the banks and take fish from those who have caught them. Id.

41 See id. at 675 n.246 (recounting a conversation with William Miller on this point).

42 Cf. BARZEL, supra note 27 , at 85 (observing that "[t]he ability to consume commodities, including those necessary to sustain life, implies possession of the rights over them").

43 See supra note 33 (distinguishing between resource systems (or "stocks") and resource units (or "flows"); Lueck, supra note 33, at 202 (providing examples where people are allowed to appropriate resource units such as grass, oil, and fish, while the resource stock remains under common ownership).
} 
when one does not have to take account of the costs the transfers inflict on the commons. Likewise, one's own contributions to the common enterprise are compensated at less than full value, where one cannot capture the benefits bestowed on the collectivity. ${ }^{44}$

It is often possible to cast a particular collective action problem as either a problem of underinvestment or a problem of overuse. For example, consider a dirty carpet in a common room of a group house. The problem could be couched either as "overuse" of the carpet by people with muddy shoes, or as "underinvestment" in mud-avoidance, shoe-cleaning, or carpet-protection activities. ${ }^{45}$ Nothing turns on which way a particular commons problem is classified, as long as the dynamic creating the specific problem in question is well-understood. ${ }^{46}$ Alternatively, one tragic tendency might anticipate and reinforce the other. Knowing that other ranchers will overgraze the field, no rancher has an incentive to irrigate the land to encourage the growth of grass. The anticipation of overuse thus exacerbates the preexisting tendency to underinvest in a resource whose benefits will be shared by others, because it suggests that the investor will receive an even smaller return on her investment as a result of the dissipation generated by later overuse. ${ }^{47}$

44 This does not mean that people will always fail to engage in activities that produce positive externalities; the internalized portion of the reward may be sufficient to prompt their actions. See DAVID D. HADDOCK, IRRELEVANT INTERNALITIES, IRRELEVANT EXTERNALITIES, AND IRRELEVANT ANXIETIES 28-29 (Northwestern U. School of Law, Law \& Economics Research Paper, No. 03-16, 2003), available at http://www.papers.ssrn.com/abstract=437221. Likewise, people will not always engage in activities that produce negative externalities; the internalized portion of the cost might itself be a sufficient deterrent. There is also a flip side to each of these observations: People who engage in activities with negative externalities, or refrain from activities with positive externalities, might still do the same even if the costs and benefits were internalized. See infra Part II.B.1.

45 A classic example of this potential for alternative characterizations of the same phenomenon is found in Pigou's discussion of smoking chimneys. A.C. PIGOU, THE ECONOMICS OF WELFARE 160-61 (1920) (observing that "resources devoted to the prevention of smoke from factory chimneys" provide an "uncompensated service," while the smoke itself "inflicts a heavy uncharged loss on the community"); see, e.g., Ronald H. Coase, The Problem of Social Cost, 3 J.L. \& ECON. 1, 35 (1960) (observing that Pigou characterizes those who keep their chimneys from smoking as "render[ing] services for which they receive no payment"); Krier, supra note 14, at 325-26 n.3 (discussing Pigou's view of pollution control as generating a positive externality). This observation lines up with a broader point about the permeability of the line between harms and benefits. See, e.g., Lucas v. S.C. Coastal Council, 505 U.S. 1003, 1024 (1992) (noting that the challenged land use restriction could be characterized either as securing a benefit or preventing a harm); Frank I. Michelman, Property, Utility, and Fairness: Comments on the Ethical Foundations of 'Just Compensation' Law, 80 HARV. L. REV. 1165, 1196-97 (1967) (discussing difficulty of distinguishing harm-producing actions from those that fail to confer benefits).

${ }^{46}$ But see OSTROM ET AL., supra note 37, at 14-15 (suggesting that it is analytically useful to distinguish "supply side" problems of provision and maintenance from "demand side" appropriation problems). While I agree that separating out different problems within the context of a complex resource system is crucial to understanding what might be done to improve matters, the question of whether any particular problem is best classified as one involving the "supply side" or the "demand side" seems to me of little significance, especially in contexts where the suppliers and the appropriators are exactly the same people.

47 See Demsetz, supra note 14, at 351 ("Because of the lack of control over hunting by others, it is in no person's interest to invest in increasing or maintaining the stock of game."). 
Other examples of these mutually reinforcing tragic tendencies are arguably found in certain intellectual property contexts. Scientific research and other forms of creative and innovative work exhibit complementarities and synergies, so that freely sharing them in an intellectual "commons" can yield benefits, including ideas for new work, that will exceed the sum of the contributions. $^{48}$ However, if the group members cannot capture a share of the resulting benefits that is roughly proportionate to the contributions that each member makes, we would expect fewer contributions. ${ }^{49}$ The situation becomes even more difficult and interesting when we recognize that a form of "overgrazing" can also occur simultaneously in conjunction with an intellectual commons.

Intellectual goods exhibit "nonrivalry" in consumption, insofar as the transmission of a song or theory from me to you does not leave any less of the song or theory for me. ${ }^{50}$ Nevertheless, these goods are subject to a form of overgrazing, insofar as consumers have limited attention. ${ }^{51}$ The replication of a given expression or innovation may simply spread surplus around to other producers or to consumers through competition, or it could actually reduce the total amount of surplus associated with that particular product. ${ }^{52}$

48 See, e.g., LAWrence Lessig, The Future of IDEAs: The FAte of The COMmons IN A CONNECTED WORLD 203 (2001) (observing that "[i]ntellectual property is both an input and an output in the creative process"); Rebecca Eisenberg, A Technology Policy Perspective on the NIH Gene Patenting Controversy, 55 U. PITT. L. REV. 633 (1994) (observing the extent to which biomedical research has grown through building upon past work in the public domain); Lemley, supra note 4, at 997 (discussing cumulative nature of knowledge); Robert P. Merges, Property Rights Theory and the Commons: The Case of Scientific Research, 13 Soc. PHIL. \& POL'Y 145 (1996) (noting value to researchers of shared access); cf. Carol M. Rose, Romans, Roads, and Romantic Creators: Traditions of Public Property in the Information Age, 66 LAW \& CONTEMP. PROBS. 89, 97-98 (2003) (noting that commerce and communications exhibit synergies and network benefits, justifying public access to them).

49 See, e.g., LESSIG, supra note 48, at 95-96 (noting concerns with providing appropriate incentives to produce intellectual goods); RICHARD A. POSNER, ECONOMIC ANALYSIS OF LAW 38 (6th ed. 2003) (observing that, in the absence of patents, innovation may suffer or may be skewed "toward inventions that could be kept secret").

50 See, e.g., LESSIG, supra note 48, at 22, 94-95 (discussing the nonrivalrous character of intellectual property); Douglas G. Baird, Common Law Intellectual Property and the Legacy of International News Service v. Associated Press, 50 U. CHI. L. REV. 411, 413 (1983) (discussing the distinction between information, which many can share without reducing the value of the information to each other, and a tangible resource like wheat, which cannot be possessed in its entirety by more than one person simultaneously).

51 See William M. Landes \& Richard A. Posner, Indefinitely Renewable Copyright, 70 U. CHI. L. REV. 471, 485-86 (2003) (discussing forms of "overgrazing" possible in the case of intellectual property, including the chance that overuse of a particular image might generate "confusion, the tarnishing of the image, or sheer boredom on the part of the consuming public"); see also Michael J. Meurer, Copyright Law and Price Discrimination, 23 CARDOZO L. REV. 55, 96-97 (2001) (observing that limited consumer attention is a common pool resource that producers of works will tend to overharvest).

52 See Landes \& Posner, supra note 51, at 486 (distinguishing between "pecuniary" externalities that alter wealth distributions and "technological" externalities that lead to a net reduction in overall utility). The former is not, strictly speaking, an "overgrazing" problem, insofar as the appropriations in question do not operate to reduce the total amount of surplus associated with the existing intellectual product. However, such appropriations would still have the effect of reducing the expected return on intellectual work, and intensifying the tendency toward underinvestment. 
The tendency towards overgrazing could thus reinforce one towards underinvestment, ${ }^{53}$ leading to a commons featuring too few, and too intensively exploited, intellectual products - at least in the absence of legal rules or norms designed to cabin these tendencies. ${ }^{54}$

These questions are tremendously complex ones that have been extensively analyzed by other scholars; I raise them here only by way of illustration. What drives the reinforcing tendency in these examples is the fact that the group members' investments create a common pool resource that features both difficult exclusion and subtractibility, such that individual resource units (grass, fish, or consumer attention ) can be taken away, leaving less behind for others. ${ }^{55}$ A true public good, on the other hand, features nonexcludability coupled with nonrivalry in consumption-that is, each person's use of the resource does nothing to diminish anyone else's. ${ }^{56}$ In cases where investments combine to produce a public good, such as public television, the fact that free-riders cannot be excluded from the good still creates a problem of underinvestment. ${ }^{57}$ But it will not in those cases be exacerbated by the further prospect of overextraction, because the resource in question does not exhibit subtractibility. ${ }^{58}$

2. Distributive Questions Distinguished.-In order for a situation to take the shape of a tragedy of the commons, two basic requirements must

53 The compound problem I describe here is present when consumer interest is generated and focused through specific investments and thereafter "overgrazed." However, we might also worry about races to harvest preexisting, unfocused consumer attention that is not the product of any specific, identifiable investment. See infra note 54. Recent literature on competition for attention includes, for example, Thomas H. Davenport \& John C. Beck, The Attention Economy: Understanding the New CURRENCY OF Business (2001), and JOSEF FALKINGER, ATTENTION ECONOMIES (CESifo Working Paper, No. 1079, 2003), available at http://ssrn.com/abstract $=466580$.

54 Securing strong property rights in creators to address underinvestment concerns may generate other problems, of course, including the possibility of wasteful races to obtain those rights. See, e.g., PoSNER, supra note 49, at 37 (analogizing difficulties presented by patents to wasteful races to salvage sunken treasure); William Fisher, Theories of Intellectual Property, in NEW ESSAYS IN THE LEGAL AND POLITICAL THEORY OF PROPERTY 168, 179-80 (Stephen R. Munzer ed., 2001) (summarizing and citing the literature on races to innovate); Meurer, supra note 51, at 96-97 (describing wasteful races to get to market first).

55 See, e.g., Elinor Ostrom, Private and Common Property Rights, in ENCYClOPEDIA OF LAW AND ECONOMICS 332, 337-38 (Boudewijn Bouckaert \& Gerrit De Geest eds., 1999), available at http://encyclo.findlaw.com/index.html (discussing subtractibility).

56 See, e.g., CORNES \& SANDLER, supra note 8, at 6-7 (1986) (discussing characteristics of public goods); OSTROM ET AL., supra note 37 , at $7 \&$ fig.1.1 (presenting a schema that distinguishes public goods from common-pool resources based on the degree of subtractibility that the good exhibits).

57 See HARDin, COllective ACtion, supra note 8, at 20 (explaining that "the costliness or de facto infeasibility of exclusion from consumption of a collectively provided good usually eliminates any direct incentive for individual consumers to pay for the good").

58 The situation might be different if watching public television increased one's access to scarce resources or opportunities - for example, if it enabled one to make more intelligent conversation and to compete more effectively in professional or personal spheres. In that case, more widespread watching of public television could diminish one's ability to profit in these ways from watching public television. 
be met. ${ }^{59}$ First, the individual actors must fail to internalize all the costs or benefits of their actions. The tendencies towards overgrazing and undercultivation both arise from a failure to concentrate within the same decisionmaker all of the costs and benefits associated with a given action. ${ }^{60}$ This mismatch between internalized and actual costs and benefits skews a decisionmaker's assessment of whether a given action is beneficial, and can lead to inefficient choices about resource use. ${ }^{61}$

Second, the total returns to the group's members must be larger in the case of cooperative action than in the case of defecting action. ${ }^{62}$ To put it

59 These criteria bear some resemblance to the two that Elinor Ostrom and her coauthors associate with common pool resource dilemmas: "suboptimal outcomes" and "institutionally feasible alternatives." OSTROM ET AL., supra note 37, at 15-16. My focus on the total size of the pie, see infra text accompanying notes 62-63, captures the idea of "suboptimal outcomes," and the requirement that externalities be present, see infra text accompanying notes 60-61, signals at least some hope for improvement (through, for example, mechanisms designed to internalize the externalities). While I do not focus on whether improvements are institutionally feasible, this is consistent with the fact that I am here attempting to set out the conditions for "tragedy"-which could exist even if no improvement were institutionally possible. In contrast, Ostrom and her coauthors were focusing on defining a category of "dilemmas" from which escape was possible; they recognized that other common pool resource "situations" could exist. OSTROM ET AL., supra note 37, at 16.

60 See, e.g., MuNDELL, supra note 35, at 185 (defining externalities as benefits and costs that do not accrue to the chooser); POSNER, supra note 49, at 71-74 (discussing incentive problems that can result when one does not reap the full benefit of one's inputs); Ellickson, supra note 1, at 1326 (making the same point in the context of group-owned land).

${ }^{61}$ Of course, outright owners of resources sometimes engage in objectively wasteful or destructive conduct, even though all of the costs and benefits of that conduct are concentrated on them. See, e.g., Edward J. McCaffery, Must We Have the Right To Waste?, in NEW EsSAYS IN THE LEGAL AND POLITICAL THEORY OF PROPERTY, supra note 54, at 76 (discussing common law right to destroy one's own property); Symposium, Time, Property, Rights, and the Common Law-Round Table Discussion, 64 WASH. U. L.Q. 793, 845-46 (1986) (comments of R. Ellickson) (questioning whether people can really destroy their own property without being restrained or committed); LIOR STRAHILEVITZ, THE Right to Destroy, (U. Chi. Law and Econ., Olin Working Paper No. 205, 2004), available at http://ssrn.com/abstract=488847 (assessing legal limits on the right to destroy). One might explain some instances of destruction (or inadequate cultivation) of one's own property by invoking the notion of "internalities" - costs imposed on (or benefits enjoyed by) later selves, which the current self does not properly take into account. See, e.g., Jonathan Gruber, Case Study: Government Policy Towards Smoking: A View from Economics, 3 Yale J. Health Pol'y \& Ethics 119 (2002) (discussing internalities in context of the self-damaging behavior of smoking); Adam J. Hirsch, Spendthrift Trusts and Public Policy: Economic and Cognitive Perspectives, 73 WASH. U. L.Q. 1, 23-24 \& nn. 76-77 (1995) (discussing myopic decisionmaking and the notion of "internality"). In other words, people might suffer from an internal tragedy of the commons in which each successive self overextracts or underinvests without heed for the costs imposed on later selves. As intriguing as this line of inquiry is, I will set it aside here to focus on spillovers that affect other people.

62 Sometimes this point is made explicit in discussions of common pool resources. See OSTROM ET AL., supra note 37, at 15-16 (discussing "suboptimal outcomes" as a feature of common pool resource dilemmas). It is also implicit in the goal of ensuring that a resource system remains "sustainable" over time. See, e.g., Ostrom, supra note 55, at 338 (discussing the goal of sustainable use in designing a property regime for governing a common pool resource). The notion of sustainability implies that a different set of actions would make the resource nonsustainable and hence incapable of producing as valuable a stream of resources. 
another way, cooperation has to do more than merely change the distribution of a pie of fixed size; it must actually increase the amount of pie that there is to go around. For this reason, any tragedy of the commons is by definition an inefficient occurrence, although it often also has results that seem distributionally unfair. ${ }^{63}$

Focusing on these two criteria in tandem allows us to distinguish a true tragedy of the commons from mere distributive realignments of resources that may occur in a commons. The latter exhibit the first criterion, but not the second. For example, imagine a fixed pile of money that four individually sequestered people can draw upon via a computer interface. This is a pure game of distribution. People may behave selfishly or unselfishly in their appropriation behaviors, but it does not change the overall amount of money in the pile available for someone to get. The gain to one person from selfish behavior is not outweighed by a larger social cost; instead, the rest of the group loses by exactly the amount that the greedy person gains. ${ }^{64}$ There may be opportunism and unfairness, but there is no inefficiency. ${ }^{65}$

Likewise, no true problem of inefficient underinvestment is present when the cooperative contributions in question will not increase the total amount of resources involved, but will only facilitate redistribution. If people with a fixed amount of money choose to pool their funds, their contributions to the common fund do nothing to increase the financial resources available to the group members as a whole. ${ }^{66}$ The pooling arrangement will likely alter the distribution of those resources, but any loss that one group member suffers as a result of having contributed to the pool is exactly offset by gains to other group members.

63 This convergence of distributive justice and efficiency concerns turns the "tragedy of the commons" into a story with a strong moral: greed ruins things for everyone. This is an interesting inversion of the usual market rhetoric in which greed (more palatably termed "self-interest") helps everyone by generating a larger social product. See ADAm Smith, AN INQUiRY INTO the NATURE AND CAUSES OF THE WeALth OF NATIONS 14 (Edwin Cannon ed., 1994) (1776) ("It is not from the benevolence of the butcher, the brewer, or the baker, that we expect our dinner, but from their regard to their own interest."). The inconsistency can be reconciled by making out a moral claim for private property as a mechanism for channeling self-interest. See Heller, supra note 12, at 86 (observing that "the tragedy of the commons metaphor" can be used, inter alia, "to provide moral justification for private property regimes").

${ }^{64}$ I set aside here the possibility that the distribution itself can have efficiency impacts due to the diminishing marginal utility of money or other differences in the utility that money generates in different hands. I will take up that complication below. See infra notes $72-73,108$, and accompanying text.

${ }^{65}$ In other words, the game is zero-sum. Each move in the appropriation game generates winners and losers, but the wins precisely balance out the losses. See Robert Cooter, The Cost of Coase, $11 \mathrm{~J}$. LEGAL STUD. 1, 16 (1982) (describing zero-sum games). Moreover, once the appropriations game has been completed, nobody can be made better off without making someone else worse off. See infra note 102 (discussing Pareto efficiency). The proviso that the people be individually sequestered avoids a source of inefficiency that will be discussed infra Part I.A.3.

${ }^{66}$ I set aside here the possibility that the pooling itself generates gains by, for example, enabling contributors to diversify their holdings or to secure access to a lumpy good. Similar gains from entitlement assembly will be taken up presently. See infra notes 74-77 and accompanying text. 
These examples elide the question of where the money came from, and it is certainly true that the distributive consequences could generate inefficiencies by reducing each group member's willingness to earn money and to participate in such pooling arrangements. But the concept of a fixed pot of resources is highly relevant to many nonrenewable natural resource contexts where such incentive effects operate more weakly or not at all; no human agent created the resource or can add to its quantity, except perhaps at the margin through more careful extraction methods.

3. Fixed-Pot Resources and the Resource-Gathering Environment.-

Of course, in most real-world situations, even if the resource itself does not shrink as a result of selfish behavior, other costs are imposed on the parties as a result of such behavior that reduce the net value of their draw. For example, imagine a large cache of gold has just been discovered. Mining faster does not alter the total amount of gold to be distributed among the miners, but it may impose other kinds of costs on participants in the form of overinvestment in mining equipment, accidents resulting from mining too many hours each day or attempting to extract the gold too quickly, fights among rival miners, and so on. ${ }^{67}$ All of these costs reduce the net benefit associated with the gold that the miners obtain. ${ }^{68}$

One way of thinking about these fixed resource situations is to recognize that they involve not only the fixed common resource (e.g., a fixed quantity of gold) but also another "commons" that is relevant to the participants' payouts - the resource-gathering environment. The overlay of this second commons adds the second criterion for tragedy: the total returns available to the group are larger under cooperative conditions than under noncooperative conditions. That one individual ends up with a bigger share

${ }^{67}$ See Terry L. Anderson \& Fred S. McChesney, Introduction: The Economic Approach to Property Rights, in PROPERTY Rights: COOPERATION, CONFLICT, AND LAW, supra note 33, at 1, 5 ("The competition for open access resources is costly because the same time and effort spent competing for resources could be expended in other ways."). The same problem is presented by sunken or buried caches of treasure, which are likely to elicit excessively costly recovery efforts. See POSNER, supra note 49, at 35-36.

68 A growing body of literature addresses the societal arrangements that actually governed gold mining in California. See, e.g., Richard O. Zerbe, Jr. \& C. Leigh Anderson, Culture and Fairness in the Development of Institutions in the California Gold Fields, 61 J. ECON. HIST. 114 (2001) (focusing on the role of norms in establishing order); John Umbeck, Might Makes Right: A Theory of the Formation and Initial Distribution of Property Rights, 19 ECON. INQUIRY 38 (1981) (providing a somewhat different account); see also Andrea G. McDowell, From Commons to Claims: Property Rights in the California Gold Rush, 14 YALE J.L. \& HUMAN. 1 (2002) (providing an historical account of the evolution of property rights during the gold rush, based primarily on a review of numerous letters and diaries); John Umbeck, The California Gold Rush: A Study of Emerging Property Rights, 14 EXPLORATIONS ECON. Hist. 197 (1977), discussed in BARZEL, supra note 27, at 85-86 (observing that, notwithstanding the limited amount of violence in the gold rush, many costs were incurred in establishing and delineating rights); Karen Clay \& Gavin Wright, Order Without LaW? Property Rights During the California GOLD RUSH (Stanford U. Economics Working Paper, No. 03-008, 2003), available at http:// www.ssrn.com/abstract_id $=420960$ (emphasizing the importance of understanding gold mining as a high-stakes race to capture shares of a nonrenewable resource). 
is not socially costly in itself (the gain to that individual perfectly offsets the loss imposed on other members of the pool), but the way in which the individual makes that appropriation is likely to involve actions that are on net costly in the linked commons of the resource-gathering environment.

When the two commons are considered together, we see that people are merely "overgrazing" in the usual sense when they fight over resources. People take resource-appropriation actions that are socially costly because they internalize the benefits of those actions (by capturing a larger share of the underlying resource) without also internalizing all of the associated costs. This is obvious where the resource-appropriation activities involve costs that are wholly or partially externalized (e.g., shoving aside other people, or fighting with them, in an effort to get more gold). But it is also true in the case where the wasteful costs incurred in the resource-gathering environment are internalized to the actor (e.g., accidentally driving a pick into one's own hand as a result of haste and exhaustion, or paying a team of workers for overtime). There, the action imposes externalities on the other participants by creating a rate of resource depletion that forces the other actors to either accept a smaller share of the underlying resource or incur additional appropriation costs of their own (their own accidents and overinvestments). The net result is less value distributed among the group as a whole than would be achievable through cooperation.

We can also see the underinvestment problem at play in the resourcegathering environment. It might be the case that everyone would enjoy the activity of harvesting the resource more if the individual actors took time with pleasantries, treated each other with civility, and so on. Yet these activities generate positive externalities in the resource appropriation environment that are not wholly internalized by those making the contributions. Moreover, these activities tend to reduce the share of the underlying resource that the actor in question can gather. In deciding how to behave in a resource-gathering situation, people will, of course, take account not only of the resources they obtain, but also the costs that are incurred (or benefits enjoyed) in the gathering. Therefore, they would be willing to trade off some amount of the underlying resource in exchange for a better resourcegathering environment. But even if everyone would prefer somewhat less of the resource and a nicer resource-gathering environment, it is impossible to achieve this result unilaterally.

Once we begin to recognize the resource-appropriation environment as a commons unto itself, we can see that tragic tendencies can play out even with regard to resources that are allocated through market mechanisms or that enjoy various sorts of property protections. Arguably, uncivil or aggressive conduct does not influence the share of the underlying resource one receives in a privatized system to the same extent as it does where the resource is under common control; hence, we might expect fewer deviations from the social optimum in the resource-gathering environment where market-rationed resources are involved. For example, if prices are set appropri- 
ately, ordinarily one need not trample or elbow one's fellow shoppers to get to the cheese display first; one's willingness to pay the going price is enough to secure one's appropriation rights. ${ }^{69}$

However, more subtle tragedies of the commons can occur in the resource-gathering environments associated with market capitalism. For example, perhaps every member of a community enjoys strolling and browsing through a quaint downtown filled with unique, locally-owned shops, but prefers to purchase products at lower prices at bland suburban supercenters. This problem can be characterized as one of underinvestment in the ambience produced by the local businesses. Each member of the community who pays a higher price at the local stores bears the full financial burden of doing so, but enjoys only a share of the ambient benefits produced as a result of the solvency of the Main Street businesses. Because everyone is better off letting someone else pay the higher prices, nobody shops on Main Street. ${ }^{70}$ The result is a net drop in the overall surplus associated with the shopping experience.

Where a fixed pool of resources is involved, and where no gains or losses attach to actions in the resource-gathering environment, are gains and losses still possible as a result of the distribution itself? There are at least two distinct reasons for thinking this could be the case. The first stems from the impact of resource distribution on wealth. ${ }^{71}$ If one assumes a diminishing marginal utility of money, wealth differences wrought by initial resource distributions could influence aggregate utility. ${ }^{72}$ Here, we confront

69 This does not work perfectly. For example, there can be "runs" on popular items that result in costly rushing. Likewise, if identically-priced items are heterogeneous, early arrivals can pluck up the best deals, and later arrivals must make do with the "picked over" remains. See BARZEL, supra note 27, at 102 (explaining that "[w]hen supermarket shoppers are allowed to choose items such as apples, they are in a position to capture the value of the better apples, which are sold at the same price as the inferior apples" even though this selection effort is costly).

70 This simple summary suppresses an important aspect of this example: The good in questionambience from thriving local merchants - is probably close to being a "step good," if we assume that there is relatively narrow range of cooperative activity (Main Street shopping) that makes the difference between a viable Main Street and a defunct Main Street. See infra Part II.C.2 (defining and discussing step goods).

${ }^{71}$ If transaction costs are sufficiently low, trade following the initial distribution or harvesting of resources will move the resources themselves into the hands of those who value them most highly. For example, if one fisher more highly values a particular type of fish, the fish would end up in her hands, even if someone else initially withdrew the fish from the pond. Nevertheless, the transaction will leave the purchasing fisher with less wealth than she would have had if she had initially withdrawn the fish herself. Hence, the initial distribution has lasting implications for the distribution of wealth, even after all efficient trades have been completed.

72 See, e.g., Richard A. Posner, THE ECONOMICS OF Justice 80 (1981) (explaining that utilitarians often "derive an income-equalization goal from a combination of the principle of diminishing marginal utility of money income and the hunch that people's utility functions are pretty much alike (or at least not positively related to wealth)"); AMARTYA K. SEN, INEQUALITY REEXAMINED 95-96 (1992) (explaining that Hugh Dalton combined assumptions about identical utility functions with the assumption of a diminishing marginal utility of money to conclude that transfers toward equality would increase total social welfare). 
familiar problems about the difficulty of making interpersonal utility comparisons. $^{73}$ A second reason that distribution could produce gains and losses relates to the optimal degree of fragmentation or aggregation of resource units. For example, the total value of a tract of land will fall if it is broken up into pieces that are each too small to be of much use. In other words, fragmentation itself can generate a loss. ${ }^{74}$ This might be because boundary problems or coordination problems are exacerbated, ${ }^{75}$ because economies of scale or other complementarities among resources cannot be realized, ${ }^{76}$ or because additional transactions are necessary in order to aggregate a usable physical quantity of the resource. ${ }^{77}$ Such possibilities lead us directly to the conceptual twin of the commons, the anticommons.

73 See, e.g., POSNER, supra note 49, at 470 (observing that the utility curves of different individuals might vary in height and shape); Lionel Robbins, Interpersonal Comparisons of Utility: A Comment, 48 ECON. J. 635, 636-37 (1938) (noting difficulties in assessing levels of satisfaction experienced by different individuals), cited in AMARTYA SEN, ON ECONOMIC INEQUALITY 81 (1973). Abba Lerner suggested that this difficulty could be overcome by focusing on expected marginal utility, based on a probabilistic analysis. See Louis Kaplow \& SteVen ShaVell, Fairness Versus Welfare 30 n.58 (2002) (explaining that, under Lerner's approach, differing utility functions do not weaken the argument for equal distributions); SEN, supra, at 83-85 (giving a formal presentation of Lerner's result). But see POSNER, supra note 49, at 470 (observing that Lerner's approach does not allow for the possibility that wealthy people, on average, derive greater pleasure from money than poor people - a possibility that Posner finds plausible); Bertrand De Jouvenel, The Ethics of Redistribution, in INEQUALITY AND POVERTY 6, 7 (Edward C. Budd ed., 1967) (noting that Lerner's solution assumes "that the holders of incomes have not developed their lives and tastes in accordance with their incomes"). Our inability to prove that people have identical utility functions does not, of course, establish the contrary proposition - that each dollar generates the same utility regardless of the wealth of its holder - a view that is "equally unjustified and quite contrary to the subjective experience of most individuals." Herbert Hovenkamp, Positivism in Law \& Economics, 78 CAL. L. REV. 815, 848-49 (1990).

74 In fact, this is just one subset of a more general difficulty: Where transaction costs are significant, resources may never make it into the hands of those who value them most highly, or may do so only after significant value has been dissipated in the process. Even where there is no issue of fragmentation or aggregation, inefficiencies could result from an initial distribution that vested ownership in a lower-valuing party, where transaction costs are positive. This is one reason why it is difficulty to find real-world examples of "purely distributive" resource problems. See infra note 108.

75 See, e.g., Ellickson, supra note 1, at 1332 \& n.62 (noting the inverse relationship between tract size and the per-acre cost of fencing or monitoring the perimeter); Eric T. Freyfogle, The Tragedy of Fragmentation, 36 VAL. U. L. REV. 307, 323-36 (2002) (discussing the increase in boundaries that accompanies fragmentation of land and the related increase in opportunities for spillovers to cross boundaries).

76 See Lloyd Cohen, Holdouts and Free Riders, 20 J. LEGAL STUD. 351 (1991) (presenting a land assembly example that assumes that scale economies will be realized). I am setting aside in this paper the intriguing problems presented by that most heterogeneous and interactive of resources, human capital. The possibility that the patterns of pools into which people sort themselves for various purposes could have impacts on the total social value created has been explored in, for example, Lee Anne Fennell, Beyond Exit and Voice: User Participation in the Production of Local Public Goods, 80 TEX. L. REV. 1 (2001).

77 This would be the case when an entitlement is split up functionally so that no one person holds the right to make meaningful use of it, or when individual resource units that fit together in ways that add value are extracted separately. An example of this latter sort of fragmentation occurs whenever a habitat is overfished or overharvested, so that too many pieces of the overall system have been removed to leave the balance viable. 


\section{B. Tragedies of the Anticommons}

As the discussion above indicated, one of the possible costly outcomes of a tragedy of the commons is the creation of inefficiently fragmented property. This can happen spontaneously (for example, through the splitting of land into uselessly tiny pieces), ${ }^{78}$ or it can be the result of responses to the tragedy of the commons (e.g., assignment of legal or de facto veto rights over resource use to a variety of parties). In either case, the resulting fragmentation of entitlements may generate inefficiencies of the sort associated with the tragedy of the anticommons.

1. Two More Tragic Tendencies.-The most commonly discussed tragedy of the anticommons is usually termed "underuse."79 In the prototypical anticommons, everyone has the power to exclude everyone else from a resource, but nobody has the power to enter or use that resource without the permission of everyone else. ${ }^{80}$ In the real world, we are more likely to encounter a limited-access anticommons-a resource use over which some limited number of people have independent veto power. ${ }^{81} \mathrm{Mi}-$ chael Heller posited that this structure of entitlements contributed to the persistence of empty storefronts in post-socialist regimes, given the number of permits that were required from different actors in order to set up shop. ${ }^{82}$

The same structural problem exists any time a number of entitlements must be assembled together (or "bought up") in order to enjoy any particular use of a given resource. Recognizing the conceptual commonalities, scholars have applied the anticommons metaphor to a diverse array of re-

78 See Heller, supra note 2, at 651 (discussing "spatial anticommons" that results when land is split into parcels too small to be used). Heller discusses an extreme example: the Quaker Oats "Big Inch" promotion, in which millions of customers were granted 1-inch square pieces of property in the Yukon. Id. at 682-83. More pressing problems of excessively fractionated land interests developed on Indian reservations as land allotments held in trust splintered again and again while descending to successive generations. See, e.g., Hodel v. Irving, 481 U.S. 704, 707-08, 712-13 (1987) (describing situation in which the ownership of many land parcels was divided among multiple individuals, and one notable forty-acre parcel had 439 owners); Heller, supra note 2, at 685-87 (discussing the fragmentation of Native American land holdings).

79 E.g., Buchanan \& Yoon, supra note 3, at 1; Heller, supra note 2, at 624; Hsu, supra note 3, at 814. While the term "underuse" produces a striking mental image of a valuable resource lying fallow and simply "going to waste," it is important to understand that it is not the lack of use itself that constitutes the anticommons problem, but rather the processes that cause this to happen. Outright owners of resources can also fail to make good use of them, and this does not present an anticommons problem. Nevertheless, like the striking mental image of greed that supplies a moral undertone for the commons tragedy, see supra note 63 , the idea of idle resources adds a moral undertone to the anticommons idea that likely adds to its intuitive resonance. For a discussion of the ethical and economic implications of leaving nonlabor resources idle, see JAMES M. BuCHANAN, ETHICS AND ECONOMIC PROGRESS 120-28 (1994).

80 See Michelman, supra note 1, at 6, 9 (describing this idealized anticommons); Ellickson, supra note 1 , at $1322 \mathrm{n} .22$ (discussing same).

81 See Heller, supra note 2, at 667-69 (redefining anticommons property in this way).

82 Id. at $633-40$. 
source use problems. ${ }^{83}$ Because obtaining permission from any significant number of people is likely to be prohibitively costly, the result is a resource which nobody is able to use. Often, although not always, this leads to an inefficient result. ${ }^{84}$ Where this is the case, the result is usually understood as a tragedy of the anticommons.

The term "anticommons," then, has become a shorthand way of referencing a broad class of entitlement assembly problems. Of course, the difficulties associated with assembling entitlements for resource use was recognized well before the anticommons terminology came into vogue ${ }^{85}$ but the term "anticommons" has made these difficulties more salient. Instead of everyone having too much freedom to allocate resources between themselves and the collectivity, as was the case in the tragedy of the commons ${ }^{86}$ participants in an anticommons dilemma lack the ability to put together entitlements into bundles that would make them usable. ${ }^{87}$ This powerlessness can be better understood as a dispersal of power-the power of individual fragment holders to refuse a transfer at a price acceptable to the would-be assembler.

The high price placed on the fragment by the fragment holder could be an entirely honest expression of its value to the fragment holder. If so, and if the would-be assembler is unwilling to pay the prices honestly set by the fragment holder, then assembly would not have been efficient, and no inefficiency results when it fails to materialize. ${ }^{88}$ However, the fragment holder's price might instead be strategically set in an effort to garner a larger share of the surplus that will be generated by the assembly of the fragments. ${ }^{89}$ If so, then inefficiency results if the artificially-high prices (or strategic refusals to deal) prevent assembly of the interests in the hands of

83 See supra note 9 (citing sources that have made varied uses of the anticommons template).

84 Fragmentation does not necessarily portend inefficiency. Indeed, it is possible that fragmentation is functional, as where it generates transaction costs that stop bargains that would otherwise have occurred, but that would not have been efficient because they would not have taken into account the interests of all of the affected parties (e.g., future generations). A recent paper extolling the virtues of blockage associated with fragmented interests is Bell \& Parchomovsky, supra note 3.

85 See, e.g., Kenneth J. Arrow, The Property Rights Doctrine and Demand Revelation Under Incomplete Information, in ECONOMICS AND HUMAN WELFARE 23, 24-25 (M. Boskin ed., 1979), reprinted in 4 COLleCted PAPERS OF KENNETH J. ARROW: THE ECONOMICS OF INFORMATION 216, $217-$ 18 (1984) (discussing the difficulties that a factory owner might face in attempting to buy the rights to clean air held by a number of nearby landowners, and the resulting impediments to efficient bargaining outcomes).

86 See supra Part I.A.

87 See Heller, supra note 2, at 640 (explaining that "[m]oving a storefront from anticommons to private property ownership requires unifying fragmented property rights into a usable bundle"); Heller, $s u$ pra note 12, at 88 (observing that "[o]nce an anticommons emerges, collecting rights into usable private property is often brutal and slow").

88 The distributive results may be undesirable, however. See infra Part I.B.2 (discussing distributive issues).

89 Arrow, supra note 85, at 218 (discussing the incentives that landowners would have to misstate their preferences, when approached by a factory owner seeking to buy permission to emit smoke). 
the person who values them more highly. Importantly, the strategic behavior in question can be anticipated rather than actual, discouraging a wouldbe assembler from bothering to incur the cost of attempting an assembly. ${ }^{90}$

Holdout behavior ${ }^{91}$ imposes externalities on other people in two ways. First, it generates costs ${ }^{92}$ that are borne in part by the would-be entitlement assembler, rather than wholly by the holdout. The assembler cannot simply take the holdout at her word when she says she will not sell at a particular price, for this could be a strategic ploy. Hence, the assembler must spend time and effort attempting to determine the true reservation prices of all the fragment holders before she can determine whether the deal is viable. Second, if the transfer of the fragment does not occur, the opportunity cost associated with unfulfilled gains from trade are not wholly internalized to the holdout, but instead destroy surplus that would otherwise be enjoyed by the

90 See, e.g., Cohen, supra note 76, at 359 (noting that entrepreneurs who anticipate significant holdout and free rider problems may either abandon their projects or engage in costly efforts to keep their assembly plans secret); Robert C. Ellickson, Suburban Growth Controls: An Economic and Legal Analysis, 86 YALE L.J. 385, 445 n.167 (1977) (assuming, for purposes of an example, "that fear of holdouts would deter suburbs from trying to buy up consumers' and landowners' rights to enjoin efficient antigrowth programs"); Michael A. Heller \& Roderick M. Hills, Jr., The Art of Land Assembly 5 (Jan. 2004) (unpublished partial draft, on file with author) (noting that would-be assemblers' anticipation of holdout problems may lead them to choose other investments or delay assembly efforts), available at http://www.law.uchicago.edu/Lawecon/workshop-papers/Heller.pdf.

91 By "holdout behavior," I mean strategically-motivated refusals to deal, or price demands that are in excess of private valuations, arising out of a desire to obtain a larger share of the surplus that will be generated through the assembly of the entitlements. See Cohen, supra note 76, at 362 (defining a holdout as an owner who recognizes that, because of scale economies or other advantages generated by assembly, his parcel has become "more valuable to the entrepreneur"); Jeffrey E. Stake, Toward an Economic Understanding of Touch and Concern, 1988 DuKE L.J. 925, 936 (explaining that "[a] holdout problem develops when one party insists on more than a proportionate share of the price that a willing buyer will pay for a right held jointly by all members of a group, or when that party insists on more than the value he places on the right simply because others are receiving a higher amount."). I do not number among the holdouts those who honestly value their fragments at a prohibitively high price. See Gideon Parchomovsky \& Peter Siegelman, Selling Mayberry: Communities and Individuals in Law and Economics, 92 CAL. L. REV. 75, 128-29 (2004) (limiting the term "holdout" in this fashion and using the term "holdin" to designate a person who chooses not to sell because of a high subjective valuation); infra Part I.B.2 (discussing distributive results associated with holdins).

92 The costs associated with holdout behavior are sometimes treated as an important subcategory of transaction costs. See, e.g., Robert C. Ellickson, New Institutions for Old Neighborhoods, 48 DUKE L.J. 75, 103 (1998) (observing that "holdout strategies" could greatly increase transaction costs); Thomas G. Krattenmaker \& Steven C. Salop, Anticompetitive Exclusion: Raising Rivals' Costs to Achieve Power Over Price, 96 YALE L.J. 209, 273 (1986) (discussing "transaction costs in the form of 'hold out' problems"). At other times, holdout problems are treated as a separate category from transaction costs. See, e.g., Cooter, supra note 65, at 17 (suggesting that parties to bargaining interactions face "another obstacle of an entirely different kind" from transaction costs when they must decide how to divide up the surplus in the absence of a fixed price). This ambiguity is a function of the imprecise and varying ways in which the term "transaction costs" has been used. See id. at 16 (noting that "[t]he meaning of transaction cost is not well-standardized in the literature"). Here, I will use the narrower term "holdout problem" or "holdout cost" to specifically designate the class of strategic bargaining difficulties associated with holdouts, and the broader term "transaction costs" as a catch-all that encompasses a wide array of transaction-related problems, including holdout problems. 
would-be assembler and all of the other fragment holders who are now precluded from engaging in mutually-beneficial trades leading to entitlement assembly. To put it another way, the fact that a deal does not occur will hurt the holdout, but the pain will be shared by all of the other would-be parties to the transaction who would otherwise reap benefits from the deal. ${ }^{93}$

The second tragic tendency associated with an anticommons also relates to fragmentation, but this time the fragmentation gives rise not to inefficiently overprotective assertions of rights over a resource, but to inefficient underprotection of a resource. ${ }^{94}$ Consider a case where anyone who wishes to use a park must go through a door secured by ten locks, keys to which must be obtained from each of ten entitlement-holders. Here, the entitlement to enter the park has been fragmented among ten people, and must be reassembled in the hands of the would-be parkgoer before she can enter the park. But imagine further that a simple set of burglar's tools contains a skeleton key that opens every lock, so that an interloping parkgoer can gain entry through illicit means, without permission from any of the ten fragment-holders. Any fragment-holder could block this interloper's unauthorized action by enforcing her property entitlement. However, the fact that the illicit user has trenched on the property rights of not just one person but of many simultaneously means that any property owner who stands up for her own rights will also be standing up for the rights of all the other violated property owners. Hence, a free-rider problem develops. ${ }^{95}$ Any enforcer must bear the full cost of enforcement, but enforcing an entitlement in this context generates positive externalities for all of the other fragmentholders. As each fragment-holder attempts to bluff other fragment-holders into enforcing exclusion rights, inefficient incursions into the jointly held resource can result.

What makes a tragedy of the anticommons "tragic" are the same two ingredients that we saw in the context of the tragedy of the commons: first, that the individual actors fail to internalize all the costs or benefits of their actions; and second, that the total returns to the group's members are larger in the case of cooperative action than in the case of defecting action. Here, the externality-generating actions involve either inefficiently blocking resource use through refusal to transfer a fragmentary interest, or protecting a resource from illicit appropriation by someone who has not, in fact, legitimately assembled the necessary fragmentary interests. In the former case, the externality involved is negative; in the latter case, it is positive. Consequently, we would expect to see too much blocking where assembly would

93 See, e.g., Buchanan \& Yoon, supra note 3, at 4 (explaining that both commons and anticommons tragedies arise from the fact that "separate decision makers, each of whom acts in exercise of assigned rights, impose external diseconomies on others who hold similar rights"); Parisi et al., Duality, supra note 3 , at 3,6-7, 8 (discussing externalities associated with exclusion in an anticommons).

94 See Heller, supra note 2, at 676 (describing this possibility, using the example of a California coastal area along which any community member could block development).

95 Id. 
be the efficient result, and not enough enforcing where protecting the fragmented rights would be the efficient result. ${ }^{96}$

Cooperation capable of generating larger total returns means one of two things in this context. It could mean playing one's part in a set of transfers that will consolidate a fragmented entitlement and thereby facilitate its highest and best use. For this to be the case, there must be an increment of surplus associated with the assembly qua assembly. That is, the assembled entitlement must be worth more in one person's hands than its parts are worth, in the aggregate, when dispersed among many hands.

Alternatively, cooperation could mean stepping in to prevent someone from simply grabbing entitlements that she does not own. In this case, failure to prevent illicit encroachments only turns "tragic" (inefficient) if the fragments are more valuable when enforced as fragments than they are when gathered together in the hands of the interloper. If the interloper actually values the fragments when assembled more highly than the fragmentholders value them in the aggregate, the unchecked interloping introduces no inefficiency. However, because lack of enforcement encourages inefficient transfers as well as efficient ones, a general breakdown of enforcement would likely lead to inefficient results over time.

2. Distributive Questions Distinguished.-Here too, it is useful to distinguish situations in which the second of the tragic ingredients is missing from an anticommons setting, such that the problem is one of distribution rather than efficiency. Consider first the person who blocks assembly of a set of entitlements that, to an outside observer, appears as if it would be much more valuable if brought together in the hands of an assembler. The blocker might be a strategic holdout who is refusing to make the transfer in the hopes of gaining a larger portion of the surplus - that is, demanding a price in excess of her subjective valuation. If her bluff does not work and the deal fails to occur, then the result is inefficient; surplus that might have been enjoyed by the parties is lost.

However, if the bluff does work - that is, the other parties back down and accept smaller shares of the available surplus in order to finance the larger share of surplus that the bluffer is demanding - the deal occurs notwithstanding the holdout behavior. Putting aside for a moment the dissipation of surplus associated with the bluffing itself and the responses to it, ${ }^{97}$ the outcome remains efficient; only the distribution of available surplus is

\footnotetext{
96 It is possible that both lapses could occur simultaneously. Imagine a neighborhood whose members are bound together through a set of reciprocal land use covenants. One member would like to assemble permission to do something forbidden by the covenants that will yield a net benefit, such as install a safety fence in the backyard, and the rest of the neighbors become embroiled in a strategic holdout game (excessive blocking). Meanwhile, these same neighbors allow someone else to get away with a covenant breach that does not, in fact, yield more benefits than it imposes on the neighbors as a group (insufficient enforcement).

97 This will be discussed infra Part I.B.3.
} 
affected. ${ }^{98}$ If we posit a perfect bluffer who can costlessly and convincingly force others to take smaller shares of surplus, the resulting realignment of surplus is a distributive matter, not a source of inefficiency. There is no $a$ priori reason to cast moral aspersions on such a bluffer, either-without a well-defined theory of who "deserves" the surplus, the fact that one party ends up with a larger or smaller share of the available surplus merely constitutes a neutral fact. ${ }^{99}$ After all, someone has to end up with each increment of available surplus, if the surplus-generating realignment of entitlements occurs.

There is another possibility as well. The person who seems to be "holding out" might instead be what Gideon Parchomovsky and Peter Siegelman term a "holdin" 100 _ someone who subjectively values her share of the fragmentary interest above the amount that the assembler is willing to pay her. ${ }^{101}$ If a deal fails to happen because of the intractability of a person who genuinely values the fragment in excess of the best offer she receives, there is no efficiency loss. ${ }^{102}$ However, the distributive outcome could be questioned. Perhaps the holdin's tastes seem so idiosyncratic or selfish as to make her refusal to deal appear unfair. Another possibility is that intractabil-

98 See, e.g., Cohen, supra note 76, at 352-53 (observing that the ability of parties to extract some of the surplus associated with a consolidation project is a "purely distributive" matter, where transaction costs remain unchanged and the project proceeds as planned); Lewinsohn-Zamir, supra note 17, at 226 $\mathrm{n} .25$ (observing that, in efficiency terms, "[ $\mathrm{t}]$ he distribution of the gains from the transaction between the parties is not important, as long as it does not affect total efficiency"); Polinksy, supra note 17, at 107778 (explaining that the argument about "extortion" being available to property holders "relates to the goal of distributional equity, not economic efficiency").

99 See Krier \& Schwab, supra note 17, at 466-67 (critiquing the view that a holdout is engaged in a form of extortion, where there is no reason to believe that she is any less entitled to the surplus than the other parties, and observing that even a liability rule solution — which avoids holdout problems — assigns the surplus to one party rather than another).

100 Parchomovksy \& Siegelman, supra note 91, at 128-29; see Carol M. Rose, Servitudes, Security, and Assent: Some Comments on Professors French and Reichman, 55 S. CAL. L. REV. 1403, 1412 (1982) (explaining that "[s]ometimes that purported holdout has a genuine interest in his property right, however irrationally inflated that interest may seem to the world at large").

101 As Parchomovsky \& Siegelman note, it is possible for someone to be somewhere between a "holdout" and a "holdin"- that is, a person might state a genuine reluctance to sell, but have in mind the possibility of selling at a high enough price. Parchomovsky \& Siegelman, supra note 91, at 129-30. It is indeed also possible that the person holding the entitlement does not even fully know to what extent her reluctance to sell arises out of a deeply-held subjective valuation as opposed to an ingrained strategic reflex to respond to inquiries about sales with great reticence.

102 Forcing the holdin to sell to the assembler at a price below the holdin's true reservation price would clearly make the holdin worse off, preventing the transaction from being a Pareto improvement. See POSNER, supra note 49, at 12 (defining a Pareto improvement as "one that makes at least one person better off and no one worse off"). Nor would it be efficient in the Kaldor-Hicks sense, because the amount of gain that the assembler would receive would not, in fact, be enough to truly compensate the holdin at his subjective valuation of the fragment. See id. at 13 (explaining that an efficient transaction in the Kaldor-Hicks sense is one in which the "winners could compensate the losers, whether or not they actually do"); see also JULES COLEMAN, MARKETS, MORALS AND THE LAW 95-132 (1998) (discussing these criteria of efficiency). 
ity of the holdin comes not from "rational" valuation of the fragment, but from an "irrational" desire to harm someone else by withholding the fragment. ${ }^{103}$ Perhaps we think that it is distributionally better to transfer the entitlement over the objections of the spiteful or eccentric holdin, if we believe that these distributive improvements swamp any associated losses. We might also question the fairness of the allocative process that endowed the holdin with veto power in the first place. ${ }^{104}$ The important point for present purposes is to recognize where an efficiency problem is created by an anticommons structure and where instead the problem is one of distribution only. ${ }^{105}$

3. Dividing Surplus and the Surplus-Dividing Environment.--If we understand the tragedy of the anticommons as being animated by a struggle over surplus, the problem begins to look analytically much like the fixedpot resource games described earlier. ${ }^{106}$ If a particular assembly of fragments (or, alternatively, enforced nonassembly) yields some specific amount of surplus, the only interesting question would seem to be how the surplus will be divided. But, just as in the case of a fixed-pot resource like a cache of gold, the actions of the parties in their attempts to gain larger shares of the surplus will impact the value that each member of the group is able to carry away from the interaction. Like competing gold miners who sustain injuries from haste or overinvest in mining equipment, parties sparring over the distribution of the surplus associated with an assembly of fragmented interests dissipate some of that surplus in the process.

What is remarkable about the anticommons situation is the possibility that strategic posturing and wrangling may sink a deal altogether, so that the

103 In contrast to the rational actor who is concerned only with her own outcome and is indifferent to the outcomes of others, people often behave in ways that suggest they do care about the outcomes others receive and can be motivated by factors such as spite. See, e.g., Arthur Leff, Injury, Ignorance, and Spite: The Dynamics of Coercive Collection, 80 YALE L.J. 1 (1970) (discussing willingness to pay for spite); Carol M. Rose, Property as Storytelling: Perspectives from Game Theory, Narrative Theory, Feminist Theory, 2 YALE J.L. \& HUMAN. 37 (1990) (discussing the possibility that a party to a strategic interaction might have atypical preferences, and introducing one character, Malice Aforethought, who most prefers the payoffs that give his opponent the least). Empirical research suggests that people are often willing to incur positive costs in order to punish perceived unfairness. See, e.g., RICHARD H. Thaler, The Winner's Curse: PARAdOXes AND ANOMALIES OF ECONOMIC LifE 22-35 (1992) (discussing experimental literature on the ultimatum game); Christine Jolls et al., A Behavioral Approach to Law and Economics, in BeHAVIORAL LAW AND ECONOMics 13, 21-23 (Cass R. Sunstein ed., 2000) (noting that in "ultimatum games" parties typically reject offers of less than 20 percent of the total, demonstrating a willingness "to punish unfair behavior, even at a financial cost to themselves.").

104 The existence of an endowment effect that heightens attachments to held entitlements could reinforce fairness concerns by suggesting that a different initial distribution might have generated a different, but equally efficient, end result. See infra note 281 (citing sources that discuss the implications of the endowment effect for entitlement choices).

105 I do not mean to suggest that distributive concerns are less important than efficiency concerns, only that the latter fits with the typical meanings given to the tragedies in question. See supra note 11.

106 See supra Part I.A.2-3. 
entire surplus that might have been shared among the parties vanishes outright. In that case, each person walks away empty-handed. Each party would have been better off taking a "sucker's payoff" - a smaller than average share of the surplus rather than undertaking actions in the surplusdividing environment that destroyed the entire surplus.

\section{A FunCtional TAXONOMY OF TRAGEDY}

The system of classification I propose begins by bringing together both commons and anticommons tragedies under the umbrella heading of "common interest tragedies." 107 Although the term "common interest tragedies" encompasses a very broad category, it does not include problems of pure distribution that do not alter the size of the total "pie" available for the parties. ${ }^{108}$ The potential for increasing the total amount of value for the parties through cooperation is what makes the problem one of "common interest" for the parties. While it is true that the parties have interests that conflict in these settings (hence, the potential for tragedy), they simultaneously have a common interest in maximizing the total sum of value available to share.

How can this broad category of common interest tragedies be most usefully subdivided? In subpart A, I present a series of examples that illustrate weaknesses in the distinctions often drawn between tragedies of the commons and tragedies of the anticommons. I also show that the tragedies are linked to each other in interesting and underappreciated ways. In subpart B, I propose a functional distinction based on the strategic patterns that present stumbling blocks to an efficient outcome. In subpart C, I examine some wrinkles in this system of classification and add some further elaborations.

\footnotetext{
107 To my knowledge, no such umbrella term is in current usage. The generic term "collective action problem" encompasses both sorts of tragedies, but is not limited to resource-related dilemmas. It seems helpful to have a more precise term for referencing problems surrounding a resource of common interest to the group. The term "resource dilemma" is a promising candidate, but it has been employed in a somewhat more limited fashion to reference dilemmas that present a threat of resource depletion from overharvesting. See Kimberly Wade-Benzoni et al., Egocentric Interpretations of Fairness in Asymmetric, Environmental Social Dilemmas: Explaining Harvesting Behavior and the Role of Communication, 67 ORGANIZATIONAL BEHAV. \& HuM. DeCision PROCESSES 111, 112 (1996) (defining "resource dilemma").

108 It is unclear how prevalent pure problems of resource distribution are in the real world. As explained above, actions in the resource-gathering or surplus-dividing environments can "shrink the pie," as can the degree of aggregation or fragmentation of a given resource. More generally, the fact that different people can attach different subjective values to different resources presents a challenge to the notion of pure distribution. If transactions costs were zero, resource units would readily move into the hands of the person who valued them most highly, regardless of the initial distribution. Where transaction costs are significant, however, the distribution can itself "shrink the pie" if transfers from lowvaluing owners to high-valuing owners do not occur or occur only at significant cost. Moreover, to the extent one is interested in maximizing welfare rather than merely wealth, the diminishing marginal utility of money suggests that allocations of wealth, which depend on allocations of resources, are very likely to affect efficiency. See supra notes 71-73. Nevertheless, some resource-allocation problems, such as divisions of resources among people with relatively homogeneous preferences and relatively similar wealth levels, approximate problems of pure distribution.
} 


\section{A. One Big Tragedy, After All?}

A careful look at the tragedies of the commons and the anticommons reveals a number of similarities. Tragedies of the commons and the anticommons both arise from the same two conditions: a failure of actors to internalize all costs and benefits associated with a given resource, coupled with a situation in which net gains can be achieved through cooperation. Hence, the problems exhibit a certain symmetry. ${ }^{109}$ The commons and the anticommons both arise out of a fragmentation of interests, if we allow the idea of "interests" to be broadly understood. ${ }^{110}$ In the case of the tragedy of the commons, individual people have atomistic, uncoordinated self-interests that conflict. What is splintered in that case is access to the resource in question. Everyone has his or her own door to the common pool, so to speak, and can withdraw or damage the resources found within. ${ }^{111}$ In the case of the anticommons, the fragmentation is reflected in a dispersal of complementary property interests among a number of individuals. The problem here can be understood as a single door that can be legitimately accessed only by obtaining keys from a number of individuals, but which may in some circumstances be vulnerable to breach.

But how can we really tell a commons problem from an anticommons problem when we encounter one in the real world? Two distinctions are commonly employed: a distinction between overuse and underuse, and a distinction between use privileges and exclusion rights. Neither distinction withstands scrutiny. I will consider each in turn.

1. Overuse Versus Underuse.-In the literature, commons problems and anticommons problems are typically associated with overuse of a resource and underuse of a resource, respectively. ${ }^{112}$ Examination of the tragedies, as surveyed above, reveals that this distinction is problematic. The second type of commons tragedy (undercultivation) tends to generate underuse of a resource, while the second type of anticommons tragedy (underprotection) tends to generate overuse of a resource. ${ }^{113}$ Yet even if we

\footnotetext{
109 Indeed, Buchanan and Yoon have termed them "symmetric tragedies." Buchanan \& Yoon, supra note 3.

${ }^{110}$ See Parisi et al., Duality, supra note 3, at 9 (observing that it is the lack of alignment between use privileges and exclusion rights that creates tragedy in both cases).

111 To put it another way, members have "first possession" rights in the resource flows that they can individually capture. Lueck, supra note 33 , at 202. Alternatively, members can effectively use up resource units by offloading "bads" into the commons, or reduce the number of resource units by withholding their own cultivation efforts.

112 See, e.g., Buchanan \& Yoon, supra note 3, at 1 (analyzing "the anticommons problem in which resources are inefficiently underutilized rather than overutilized, as in the familiar commons setting"); Heller, supra note 12, at 87 (associating the tragedy of the commons with a tendency towards overuse and the tragedy of the anticommons with a tendency towards underuse); Hsu, supra note 3, at 814 (same).

113 Heller points out that underuse in a commons and overuse in an anticommons are "theoretically possible," but goes on to note that most real-world examples seem to follow the patterns with which the
} 
dismiss these "second tragedies" as less important or ignore them altogether, the distinction still does not withstand scrutiny. Even when we limit our attention to just the first tragedy of the commons (overgrazing) and the first tragedy of the anticommons (overexclusion), taking either idea to its logical conclusion demonstrates the vulnerability of any simple dichotomy between overuse and underuse - at least insofar as we associate "overuse" with more intensive resource use, and "underuse" with less intensive resource use.

First, while the prototypical examples of commons tragedies involve a too-intensive use of a common pool resource, the same logical problem attends "draws" against a common pool resource - such as space - that actually result in a less intensive pattern of use. Consider the appropriation of empty space in a common parking lot. Unless guided by painted lines or parking attendants, people create their own space buffers between cars. The fact that these space buffers are not always of an optimal size can be readily understood as a tragedy of the commons. A person parking her car on the end of an existing row of cars can appropriate a buffer that is nearly as large as the smallest vehicle that could potentially park in the lot and thereby gain some incremental comfort in exiting the car and some marginal increase in protection against door dings. She does not, of course, bear the costs associated with the appropriation of this extra-large space buffer; those costs are borne by later-arriving would-be parkers who find the lot less than densely filled, but without any usable parking spaces remaining. The result is too little use of the parking lot.

To be sure, once the lot is inefficiently filled with cars, we could recast the resulting problem as an anticommons dilemma. The extra fragments of space between cars are unusable unless aggregated together, and this is impossible without the consent and participation of a number of car owners (who would have to be persuaded to give up or sell their buffer spaces, and move their cars over to make room for a new car). However, the initial decision to take "too much" space fits neatly within the usual notion of a tragedy of the commons. This example illustrates not only how a commons tragedy can result in underuse (that is, a less intensive use), but also how an anticommons problem may follow upon the heels of a commons problem.

Likewise, although the tragedy of the anticommons is usually stated in prototypical form as a problem of physical exclusion from a commons resource and a resulting "underuse" of the resource, the tendency in question is actually much broader in scope and encompasses all inefficiencies resulting from an inability to aggregate the requisite property rights in order to enjoy a particular resource. Fragmentation of property rights can keep people from enjoying a resource cleared of certain kinds of intrusions, just as surely as it can prevent people from using a resource in a particular way themselves. ${ }^{114}$

terms are more usually associated. Heller, supra note 2 , at $675-76$ \& fig. 6.

114 Cf. Duncan Kennedy \& Frank Michelman, Are Property and Contract Efficient?, 8 Hofstra L. 
This is really just a question of properly specifying the resource in question. For example, the resource in question might be "silence" or "clean air" which nobody can "use" without obtaining consent from every noisemaker and polluter with the power to "exclude" people from their enjoyment of these resources. Enjoying the resource of silence or clean air precludes, and requires the relinquishment of rights over, a myriad of other uses. ${ }^{115}$ In these cases as well, the problem can be couched as "too much property" 116 in too many hands - here the entitlement to make noise or emit pollution is fragmented among a set of people within earshot and airflow range.

One might argue that this is really a garden-variety tragedy of the commons, a case of "overgrazing" the air, not a tragedy of the anticommons. It seems more accurate to suggest it is both. The individual actions that people take with regard to making noise and polluting have the character of actions taken in a commons without regard for negative externalities. But if we posit a person (or set of persons) interested in aggregating the necessary entitlements to stop the air and noise pollution, then the difficulties that they face in doing so look remarkably like the sort of fragmentation challenge associated with an anticommons. Thus, a tragedy of the commons (the tendency to overgraze the air) can morph before our eyes into a tragedy of the anticommons once we take note of the fragmentary interests that facilitate the overgrazing and consider the possibility of putting them together under one person's control to stop it from happening. ${ }^{117}$ Indeed, any tragedy of the commons contains within it the potential for a surplus associated with moving from universal defection to universal cooperation. To simplify a little, the tragedy of the commons tells us why things are likely to

REV. 711, 750 (1980) (describing a large-scale anticommons-like regime, in which everything, including labor, is owned by "the whole world"-so that one must gain the consent of everyone in the world to do things or use resources and also to refrain from doing things or using resources). As this example shows, a structural problem associated with acquiring consent can exist regardless of the content or valence of the choice or benefit that requires consent.

115 Consider the following analogy: an empty canvas, a set of people who would like to paint on it, and one person who would like to keep it empty. If the would-be painters all have paints and paintbrushes in their hands and are allowed to use them, the person who wants to keep the canvas empty must buy the paints and brushes from the individual painters if she is to keep the canvas empty. If she succeeds in this, the resulting "use" of the canvas is of a field-occupying nature-it precludes all of the other intended uses. This observation echoes Coase's point about the reciprocal nature of land use conflicts. See Coase, supra note 45 , at 2.

116 The anticommons has been associated with the existence of "too much" property. E.g., Heller, supra note 12, at 92. Of course, the commons also involves a problem of "too much" property, to the extent parties have entitlements that let them capture resource units at will, withhold their own contributions, and despoil the resources within the commons with impunity.

117 In some contexts, such a solution may seem wildly implausible. For example, Freyfogle suggests that we cannot "hope to solve the tragedy of the commons by awaiting a wealthy patron who pays all graziers to refrain from overgrazing." FREYFOGLE, supra note 27, at 198. While awaiting a benevolent donor to solve a commons dilemma is surely foolhardy, the solution of buying up grazing privileges would not sound so implausible if there were a way for an entrepreneur to capture the gains associated with the resulting grazing reductions. 
fall apart, and the tragedy of the anticommons helps explain why it is often so hard to get them back together.

A legal response that grants everyone the right to stifle offending uses would skip past the anticommons difficulty just described and provide an immediate antidote to the commons dilemma. ${ }^{118}$ However, it would introduce a new problem. Under such an entitlement regime, anyone wishing to engage in one of the forbidden uses would have to assemble permission from all of the rights-holders, and as a result, we would be likely to see too few of these uses. ${ }^{119}$ This, of course, is a standard anticommons problem, and the basis for the tradeoff that anticommons scholars have identified: Attempting to solve the commons problem through increased "propertization" risks an anticommons. ${ }^{120}$ The less-recognized point is that leaving a commons dilemma unsolved also presents a difficulty that is structurally similar, in that it likewise involves a dispersed set of entitlements capable of blocking access to a desired resource.

2. Use Privileges Versus Exclusion Rights.-The anticommons has also been distinguished from the commons based on the nature of the entitlements that the parties hold, as follows: In a commons, the parties hold use privileges but do not hold the right to exclude each other, while in an anticommons, the parties hold exclusion rights but not use privileges. ${ }^{121}$ This distinction works well enough when the anticommons is considered in its pure or prototypical form as an entirely empty, unused resource - as it was in its

118 Ezra Mishan developed a theory of "amenity rights" decades ago that contemplated granting individuals veto authority over all manner of spillover-causing uses. Anyone who wished to engage in such a use would have to buy up the rights. Mishan explains how these rights might operate with regard to a gasoline-powered lawnmower in a residential neighborhood:

The din produced by any one man [operating a lawnmower] is invariably heard by dozens of families who, of course, may be enthusiastic gardeners also. If they are all satisfied with the current situation or could come to agreement with one another, well and good. But once amenity rights were enacted, at least no man could be forced against his will to absorb these noxious by-products of the activity of others. Of course, compensation that would satisfy the victim (always assuming he tells the truth) may exceed what the offender could pay. In the circumstances, the enthusiast would have to make do with a hand lawn-mower until the manufacturer discovered means of effectively silencing the din.

EZRA J. Mishan, THE COSTS OF ECONOMIC GROWTH 71 (1967).

119 James Buchanan recognized this flaw in Mishan's theory of "amenity rights." See JAMES BUCHANAN, The Institutional Structure of Externality, in 15 COLLECTED WORKS OF JAMES BUCHANAN: EXTERNALITIES AND PUBLIC EXPENDITURE THEORY 174, 179 (2001) (explaining, after presenting an example of how such a regime might overrestrain, that "[ $t$ ]his possible tendency toward an underproduction of the externality-generating good or service is the central flaw in the proposals to resolve environmental quality problems by the creation and assignment of new 'amenity rights' to citizens").

120 See supra note 12 and accompanying text.

121 See Heller, supra note 2 (suggesting that a tragedy of the commons may follow "when too many individuals have privileges of use in a scarce resource," while a tragedy of the anticommons may ensue "when too many individuals have rights of exclusion in a scarce resource"); see also Dibadj, supra note 3, at 1050 (defining an anticommons "as a legal regime where the Hohfeldian right to exclude is created without granting the 'bundle of rights' that constitutes property"). 
original "thought experiment" incarnation. ${ }^{122}$ But the distinction becomes unstable when one attempts to spot an anticommons in its natural habitat. The reason is suggested by the discussion above. When people hold one sort of use privilege in a densely-interwoven social context, they also implicitly have the ability to exclude each other from an enjoyment of the resource free of the limits imposed by exercise of that use right. For example, if everyone is allowed to run screaming through a public green space, each such screaming person effectively excludes everyone else from the resource of a reasonably quiet park site for hearing subtle musical performances or carrying on an ordinary conversation.

To take another example, consider a swimming pool frequented by some people who would like to swim laps, and others who would like to randomly bob around in the water. If the bobbers could leave a contiguous strip of water free of bobbing, the lap swimmers could swim laps. The amount the lap swimmers would gain from this arrangement, let us assume, would far exceed the marginal cost to the bobbers in restraining their movements. Is the pool "commons property" or "anticommons property"? ${ }^{123}$ Do the bobbers have "use privileges" or "exclusion rights"? On the one hand, the bobbers are taking up more space with their movements than is efficient; they garner all the benefits of free movement, but bear none of the costs they impose on the lap swimmers (or, indeed, on each other). This makes it look like a commons problem. But from another perspective, it looks like an anticommons problem. The bobbers are effectively excluding the lap swimmers from enjoying a whole lap lane at a time. The would-be lap swimmers would need to buy up "bobbing rights" from each bobber with respect to a contiguous, swimmable strip of the pool in order to be able to gain access to the resource of a lap lane.

Such interactions between use privileges and exclusion rights are not limited to a small class of idiosyncratic examples; rather, they are at the heart of most, if not all, real-world resource conflicts. It is not even necessary for there to be two conflicting uses of a given resource in order for this use/exclusion interface to exist. For example, overfishing is a standard commons tragedy, but it also (at the extreme) breaks up a viable population of fish into harvested fragments that are scattered to the four winds. Getting (or keeping) those fish into one place so that they can continue to reproduce is a prerequisite to anyone's enjoyment of the resource of a viable fish population, but this result cannot be guaranteed without buying up fishing privileges from all of the people presently holding them. Absent this, any fisher can exclude all the other fishers from access to a viable fish population by taking too many fish out of the pond. This convergence of

\footnotetext{
122 See Michelman, supra note 1, at 6, 9 (presenting the hypothetical regulatory regime that became known as a prototypical anticommons); DUKEMINIER \& KRIER 5TH, supra note 6, at 56 (describing the original formulation of the anticommons as a "thought experiment").

123 Heller, supra note 12, at 87 (suggesting that "[a]nticommons property can be best understood as the mirror image of commons property").
} 
use and exclusion in one resource problem exists even when we assume that the reason people desire access to a viable fish population is the very same reason that people are tempted to overfish in the first place - the wish to derive profits from extracted, marketable fish.

One might object that I am using "exclusion" in a nonstandard way when I use it to refer to the blocking associated with incompatible resource use. ${ }^{124}$ To be sure, the kind of exclusion that typically accompanies private property ownership involves the "fencing in" of a resource so that it may be used without interference in any number of ways, or in no way at all, ${ }^{125}$ by its owner, and by those whom its owner chooses to admit. ${ }^{126}$ In the standard anticommons story, however, the excluders are not full owners, and hence do not enjoy discretion to choose among an array of resource uses behind an exclusionary fence or even to selectively permit others to access the resource. ${ }^{127}$ Instead, each person holds only the bare right to block others from using the resource. The same blocking ability is conferred upon anyone who is granted a privilege of use that is inconsistent with access to the resource in question. ${ }^{128}$ In the latter case, each person's privilege to engage in an incompatible use constitutes a barrier to any other person's unimpeded enjoyment of the resource.

Another possible objection to this line of reasoning would focus on Wesley Hohfeld's distinction between privileges and rights. ${ }^{129}$ In Hohfeldian terms, a right has the backing of state force, while a mere privi-

124 This notion of exclusion is directly analogous to the exclusion that accompanies consumption of a rival good (when I eat a berry, I am effectively excluding everyone else in the berry patch from any use of that berry as a resource).

125 See J.E. Penner, The “Bundle of Rights" Picture of Property, 43 UCLA L. REV. 711, 745 (1996) (conceptualizing the right of property "not only as an interest in dealing with things without interference, but as an interest in dealing with them or not dealing with them, as one chooses").

126 J.E. Penner has said that "[t]he right to property is a gate, not a wall," $i d$. at 744, to emphasize that the exclusion associated with property ownership also encompasses the power to selectively include others in one's use of resources.

127 Access depends on the unanimous consent of everyone holding a veto right, which makes it beyond the power of any individual veto-holder to confer.

128 One could argue that in some settings an incompatible use is capable of blocking only another specified use, rather than blocking a set of uses broad enough to be understood as foreclosing "access to the resource." See Henry E. Smith, Exclusion Versus Governance: Two Strategies for Delineating Property Rights, 31 J. LEGAL STUD. S453, S467 (observing, in distinguishing "exclusion" from "governance," that "[e]xclusion bundles a large class of uses together such that we can speak of regulating access to a resource"). But this distinction, which is highly useful in assessing the relative costs and benefits of broad-gauged exclusion technologies as opposed to finer-grained governance mechanisms for controlling property rights, see generally id., holds no significance here. The narrowness or breadth of the entitlement at issue may bear on the stakes involved in assembling fragmented pieces into a usable whole, but it does not systematically change the shape of the strategic interaction associated with that assembly.

129 See Wesley Newcomb Hohfeld, Fundamental Legal Conceptions as Applied in JUDICIAL REASONING 36-42 (Walter Wheeler Cook ed., 1964) (1919). 
lege cannot command the coercive power of the state. ${ }^{130}$ Hence, private action can counter a privilege and keep it from being exercised. ${ }^{131}$ Based on this, one might be tempted to argue that a "right" of exclusion blocks access to a resource in a different and more meaningful way than can any "privilege" of use. ${ }^{132}$ But the Hohfeldian correlative to a "privilege" is "noright," which means that the force of law cannot be brought to bear against a person who is exercising a privilege. ${ }^{133}$ Most of the imaginable private means of keeping a person from exercising a use privilege would not only be temporary, labor-intensive, and unpleasant, but would also be very likely to violate some right of the privilege-holder, such as a right against trespass or assault, to which the law would appropriately respond. Finally, even a "right" of exclusion does not guarantee that exclusion will be perfect; not every violation will be detected, and not every detected violation will be prosecuted. Hence, whatever metaphysical distinction may exist between the strength of the two sorts of entitlements does not form a robust basis for distinguishing between types of common interest tragedies.

If "commons" and "anticommons" retain a core of meaning that makes the concepts useful as ordinarily employed, then it might seem a pointless stunt to show that they can be logically stretched to the point of overlap and made to shape-shift into each other. My reason for demonstrating their conceptual overlap and logical resemblance, however, is not to debunk their use as shorthand terms, but rather to suggest that the usual bases of distinguishing between the dilemmas - overuse versus underuse, and use privileges versus exclusion rights - are inherently unstable and ultimately less useful than a different, functional understanding of the dilemmas, based on types of strategic interactions. ${ }^{134}$

\footnotetext{
130 See Arthur L. Corbin, Jural Relations and Their Classification, 30 YALE L.J. 226, 229 (1920) (explaining that if person A has a "right" within Hohfeld's schema, this means that the "giant" of the law will "aid A by forcibly controlling B's conduct," whereas the holder of a "privilege" is merely free of legal constraint).

${ }^{131}$ Hohfeld explains, building on an example about a shrimp salad that was originally introduced by Professor Gray:

A, B, C, and D, being the owners of the salad, might say to X: 'Eat the salad, if you can; you have our license to do so, but we don't agree not to interfere with you.' In such a case the privileges exist, so that if $\mathrm{X}$ succeeds in eating the salad, he has violated no rights of any of the parties. But it is equally clear that if A had succeeded in holding so fast to the dish that X couldn't eat the contents, no right of $\mathrm{X}$ would have been violated.

HOHFELD, supra note 129 , at 41.

132 See, e.g., Morris, supra note 17, at 832 \& n.28 (1993) (describing a right as "a more robust grant of access" than a privilege, and arguing that only the former can confer the ability to exclude others).

133 See HoHFELD, supra note 129, at 36, 38-39; see also Corbin, supra note 130, at 229, 233 (defining "privilege" and its correlative, "no-right," and offering an example in which person A gives person B leave to knock A's hat off; B has a "privilege" in this case, and the "social giant" of the law "would neither help B to get the hat off nor help A to keep it on").

134 As Felix Cohen explained in his dialogue regarding the meaning of private property,

asking whether a definition is true or false is a meaningless question. But we can ask whether a definition is useful or useless. And that may depend upon whether the definition can be used in a
} 


\section{B. Drawing Functional Distinctions}

There are many reasons why people - individually and collectivelymake suboptimal decisions with regard to resources under common or interdependent control. They may lack information or the means to communicate with each other, they may fall prey to cognitive biases or strong emotions, or they may suffer from wealth, liquidity, or power differentials that leave some options unavailable. However, two specific reasons why people often make suboptimal resource-allocation decisions are at the heart of what is most uniquely interesting and maddening about common interest tragedies. First, people often effectively wear blinders in making allocation decisions, insofar as they do not account for positive and negative externalities that their decisions generate. ${ }^{135}$ Second, people often recognize and attempt to capitalize on opportunities to bluff each other into ceding more of a given surplus or bearing more of a given cost. ${ }^{136}$ I posit that these are the signature difficulties associated with the commons and the anticommons respectively, even though many other things might be going on in any realworld resource-allocation problem. ${ }^{137}$

The functional taxonomy that I develop here categorizes tragedies based on the strategic interaction that forms the primary stumbling block to an efficient outcome. The tragic tendencies that have been most closely associated with the commons and the anticommons, respectively, can be understood as roughly corresponding to two strategic templates: the Prisoner's Dilemma ${ }^{138}$ and the Chicken Game. ${ }^{139}$ The Prisoner's Dilemma

self-consistent manner and whether it can help to clarify the problems with which we want to deal.

Felix S. Cohen, Dialogue on Private Property, 9 Rutgers L. REV. 357 (1954).

135 See, e.g., Epstein, supra note 13, at 559 (explaining that "[t] he social problem with externalities arises because A does not take into account the welfare, negative or positive, of B when A is able to act unilaterally"). I use the notion of "blinders" here not to suggest that people are literally unaware of the costs and benefits that fall on others, only that they ignore them in making their decisions.

136 See id. (describing holdout problems that can develop under circumstances in which consent must be obtained from multiple parties); $i d$. at 557 (identifying holdouts and externalities as the two key impediments that must be taken into account in choosing a legal rule).

137 Although I will use the words "commons" and "anticommons" to designate resource allocations plagued by the "blindered" and "bluffing" strategic interactions, respectively, nothing turns on whether a reader agrees with my reformulated usage of these terms; we could use different words to signify the functional differences I am here highlighting without altering the analysis.

${ }^{138}$ In the original Prisoner's Dilemma story, each of two prisoners must individually choose whether to cooperate (with the other prisoner) by remaining silent, or defect by confessing. Because of the payoff structure of the sentences, each prisoner does better by confessing, regardless of what the other prisoner does, even though the pair would do better jointly if both refused to testify. See BAIRD ET AL., supra note 8, at 33; Charles J. Goetz, LAW AND ECONOMICS: CASES AND MATERIALS 8-17 (1984); infra Part II.A.1.

${ }^{139}$ Chicken takes its name from a dangerous driving game played by reckless teens: Two cars drive toward each other, and the first driver to swerve is called a "chicken" and loses the game. However, this ignominious outcome is better for the loser than a head-on collision-the result if neither party swerves. See GOETZ, supra note 138, at 17; infra Part II.A.2. 
has often been explicitly equated with the tragedy of the commons. ${ }^{140}$ The Chicken Game has been explicitly invoked to describe land assembly problems ${ }^{141}$ which involve an anticommons-like structure, ${ }^{142}$ the link between the Chicken Game and the anticommons is also implicit in the focus on holdouts in the anticommons literature. ${ }^{143}$ While not all strategic interactions fall into one of these two structural patterns, ${ }^{144}$ these game templates provide a good starting point for distinguishing among common interest tragedies.

Significantly, my approach abandons the use of the terms "commons" and "anticommons" to denote formal differences in property entitlements or in the intensity of resource use. Instead, it brings to the forefront the strategic interactions involved. By focusing on the strategic "sticking points" that accompany a resource-allocation dilemma rather than on linguistically pliable descriptors, this approach better advances the project of devising workable solutions.

1. Externalities as Blinders.-Rational actors make decisions based on the costs and benefits that those decisions will generate for them. This implies an indifference to externalities. ${ }^{145}$ Externalities may be benign (from an efficiency perspective) in a given instance, or over a given range. ${ }^{146}$ Externalities only lead to tragedy when they cause actors to do things differently than they would have if the costs were internalized. This will not always be the case. For example, people taking fish for personal consumption from a well-stocked pond might pay no heed to the costs that their fishing imposes on the group, but the benefits of their extractions might easily exceed the costs imposed on the whole group. If so, the extraction is efficient, notwithstanding the blindered character of the extraction decisions. ${ }^{147}$ Alternatively, people will not extract fish in situations

\footnotetext{
140 See, e.g., Dagan \& Heller, supra note 21, at 555 \& n.12; Ostrom, supra note 7, at 3.

141 See, e.g., GOETZ, supra note 138, at 35 (describing a land use assembly problem as "chicken in

142 See Heller \& Hills, supra note 90, at 3.

143 See, e.g., id. passim (discussing holdout problems in the land assembly context); Dibadj, supra note 3 , at $1050 \mathrm{n} .42,1114$ (discussing the link between holdouts and the anticommons).

144 See infra Part II.C.3 (discussing this point).

145 As a result of interdependent utility functions, norms, conscience, and many other factors, peo-
} action"). ple may actually care about the costs and benefits that fall on others. To the extent this is the case, payoffs will incorporate additional elements, altering the game structure and likely strategies undertaken within it. See infra notes 200-03 and accompanying text.

146 See James M. Buchanan \& Wm. Craig Stubblebine, Externality, 29 ECONOMICA (n.s.) 371, 38081 (1962) (distinguishing Pareto-relevant externalities from externalities generated in situations in which "[t]he internal benefits from carrying out the activity, net of costs, may be greater than the external damage that is imposed on other parties"); see also DUKEMINIER \& KRIER 5TH, supra note 6, at 51-52 (discussing the possibility that externalities will not generate inefficiencies); HADDOCK, supra note 44 (discussing irrelevant externalities).

147 See, e.g., Louis De Alessi, Gains from Private Property, in Property Rights: COOPERATION, CONFLICT, AND LAW, supra note 33, at 90, 91 (observing that "[o]pen access does not present a problem as long as the supply of a resource is so great relative to the demand that there is no (net) gain from 
where their internalized shares of the cost are larger than the benefits they stand to gain, even though their fishing might also impose externalities on other people. In either case, the existence of externalities does not change behavior. In other cases, however, externalities are likely to distort decisions. If the personal benefit of fishing is well above the fisher's internalized share of the costs, but well below the total costs imposed on the pool, overfishing is likely to result. ${ }^{148}$

The same logic holds for positive externalities. In deciding whether to put a rose garden in my front yard, I will (let us assume) pay no heed to the positive externalities the garden will generate. The presence of externalities, and my choice to ignore them, may not lead to an inefficient decision. I might internalize so much enjoyment from the rose garden that it is worth the full cost to me; in that case, I will install it anyway, even though I ignore the positive externalities. ${ }^{149}$ Alternatively, I might decide in a blindered fashion that the garden is not worth the cost. This would be a completely benign result if the benefits for the whole neighborhood would not have justified the cost, even had I taken them into account. On the other hand, my disregard of positive externalities might lead me to make a decision that is inefficient. If my internalized benefits from the rose garden do not justify its cost, but the total benefits of the garden (including those bestowed on my neighbors) make the garden worthwhile, I may decline to put in a garden that would have been efficient.

Figure 1 shows the possible impacts of blindered decisionmaking.

conserving or improving it"); Richard A. Epstein, On the Optimal Mix of Private and Common Property, in PROPERTY RIGHTS 17, 28 (Ellen Frankel Paul et al., eds. 1994) (explaining that when water is abundant, "an initial low-level set of diversions should, at least under some circumstances, produce private gains that exceed the losses to the commons").

148 Of course, there are many informal mechanisms that can restrain selfish behavior, and many settings in which interdependent utility functions create their own brakes on self-interested behavior. This makes it impossible to predict with perfect accuracy when a particular individual will begin to engage in noncooperative behavior as a result of externalities. However, the structure of the payoffs just described would be expected to induce such defection in the absence of countervailing considerations.

149 This assumes that there is nobody else around whom I could potentially bluff into paying for part or all of the garden. If there is such a bluffable other, then the outcome becomes less certain. See infra Part II.C.1. A parallel possibility exists in the case of activities producing negative externalities. A party might engage in an annoying activity that yields her less utility than it costs her (or threaten to do so) if others who will be affected by the activity could be bluffed into paying her to desist. 
Figure 1: Decisionmaking with Blinders

\begin{tabular}{|l|l|l|}
\hline & $\begin{array}{l}\text { Internalizing All } \\
\text { Costs and Benefits } \\
\text { Yields Same Decision }\end{array}$ & $\begin{array}{l}\text { Internalizing All Costs } \\
\text { and Benefits Yields } \\
\text { Different Decision }\end{array}$ \\
\hline $\begin{array}{l}\text { Negative } \\
\text { Externalities }\end{array}$ & $\begin{array}{l}\text { Benign Grazing } \\
\text { or } \\
\text { Self-Motivated Restraint }\end{array}$ & Overgrazing \\
\hline $\begin{array}{l}\text { Positive } \\
\text { Externalities }\end{array}$ & $\begin{array}{l}\text { Benign Neglect } \\
\text { or } \\
\text { Self-Motivated Provision }\end{array}$ & Undercultivation \\
\hline
\end{tabular}

A resource-allocation situation can shift from the left-hand column (internalizing all costs and benefits yields the same decision) to the right-hand column (internalizing all costs and benefits yields a different decision), or vice versa, as conditions change over time. For example, a bucolic fishing scenario featuring benign draws against a common pool could escalate into a situation involving quite inefficient extractions. ${ }^{150}$ In a typical commons scenario, one will continue making draws against the commons until the marginal benefit one gleans just equals one's internalized share of the marginal cost. ${ }^{151}$ In any situation involving negative externalities, one's internalized cost of an additional draw will be lower than the cost imposed on the whole group. Hence, a rational actor would be expected to continue making draws beyond the efficient stopping point, because she is only internalizing some of the costs. Even if extractions generating externalities are efficient within some range, ${ }^{152}$ ultimately extraction reaches a point where it becomes inefficient. Once within that range, the situation resembles a Prisoner's Dilemma.

To illustrate, consider a simple example involving just two individuals, Rowena and Columbo, who share a grazing land between them. When we first meet them, they have already added cattle up to the point that is optimal for the land. Now each must decide whether to add yet another head of cattle. At this point, suppose that each additional head of cattle generates ten in benefits but imposes costs of fourteen on the grazing lands. However, each party gains the full ten by adding a head of cattle, but suffers only half of the cost to the grazing lands, so that each addition still yields a personal benefit of three, ${ }^{153}$ even as it imposes a net social cost of four. ${ }^{154}$

${ }^{150} C f$. Demsetz, supra note 14, at 351 (discussing historical changes in the market for fur and positing that the increasing value of the fur trade increased the costs associated with externalities).

${ }^{151}$ Beyond that point, one's own internalized share of the cost exceeds the benefits one receives, so that one begins to exercise self-motivated restraint - a move back to the left-hand column in Figure 1.

152 The range could be different for different actors, given the possibility of heterogeneity in the benefits that each derives from resource extraction.

$15310-(14 / 2)=3$. 
Adding cattle is inefficient, but rational players will still do it. Figure 2 depicts the payoffs the players face.

\section{Figure 2: A Prisoner's Dilemma}

Payoffs for (Rowena, Columbo)

\begin{tabular}{|l|c|c|}
\hline & $\begin{array}{c}\text { Columbo Refrains } \\
\text { From Adding Cattle }\end{array}$ & $\begin{array}{c}\text { Columbo Adds } \\
\text { Cattle }\end{array}$ \\
\hline $\begin{array}{l}\text { Rowena Refrains From } \\
\text { Adding Cattle }\end{array}$ & I. $(0,0)$ & II. $(-7,3)$ \\
\hline Rowena Adds Cattle & III. $(3,-7)$ & IV. $(-4,-4)$ \\
\hline
\end{tabular}

Each person must choose between the cooperative action (here, refraining from adding another head of cattle) and the defecting action (adding the cattle). ${ }^{155}$ Rowena must choose between the two rows, and Columbo must choose between the two columns. Their payoffs are shown by the parentheticals at the intersection of their two choices.

If both choose the cooperative action (Cell I) the result is the maintenance of what is presumably a profitable status quo; the zero payoffs merely indicate that neither party gains or loses anything as a result of the interaction, because both parties have refrained from adding any cattle. However, each party can improve her or his personal payoff by defecting, regardless of what the other party does. First look at things from Rowena's point of view. She recognizes that if Columbo does not add any cattle, she can improve her position by adding a head of cattle. This combination of actions will generate the payoffs shown in Cell III. In that instance, she receives a net benefit of three. This represents her internalized benefit of ten, counterbalanced by fifty percent of the cost of fourteen that her action imposes on the grazing lands. Columbo in this instance would receive the "sucker's payoff" of negative seven. He gains none of the benefits associated with Rowena's cattle-adding action, but bears half of the costs to the grazing lands.

Seeing this, Rowena must consider the possibility that Columbo will refuse to be a sucker and will defect instead by adding his own head of cattle. But by comparing her payoffs in Cell II and Cell IV, Rowena can see that she does best defecting in this case as well. If Columbo is going to defect and Rowena is fool enough to cooperate by refraining from adding cattle, she will get the "sucker's payoff" of negative seven. If she also defects, then she at least improves her position to a negative four. Therefore, she is better off defecting no matter what Columbo does.

$15410-14=-4$

155 The game works just the same way when an action that produces a positive externality is at stake; in that case, the cooperative action is to take the action, and the defecting action is to not take the action. 
Of course, Columbo faces precisely the same structure of payoffs and would be expected to look at things exactly the same way. Hence, the Nash equilibrium is for both to defect, a result that leaves both parties significantly worse off than in the case of mutual cooperation. ${ }^{156}$ This basic game structure works the same way in the case of many players. ${ }^{157}$

2. Bargains and Bluffs.-If blindered decisionmaking typifies the tragedy of the commons, the tragedy of the anticommons is more commonly associated with the strategic move of bluffing. The notion of bluffing, as I use it here, denotes a situation in which one would be better off going ahead and bearing a cost or accepting a smaller surplus, but one would prefer to bluff someone else into bearing the cost or taking the smaller surplus. Bluffing can either be successful or unsuccessful. If it is successful (another party bears the cost or accepts a smaller share of the available surplus), then a distributive event has occurred but no inefficiency has resulted - the efficient deal or action has been made possible by the other person's response to the bluff. ${ }^{158}$ If bluffing is unsuccessful, then the result is painful to both the unsuccessful bluffer and those she unsuccessfully attempted to bluff.

The strategic interaction takes the shape of a game of Chicken. In the familiar game of roadway Chicken, cooperation means "swerving" to avoid a collision. The worst outcome occurs if nobody swerves and a crash ensues, while the best outcome for each player occurs if the other party swerves. A player who swerves while the other party drives straight ahead suffers the second-worst outcome. When both parties swerve, both parties enjoy a second-best outcome-it is better than swerving while the other party drives straight ahead, and better than crashing, but worse than being the one to drive straight ahead while the other party swerves. This same structure captures, in rough form, many bargaining interactions. ${ }^{159}$ For example, two parties to a sales transaction might each attempt to capture more than a proportionate share of the surplus that the deal will generate. ${ }^{160}$ If

\footnotetext{
156 See BAIRD ET AL., supra note 8, at 33-34 (discussing the Prisoner's Dilemma); id. at 19-22 (describing and discussing the Nash equilibrium).

157 See Jon Elster, The CEMENT OF SOCIETy 27-28 \& fig.1.3 (1989) (presenting a multi-party Prisoner's Dilemma, using a graph type introduced by Thomas Schelling); see infra text accompanying notes 186-89 (describing a multi-player Prisoner's Dilemma).

158 See supra note 98 (discussing the purely distributive impact of successful bluffs). For purposes of the present discussion, I assume that bluffing and other strategic interactions are themselves costless. In fact, the posturing that accompanies strategic behavior can dissipate surplus, even if a bargain is eventually reached. See supra Part I.B.3.

159 See Cooter, supra note 65, at 20 (presenting a bargaining model "in which everyone has an interest in avoiding the worst outcomes, but the outcome which is best from one player's viewpoint is not best from another's").

${ }^{160}$ Fixed "no haggle" pricing reduces these costs in most consumer markets. As Herbert Hovenkamp explains, "[t]he general theory of price provides fairly determinate rules for how surpluses will be divided up in neoclassical markets." Herbert Hovenkamp, Bargaining in Coasian Markets: Servitudes
} 
one or the other (or both) back down, then a deal will occur. If neither backs down, no deal will occur - the worst outcome for both. Figure 3 depicts the payoff structure represented by this scenario.

Figure 3: Chicken Game

Payoffs for (Rowena, Columbo)

\begin{tabular}{|l|c|c|}
\hline & $\begin{array}{c}\text { Columbo Cooperates } \\
\text { (accepts a smaller } \\
\text { share of the surplus) }\end{array}$ & $\begin{array}{c}\text { Columbo Defects } \\
\text { (demands a larger share } \\
\text { of the surplus) }\end{array}$ \\
\hline $\begin{array}{l}\text { Rowena Cooperates } \\
\text { (accepts a smaller share } \\
\text { of the surplus) }\end{array}$ & I. $(4,4)$ & II. $(1,7)$ \\
\hline $\begin{array}{l}\text { Rowena Defects } \\
\text { (demands a larger share } \\
\text { of the surplus) }\end{array}$ & III. $(7,1)$ & IV. $(0,0)$ \\
\hline
\end{tabular}

Here, the parties have the opportunity to strike a deal with each other that will generate a total surplus of eight. The worst outcome for both parties, the failure to make a deal, is shown in Cell IV; there, both parties receive a payoff of zero. The best outcome for each player is for that player to garner a disproportionately large share of the surplus - Cell II for Columbo and Cell III for Rowena. However, this payoff is available only if

and Alternative Land Use Controls, 27 J. CORP. L. 523 (2002). More problematic are what Hovenkamp terms "Coasean markets"- - settings in which no fixed prices exist and "the division of the surplus is generally indeterminate." Hovenkamp, supra, at 523; see Cooter, supra note 65, at 17 (noting the bargaining costs that accompany situations in which no competitive price exists, and the parties must decide how to split up the surplus from trade). Even where prices are in use, they may not be set optimally. Of particular interest for present purposes are settings in which producers of complementary goods each set prices without internalizing the full impact of their own price level on the demand for the other good. See, e.g., Alfred Marshall, PrinciPles of ECONOMiCs 309-10 (8th ed. 1997) (presenting an example involving monopolistic producers of complementary products, and describing the resulting potential for bluffing over price levels); Douglas Lichtman, Property Rights in Emerging Platform Technologies, 29 J. LEGAL STUD. 615, 616-17 (2000) (discussing pricing externalities). Buchanan and Yoon model the anticommons problem in an analogous manner. See Buchanan \& Yoon, supra note 3, at 5 n.5 (explaining that " $[\mathrm{t}]$ he price-theory analogue [to the anticommons] is the model in which there exist independently acting monopolists who market fully complementary goods (for example, left and right shoes)"); see also Ben Depoorter \& Sven Vanneste, Putting Humpty Dumpty Back Together: Pricing in Anticommons Property Arrangements (unpublished manuscript, on file with author) (presenting results of experimental work examining pricing in anticommons settings). Buchanan and Yoon present an example in which the consumer must purchase a parking pass from each of two independent monopolistic suppliers in order to use the parking lot. Buchanan \& Yoon, supra note 3, at 4-5. Prices for both passes are set too high, as each supplier tries to obtain a supernormal share of the surplus, and the quantity of transactions drops. See id. We might think of the fixed prices in this example as constituting irreversible bluffs. Some customers will still engage in the two-part transaction, accepting whatever surplus remains, while others will not engage in the transaction because the combined prices exceed their own reservation prices. 
the other party agrees to accept a smaller share of the surplus (i.e., agrees to "swerve"). If both parties demand a disproportionately large surplus, no deal will occur. This is because the total demands of the parties cannot exceed the available surplus associated with the deal-eight in this example. If both parties demand payoffs of more than four, then their total demands sum to more than eight, and the deal is no longer worth doing. If both parties "swerve," then the surplus can be shared equitably and the deal will occur (Cell I).

What is most significant about this game structure is the fact that there is no one dominant strategy for either player. Each party's best move depends on what she or he expects the other party to do. If the other party is not going to swerve, one does best by swerving. Capturing a disproportionately small share of the surplus is an unattractive outcome, but it is still better than the situation in which the deal fails to occur at all. But if the other party can be bluffed into swerving, one does best by holding out for a larger share of the surplus.

Here we see the critical difference between the Prisoner's Dilemma structure and the Chicken Game structure - a distinction that can also be used to differentiate commons tragedies from anticommons tragedies. In the Prisoner's Dilemma, one always does best by defecting (failing to cooperate) regardless of what others do. For the strategic holdout in Chicken, refusal to cooperate generates opportunity costs that are always on net worse than cooperation, regardless of what the other person does. Nevertheless, competing desires to capture a disproportionately large share of the surplus may lead the parties to a stalemate. If the total demands for surplus made by the parties exceed the total amount of surplus available from the aggregation, the deal will not occur.

Figures 2 and 3 together show how a Chicken Game might follow directly on the heels of a Prisoner's Dilemma. In Figure 2, Rowena and Columbo were trapped in a Prisoner's Dilemma in which each person's dominant strategy was to defect by adding another head of cattle. However, as an examination of the payoffs in Figure 2 shows, the Prisoner's Dilemma structure contains within it some unexploited surplus that the parties could enjoy through mutual cooperation, as compared with the world in which both defect. ${ }^{161}$ To see this, compare Cell I of Figure 2 (mutual cooperation, total payoff of 0) with Cell IV (mutual defection, total payoff of negative eight). The difference between these two figures represents a surplus of eight that the parties could enjoy between them if a cooperative bargain could be struck. This is the same surplus that the parties are now contesting over in Figure 3.

161 The parties might agree on any number of institutional solutions that would secure access to the surplus. See Gary D. Libecap, Common Property, in NEW PALGRAVE DictionARY OF ECONOMICS AND THE LAW 317, 318 (Peter Newman ed., 1998) (explaining that "[c]ommon-pool losses define the gains that are possible from negotiations among competing parties" through assigning rights or otherwise regulating access). 
How might the parties get from the Figure 2 matrix to the Figure 3 matrix? We might imagine that one enterprising "prisoner" caught in the dilemma above, if able to communicate, bargain with, and effectively bind the other prisoner, could try to "buy up" the other prisoner's right to defect. Doing so would yield a surplus for the two parties that, in theory, they could contract to share. If circumstances make the beginning phases of such dealing feasible, a possible surplus might hove into view. The stage would then be set for a Chicken Game, as the parties maneuver for larger shares of the surplus that their mutual cooperation will create. ${ }^{162}$

3. Multiplayer Games, Heterogeneous Players.-A slightly more complicated example will spell out some additional dimensions of the blindered decisionmaking and bluffing behaviors that characterize the commons and anticommons problem. Imagine that four people $(A, B, C$, and $D)$ live in apartments that each share a wall with a common party room. Initially, the party room was open to any of the four residents to use for throwing parties; no permission was required from anyone. Consequently, each of the four threw a party whenever the benefits of the party outweighed the internalized costs. In other words, decisions were made in a blindered fashion, without regard for the externalities they produced. Sometimes this decisionmaking produced results that were indistinguishable from those that would have been produced had the party-thrower internalized all of the costs - these were efficient parties, whose benefits outweighed the total costs. ${ }^{163}$ In many other cases, however, the celebrations were inefficient ones, in that the benefits they produced were not sufficient to outweigh the costs inflicted on the other residents. This presented a standard tragedy of the commons or Prisoner's Dilemma. Everyone saw that they would be better off if everyone could be made to stop throwing these inefficient shindigs, but no resident had any incentive to curtail her own inefficient parties. Sensing unrest, the building manager created a rule: No one may use the party room without the permission of $A, B, C$, and $D$.

$D$, as it happens, was just about to throw her annual birthday bash. Because she has been throwing the party in the same room for many years, and because the view the room affords of the city triggers many nostalgic pangs in host and guests alike, there are no good substitutes. As a result, the benefits she and her guests derive from use of the party room are fully large enough to swamp the costs imposed on $A, B$, and $C$. Hence, it would be efficient for $A, B$, and $C$ to reach a deal with $D$ about the use of the party

162 In the original Prisoner's Dilemma, such gaming would be impossible; the prisoners would be sentenced by the state and could not reallocate their shares of the reduced sentence. But in contexts in which sharing of the surplus might be feasible, an interaction that begins as a Prisoner's Dilemma can turn into a Chicken Game. There are, however, some intervening steps that I am eliding here. See infra Part II.C.3.

163 They may, however, have had unfortunate distributive impacts. The person inconvenienced by even "efficient" noisemaking on the other side of the wall would likely not view the situation as benign. 
room. But if each of the other residents tries to get a disproportionately large share of the surplus that will be generated by the deal, $D$ 's efforts may fail. ${ }^{164}$ This would be the worst result for all involved. Figure 4 shows the interaction.

\section{Figure 4: Chicken Game with Multiple Players}

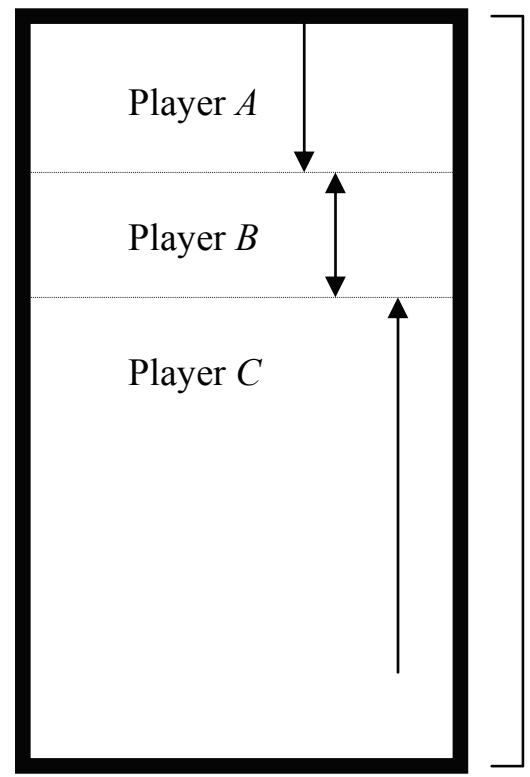

Total Surplus

As shown in Figure 4, the total surplus associated with the consolidation of the fragmented permission required to use the room forms an upper boundary on the aggregate demands for surplus that the fragment-holders may make. ${ }^{165}$ The total surplus is the amount by which $D$ 's benefit from using the party room exceeds the sum of the true reservation prices of $A, B$, and $C .{ }^{166}$ Players $A, B$, and $C$ all compete for a larger share of that surplus in a multiparty game of Chicken. As the arrows suggest, each attempts to

164 A structurally identical situation would be presented if the building manager had never made a rule restricting access, and one of the residents, such as $A$, wished to ensure that the room would be left empty on a given evening so that she could complete a take-home exam in her apartment without disturbance. This would require buying up the free partying privileges for that evening from $B, C$, and $D$, which might well turn out to be impossible. Once again, this demonstrates that the anticommons problem does not always result in the underuse of a resource.

${ }^{165} \mathrm{D}$ is also part of the competition over surplus. But because no deal can go through if the demands of the fragment holders equal or exceed the amount of surplus available, the amount $D$ stands to gain supplies an upper bound on the surplus demands of the other players.

166 See Arrow, supra note 85, at 218 (defining surplus in an analogous scenario as "the excess of the producer's profits over the sum of the reservation prices"). 
expand her share of the surplus by cutting into the surplus of the other players. ${ }^{167}$ The worst result for all, eventuating in loss of all of the surplus, is a set of demands that exceeds the total surplus associated with the deal.

One might imagine that the players would converge on a fair three-way split of the surplus. ${ }^{168}$ However, the players in the game (unlike we omniscient onlookers) cannot discern with certainty how much total surplus will be generated, or what percentage of that surplus each player will enjoy under various possible divisions. Because the private value placed on an entitlement by a given player is unknown to the other players, they cannot be sure that the sale of it at a particular price will generate any surplus for the player, much less an excessive or unfair one. If private valuations are very heterogeneous and are unknown to others, then it will be impossible for one player to tell whether another player is acting greedily or is merely attempting to recover a scintilla of value above her true reservation price. ${ }^{169}$

A rule that each player will receive the same dollar value for relinquishing a fragment would provide one solution, but it would risk the transfer of fragments at prices lower than some sellers' true reservation prices and would potentially deliver an unfair surplus to others in the interaction. Provided that the aggregation was efficient in the Kaldor-Hicks sense, we might dismiss this as a problem of distribution only. But it will be impossible to tell whether the aggregation is efficient without knowing the sum of the true reservation prices of the group, and learning this information will be difficult because of the strategic interests of the players. Subjective valuations cannot be verified or disproved, and even objective measures of value, such as the amount of financial damage parties will suffer by surrendering their rights, are vulnerable to distortion. ${ }^{70}$

167 Each player's attempted expansion of her own surplus reduces the surplus available to all of the other parties, not just the parties directly adjacent on the diagram. Hence, player $A$ 's surplus demands shrink the surplus available to both $B$ and $C$; likewise, player $C$ 's surplus demands compress the total demands that can be made by $A$ and $B$.

168 See Lewinsohn-Zamir, supra note 17, at 232 (suggesting, based on experimental evidence, that entitlement holders would typically be able to reach agreement about "division of the pie"). As Lewinsohn-Zamir recognizes, however, the success achieved in laboratory experiments may not translate into real-world settings where people enter the game with conflicting beliefs about their entitlements to shares of the pie-beliefs that are likely influenced by cognitive phenomena such as the "self-serving bias." Id. at 233; see infra note 171 and accompanying text.

169 For obvious reasons, the players cannot rely on each other's representations of their private valuations. See Arrow, supra note 85, at 218 (explaining that individual landowners holding rights to clean air will be tempted to overstate their reservation prices to a factory owner who is attempting to buy up all such rights so as to gain a larger share of the available surplus).

170 See Libecap, supra note 161, at 321 (discussing how deception and other forms of opportunism can keep parties from agreeing on institutional changes to resolve commons dilemmas) (citing O.E. WilliamsOn, MARKETS AND HiERARCHIES: ANALYSIS AND ANTITRUST IMPLICATIONS (1975)). Mechanisms designed to elicit truthful valuations depend on veiling the implications of the valuation, so that the risks of a too-high and of a too-low valuation are matched. See, e.g., Epstein, supra note 13, at 582-84; Ayres \& Talley, supra note 17, at 1029-31. 
Where heterogeneity among the players rules out any straightforward solution to the problem of dividing up surplus fairly, it also leaves room for cognitive biases to color perceptions of fairness. ${ }^{171}$ The problem is not merely a theoretical one, as Gary Libecap's study of oil unitization illustrates. ${ }^{172}$ Despite the huge gains that are available through unitization, negotiations are difficult, slow, and sometimes unsuccessful. ${ }^{173}$ Heterogeneity significantly complicates the parties' attempts to arrive at rules for sharing production revenues and costs. ${ }^{174}$ To reduce the risk of holdout problems, most states allow compulsory unitization on less than unanimous consent. ${ }^{175}$

\section{Complications and Elaborations}

While a focus on the respective roles of blindered decisionmaking and strategic bluffing in blocking efficient resource use offers a useful first cut in slicing up the universe of common interest tragedies, this simple dichotomy leaves a number of rough edges remaining. Here, I work through some of those. Far from undermining the initial functional distinction drawn above, however, these complications and elaborations actually reinforce the usefulness of making strategic patterns the taxonomic focus.

1. Blinders and Bluffs in Enforcement (and Beyond).-The functional dichotomy developed above can be used to differentiate between varieties of underenforcement that can emerge in a common interest context. Recall that the second tragic tendency associated with the anticommons involves the underenforcement of the power of exclusion from the resource. Any one of the people holding an entitlement necessary to an interloper's legitimate use of a resource would have the power to stop that interloper,

171 See, e.g., Heller \& Eisenberg, supra note 3, at 701 (discussing the potential role of cognitive biases, including the overvaluing of one's own assets and the undervaluing of those of others, in causing impasses in patent bargaining); Thompson, supra note 32, at 241 (discussing conflicting perceptions of fairness, and discussing role of cognitive biases); Wade-Benzoni, supra note 107, at 119-23 (presenting experimental results on the role of "egocentric interpretations of fairness" in resource dilemmas in which parties are heterogeneous in the benefits they derive from resource use and the burdens they will bear from resource degradation).

${ }^{172}$ See Gary D. Libecap, Contracting for Property Rights, in Property Rights: CoOPERATION, CONFLICT, AND LAW, supra note 33, at 142, 156-65 (citing and discussing empirical studies). Unitization is a means of placing under common control oil reservoirs that underlie a number of separatelyowned parcels and thereby avoiding loss of value through wasteful extraction races and the like. Id.; see supra note 32 (describing how oil extraction can constitute a tragedy of the commons).

173 Libecap, supra note 172, at 158. Even when agreement is eventually reached, the lengthy negotiating delays have often dissipated many of the gains. $I d$.

${ }^{174} I d$. at 161-65 (discussing the role of various sorts of heterogeneity). Interestingly, negotiations are much easier during the "exploration" phase, when the parties are effectively behind a veil of ignorance. See id. at 161 (explaining that simple formulas, such as those based on surface acreage, will suffice during this stage "[s]ince no party knows whether the formula is to its particular advantage or disadvantage"). As more information becomes available, heterogeneities emerge, and parties draw different conclusions from the partial information, introducing new complications. Id. at 161-62.

${ }^{175} I d$. at 162-63. Texas, however, has no compulsory unitization law. Id. at 163. 
but doing so benefits all of the other entitlement holders at the same time. On reflection, this tendency looks suspiciously similar to the "undercultivation" tendency discussed in the context of the tragedy of the commons. Whatever the underlying property regime, enforcement (which includes both monitoring and punishment) represents a collective action problem. ${ }^{176}$ While each member of the resource-using community benefits from enforcement actions that protect entitlements, each would-be enforcer will bear all of the costs while capturing only a share of the benefits. Hence, each would prefer to free-ride on someone else's efforts. Unless the group's efforts can be successfully coordinated, we would expect too little enforcement to occur. ${ }^{177}$ Explained this way, underenforcement sounds like the blindered decisionmaking characteristic of a commons dilemma.

We can distinguish between types of underenforcement problems, however, based on whether the decision that produces the underenforcement represents a blindered decision or an unsuccessful bluff. When an interloper (which could include in this context any member of the community) begins to use a resource improperly - either without the necessary permissions in the case of an anticommons, or in violation of the rules of resource-gathering that prevail in some other context - there are four possibilities. First, it might be the case that the interloper is just not worth stopping; that is, the costs of stopping her exceed the benefits that will accrue to the entire group as a result. ${ }^{178}$ The distributive realignment might be deemed "tragic" by some, but it does not constitute a tragedy as I have been employing the term here, because it does not generate a net loss, but rather a change in distribution. People may make blindered decisions about whether or not to stop the interloper, but these decisions are of the "benign neglect" variety; on efficiency grounds, the interloper should not be stopped.

Second, we might have a situation where the cost of stopping the interloper exceeds the internalized share of the benefit that will accrue to any one individual, but the total benefit that the group would share if the interloper were stopped exceeds the cost of enforcement. In such a case, each individual makes a blindered decision that is inefficient; if the person were taking into account all of the externalities, the decision would be a different one. Hence, the players are trapped in a Prisoner's Dilemma. Unless there

\footnotetext{
176 See, e.g., Krier, supra note 14, at 332-39 (describing how reliance on the "free market" or on "government" to solve commons problems begs the question of how the coordination and enforcement necessary to sustain a given regime came about); JON ElSTER, THE CEMENT OF SOCIETY: A STUDY OF SOCIAL ORDER 41 (1989) (explaining that punishment delivers diffuse benefits while concentrating costs on the punisher).

177 This is arguably true even in a norms-based system. See Krier, supra note 14, at 336 (explaining that because "ostracism itself takes time and energy" and provides collective benefits, "[t]here is likely to be an undersupply of nagging").

178 Cf. Gary Becker, Crime and Punishment: An Economic Approach, 76 J. Pol. ECON. 169 (1968) (observing that the costs of detection and punishment of crime, as well as the costs of crime itself, must be taken into account in formulating an optimal approach).
} 
is a mechanism for assembling together the diffuse interests required, everyone is better off not contributing to the policing efforts, regardless of what everyone else does.

Third, it is possible that stopping the interloper is "worth it" to each and every member of the group individually. ${ }^{179}$ The internalized benefit that each person receives as a result of the interloper being stopped exceeds the costs of personally doing the stopping. What then could explain underenforcement? Here, it becomes important that each member recognizes that it is also "worth it" to the other members to take on the enforcement. Even though each person is better off enforcing rather than letting the violation slide, the surplus associated with the enforcement will be shared by the whole group. Each member would therefore prefer to bluff someone else into doing the enforcement, so that she can glean the benefits of having the interloper stopped without personally bearing any of the stopping costs. ${ }^{180}$ Thus, we have a game of Chicken: Each person hopes that another person will stop the interloper, but the worst outcome for each person occurs if nobody stops the interloper.

Finally, it is possible that the group is heterogeneous with regard to the benefits they will derive from interloper-stopping, with some members finding it fully worth the cost to stop the interloper on their own, and other members finding it not worthwhile. Of course, a typical strategy in the Chicken Game is to try to convince others that you fall in the latter category, and hence are not susceptible to being bluffed into bearing the cost of the enforcement. The use of false disinterest as a bluffing mechanism greatly complicates the interaction by obscuring the nature of the dilemma.

This distinction between blinders and bluffs can also be used to classify other sorts of underinvestment decisions that exhibit similar features. ${ }^{181}$ Consider the problem of replacing a burned-out light bulb in a community laundry room. Quinn, a member of the community, visits the laundry room one day, notices the problem, but does not replace the light bulb. His action

\footnotetext{
179 If providing the public good in question-here, enforcement-is entirely worth the cost to even one member, the group is what Mancur Olson terms a "privileged group." OLSON, supra note 8, at 4950. According to Olson, the existence of a privileged group generates a presumption that the good will be provided, although he adds a caveat to this point. See id. at $50 \& \mathrm{n}$. 70; infra note 180.

180 Olson notes the possibility of a situation in which providing a particular good is worth it to each group member, but "each member of the group, knowing that each of the others would also be better off if they provided the good alone than they would be if no collective good were obtained, would refuse to contribute anything toward obtaining the collective good." OLSON, supra note 8, at 50 n.70. Olson suggests the problem would be self-limiting, however. See id.; infra note 182.

181 In order for an underinvestment decision to potentially implicate the Chicken Game rather than the Prisoner's Dilemma, the investment in question must be one that a single actor can make unilaterally and that will, on its own, produce results for her that are sufficient to justify the cost. In order for the latter condition to be met, the investment must produce a good that is not susceptible to overgrazing of the sort that would nullify the investment. In addition, the bluffing that accompanies the Chicken Game interaction requires the existence of a bluffable other for whom the investment is also independently worthwhile. See infra Part II.C.2.
} 
could be a simple case of benign neglect. Perhaps enough light seeps in from the street so that the investment isn't worth making even if the positive spillovers could be captured. In this case, he makes a blindered decision, but it is an efficient one. It is also possible that Quinn does not internalize enough benefit from the light bulb replacement to make it worthwhile for him, even though he would find it worth undertaking the replacement if he could capture the positive externalities associated with it. In that case, Quinn makes a blindered decision that yields an inefficient outcome. This fits within the Prisoner's Dilemma template; it is never worth it for the individual to invest, regardless of what everyone else does, absent a mechanism for capturing the positive externalities bestowed on others.

Finally, it is possible that the investment in light bulb replacement is entirely worth it to Quinn (the benefits of the lighted room over the life of the new light bulb would exceed the annoyance and trouble of buying and installing the bulb), but he holds back on installing the bulb in the hopes someone else will make the investment so that he can enjoy the benefits at zero cost. In this case, Quinn is bluffing by pretending indifference through his inaction. This strategy imposes short-term costs on him (sorting his laundry is more difficult in an unlighted room), but will potentially earn him a larger share of the surplus associated with the light bulb replacement. The other members of the community may also be bluffing when they visit the laundry room and fail to replace the bulb, or they may be making blindered decisions that are actually in their individual self-interest. ${ }^{182}$

The point can be generalized further. Recall that a Prisoner's Dilemma differs from a Chicken Game only in the relative rankings of the "sucker's payoff" (that is, the payoff one receives as a lone cooperator) and the "universal defection" payoff. Where the universal defection payoff is more attractive to an individual than the sucker's payoff, noncooperation is unambiguously dominant. Regardless of what everyone else does, and even in the event that everyone else defects, one is still better off defecting than cooperating and accepting the sucker's payoff. In that case, one makes a blindered decision that not only ignores external impacts on others, but also requires no predictions about what other people will do. ${ }^{183}$ Where the

\footnotetext{
182 People who repeatedly interact can gain insight into each other's preferences and adjust their own conduct accordingly. See HADDOCK, supra note 44, at 28 (recounting his decision to clean the countertop in the faculty lounge, which was based on his observations of his colleagues' behavior and his resultant belief that nobody else would ever clean the counter); OLSON, supra note 8, at $50 \mathrm{n} .70$ (suggesting that group members for whom provision of a public good is individually worthwhile would not long persist in withholding provision of the good out of the mistaken belief that other members would provide the good instead).

183 See Pamela Oliver et al., A Theory of the Critical Mass. I. Interdependence, Group Heterogeneity, and the Production of Collective Action, 91 AM. J. Soc. 522, 540 (1985) (explaining that where the cost of contributing to a collective good exceeds the benefits one will receive from the contribution "predictions about others' behavior are irrelevant, for contributions are irrational no matter what other people do").
} 
sucker's payoff is more attractive than the universal defection payoff, noncooperation is a bluff, because one would be better off taking the sucker's payoff than defecting - at least under some imaginable circumstances (i.e., where everyone else defects). One's best strategy depends, in that case, on what one expects other players to do. ${ }^{184}$

The sucker's payoff could dominate the universal defection outcome even in what we might think of as traditional "tragedy of the commons" settings, making the game into one of Chicken. However, this will only occur under rather special conditions involving binary choices by players who have the ability to unilaterally secure a surplus for the group. For example, imagine that five law students are about to head out into a heavy and unexpected rainstorm late one evening, after a marathon study session. They plan to borrow umbrellas from an already quite depleted common umbrella stash that an unknown administrative agent has helpfully placed near the front door of the law school. When they reach the umbrella stand, they see that there are exactly five umbrellas remaining. They remark on their good fortune; each of them has a different itinerary, making umbrella-sharing infeasible. But as they reach for the umbrellas, they hear behind them the slow footsteps of an emeritus professor of advanced years and frail health. It is clear from his purposeful advancement towards the umbrella stash that he intends to head out into the rainstorm himself and plans to secure an umbrella for the trip. Each student must decide whether to take or leave an umbrella.

Assume that each student would suffer crushing guilt if this most august member of the law school community were forced to go out into the rain without an umbrella, a venture that could potentially trigger a dangerous bout of pneumonia. Here, the sucker's payoff of leaving an umbrella behind for Professor Eminent while all of one's colleagues secure dry passage to their destinations is viewed by each law student as superior to the option of leaving Professor E exposed to the elements. But each student hopes that some other student will volunteer to accept the sucker's payoff. In this case, each law student's purposeful grasping of an umbrella is a bluff, and whether she follows through with the threatened umbrella extraction will depend crucially on what she expects the other players to do.

2. Steps and Slopes.- How can we distinguish the settings in which players will be tempted to bluff from those in which their noncooperation is simply the result of blindered decisionmaking? In order for a player to be in a position to bluff, two things must be true. First, our bluffing player, if put to the test, must have a preference for the sucker's payoff over the payoff achievable through universal defection. This means that the player's

\footnotetext{
184 See id. at 540-41 (explaining that individuals for whom provision of a collective good is independently worthwhile will provide it if they do not expect anyone else to do so, but may attempt to get others to provide it instead).
} 
unilateral cooperation must not only be capable of doing some good on its own, but must do enough good to make it worth the price of the player's cooperation in a world where everyone else defects. If the universal defection payoff dominates the sucker's payoff, then the player will simply defect, and will not concern herself with trying to predict or influence the actions of anyone else. Second, a successful bluff requires the presence of some other player or players who share a preference for the sucker's payoff over the payoff associated with universal defection, and who are therefore bluffable.

Whether these requirements will be met in a given instance depends, in part, on the shape of the production function for the surplus that cooperation produces. ${ }^{185}$ We can begin by contrasting two possibilities - a surplus that continuously increases with each increment of cooperation, and a surplus that is delivered all at once, in a sharp "step," when a particular level of cooperation is achieved. First, consider a situation involving a continuously increasing surplus. To keep the analysis simple, imagine that each member of a ten-person group faces an "all or nothing" binary choice ${ }^{186}$ - to contribute or not to contribute a lump sum of $\$ 5$ to a common enterprise. ${ }^{187}$ Assume further that all contributions made to the common pool will be magically multiplied by three before being redistributed to the group on a per capita basis. ${ }^{188}$

In this situation, each person's contribution clearly makes a difference, on its own, in the amount of surplus generated. Each $\$ 5$ contribution generates a surplus of $\$ 10$ for the group (the total of $\$ 15$, minus the original contribution of \$5). But it does not make enough of a difference in any individual's payoff to justify the costs of cooperating - at least if we assume that all of the relevant costs and benefits are captured by the dollars involved. A person contributing $\$ 5$ will receive back only one-tenth of the resulting \$10 surplus (\$1) plus one-tenth of her initial \$5 contribution (50 cents). Thus, in a world where everyone else defects, she ends up $\$ 3.50$ worse off than in a world where she also defects. But even if everyone else cooperates, she is still $\$ 3.50$ better off defecting. If the nine other people

185 See id. passim (discussing and illustrating various production functions for public goods); MARWELL \& OLIVER, supra note 18, at 24-25, 58-100 (discussing importance of production functions to collective action problems and analyzing their dynamics).

186 Many real-world cooperative choices are not binary-for example, one often chooses not only whether to contribute, but also how much to contribute. See Hardin, Collective ACTION, supra note 8 , at 51 (distinguishing step or binary contributions from "continuous levels of individual contribution").

187 Even though this example is framed in terms of "contributions," the same analysis would apply to choices about whether to refrain from extracting an excessive amount of a resource, or to refrain from some other negative activity, such as polluting or littering.

188 Public goods experiments often involve similar contribution dilemmas. See Robyn M. Dawes \& Richard H. Thaler, Anomalies: Cooperation, 2 J. ECON. PERSP. 187, 188 (1988) (explaining that a typical public goods experiment involves giving a sum of money to $n$ players, allowing the players to keep or contribute the money, multiplying the contributed money by a factor that is greater than 1 but less than $n$, and distributing the product among the group members equally). 
contribute their $\$ 5$ shares, this will generate $\$ 135$ ( $\$ 45 X 3$ ), which will then be spread among the ten participants. If our protagonist fails to contribute, she keeps her $\$ 5$ and also receives $\$ 13.50$, for a total payout of $\$ 18.50$. If she also contributes, the total pot rises to $\$ 150$ ( $\$ 50 \times 3)$, but she only receives back one-tenth of that amount, or $\$ 15.00$. The same analysis holds for all intermediate points between universal defection and universal cooperation - the individual is always better off defecting. The parties therefore face a multi-player Prisoner's Dilemma in which noncontribution is the dominant strategy. ${ }^{189}$

A step good, in contrast, does not smoothly increase with inputs. Rather, it delivers no benefits at all until a certain contribution threshold is reached; it then delivers all of the benefits in a single lump upon reaching that threshold, and delivers no additional benefits beyond that point. ${ }^{190}$ In some of the examples we have considered, one individual's unilateral cooperative action was both necessary and sufficient to secure the entire surplus in question. In the umbrella example, the entire surplus associated with leaving an umbrella for Professor E could be accomplished in one "step" by the unilateral action of a group member, ${ }^{191}$ and additional acts of cooperation above that level did no additional good. In the fragment enforcement and light bulb examples, the same was true.

Where this is the case, the individual must compare the personal benefit she gains from cooperating to the cost she must incur. If her share of the surplus is not enough to make unilateral cooperation worthwhile, she will defect. But even if her share of the surplus is sufficient to make unilateral cooperation worthwhile (that is, the sucker's payoff exceeds the universal defection payoff), she may still try to bluff someone else into accepting the

189 The mere fact that the surplus associated with cooperation smoothly increases with inputs does not, in itself, mean that the choice situation is necessarily a Prisoner's Dilemma. If the inputs are multiplied by a factor that is greater than the number of people to whom the proceeds will be distributed, everyone will contribute as much as possible-again, without regard to what anyone else does. To return to our earlier example, imagine that the contributions were multiplied not by three, but by twelve. In that case, we would expect universal cooperation; each individual's contribution of $\$ 5$ generates a personal return of \$6. See Oliver et al., supra note 183, at 533-34 (explaining that linear production functions yield contribution decisions that follow one of two patterns, depending on the slope of the function- "[e]veryone will contribute either everything possible or nothing").

190 See, e.g., HARDIN, COlleCtive ACTION, supra note 8, at 55-61 (describing and analyzing step goods); Ido Erev \& Amon Rapoport, Provision of Step-Level Public Goods: The Sequential Contribution Mechanism, 34 J. CONFLICT RESOL. 401, 403 (1990) (discussing "public or collective goods that only exist after a substantial amount has been contributed to their production, and then do not increase in quality or quantity if more contributions are made").

191 This is because no law student had any reason to expect or fear that any other law student would attempt to extract more than just one umbrella for personal use. The binary nature of the extraction choice (take one umbrella, or take no umbrella) distinguishes this case from a typical common pool resource setting, such as a fish pond. There, a person whose own forgone extraction might be sufficient to keep a population from crashing if everyone else held their own extractions constant would have no assurance that personal forbearance would mean survival of the population. Such forbearance might instead be matched by heightened extractions on the part of others. 
sucker's payoff. Where the players lack full communication and knowledge of each other's actions, each may also fear that her own cooperation will be superfluous. For example, joint owners of a commons might all observe from their separate bedroom windows that an interloper is on the common property. Each might find it personally worth the costs of calling the police to get the person ousted. However, each might prefer to have someone else bear the costs of making the call. If each assumes that someone else has already made the necessary call, then she may be unwilling to undertake that task herself.

The assembly of fragmented permissions to use a resource in a particular way is also a "step good." This time, however, the surplus comes all in one lump upon attainment of the last necessary permission. Consider the case of a lovely common park surrounded by a high wall that no member of a 10-person group may enter or use in any fashion without obtaining a pass from each of the other group members. Permission to enter the park is a "step good," similar to a bridge. One must have the whole thing in order to have anything; a partial bridge is no better than no bridge at all. ${ }^{192}$ Here, no group member can gain any surplus from assembling permissions unless she is able to assemble all the fragments and gain admission into the walled park. ${ }^{193}$ This is depicted in Figure 5.

192 E.g., MARWELl \& Oliver, supra note 18, at 23, 24. It is possible to quibble with this example. See HARdin, COLlective ACtion, supra note 8, at 59 (explaining that "bridges vary over a near continuum from terrifying Himalayan rope footbridges to the stupefying Verrazano-Narrows Bridge"). However, a bridge offers a reasonable intuitive image of what a step good is all about, if one makes some simplifying assumptions that narrow the range of acceptable bridges in a given context.

193 See Hovenkamp, supra note 160, at 522 (presenting a similar example, in which a "factory surrounded by five landowners must purchase the right to pollute from all five or the right will be worthless"). 
Figure 5: The Walled Park

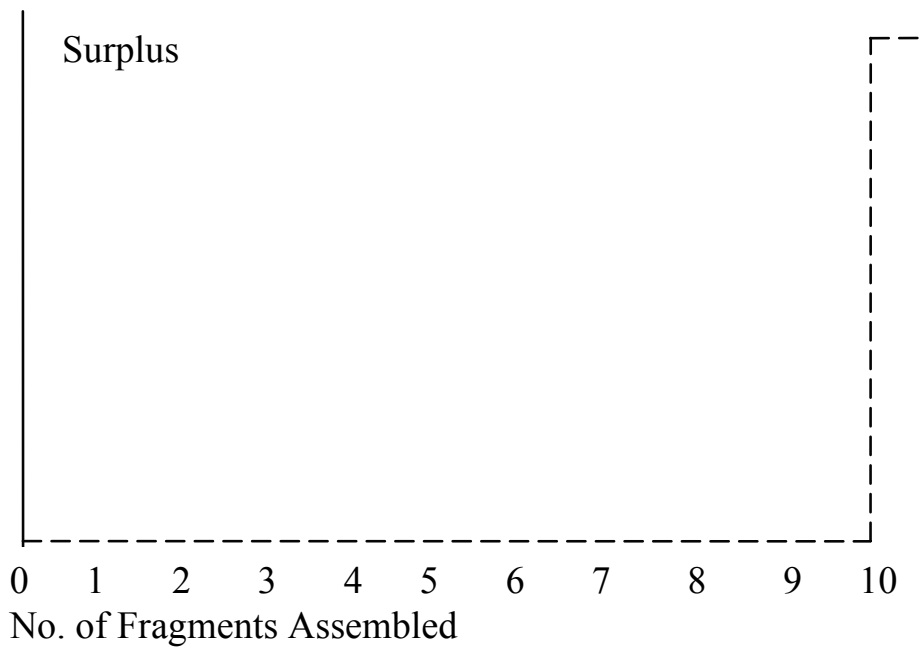

The vertical axis tracks the generation of surplus, while the horizontal axis tracks the number of fragments assembled together. The dashed line represents the production function of the surplus. As we can see, the jump from 9 fragments to 10 is responsible for the entire surplus associated with the assembly. Of course, each of the ten players would be expected to jockey for as large a share of that surplus as possible. Or, to put it differently, each player will try to be the last holdout, upon whose cooperation the entire deal hangs. ${ }^{194}$

There are many other possibilities aside from the step and continuous production functions I have presented here, and I will revisit the question of heterogeneous production functions presently. ${ }^{195}$ Two related observations are helpful at this stage, however. First, standard "tragedy of the commons" problems are likely to tend more towards the continuous end of the production function spectrum, making them more likely to yield a Prisoner's Dilemma interaction. Cases like littering, pollution, noisemaking, fishing, and so on will probably not have smoothly increasing production functions, but they may have large ranges in which no abrupt "steps" are present. In other words, individuals are unlikely to see a sharp and direct connection between their individual actions and the amount of surplus or deficit produced.

\footnotetext{
194 See Heller \& Hills, supra note 90, at 5 (discussing the incentive for a landowner to be the last seller in a land assembly effort).

195 See infra Part III.C.
} 
Where a person believes her actions will make no difference, defection is a more likely strategy. ${ }^{196}$

Second, the standard "anticommons" examples tend to involve goods that, even where they do not present sharp "steps," are at least significantly lumpy. ${ }^{197}$ There is a tighter connection between an individual's cooperation or noncooperation and the ultimate result. This connection heightens the possibility that a person will find cooperation individually worthwhile. At the same time, it sets the stage for bluffing among individuals. The threat of the sharp and precipitous loss of all surplus in the event parties do not "give in" and agree to share surplus creates a powerful dynamic that corresponds to familiar holdout problems. Therefore, at least part of what drives the functional distinction between commons and anticommons problems has to do with the typical shape of the surplus at issue in the respective cases.

3. Payoffs and Perceptions. - It would be inaccurate to suggest that every strategic interaction involving a common pool resource looks like a Prisoner's Dilemma or a Chicken Game. ${ }^{198}$ These templates are based on specific payoff patterns that cause players to rank their various options in a particular order, yielding a strategic situation with certain identifiable features. ${ }^{199}$ If a player's perception of the payoffs changes, the game changes. Factors such as altruism, reciprocity, or norms can alter perceived payoffs. ${ }^{200}$ Such factors might make a person internalize (through social shunning, a guilty conscience, or other means) the negative externalities she visits on others, and can also permit a person to internalize (through pride, group approval, a "warm glow" and so on) the positive externalities that her benefits yield others. Indeed, studies suggest that people are often "conditional cooperators" who will cooperate rather than defect if enough other

196 See UllmanN-MARGalit, supra note 8, at 28-29 (linking the "condition of individual insignificance," where individual contributions appear to have no impact on the outcome, to heightened tendencies to defect)

197 This lumpiness does not guarantee that the interaction will look like a Chicken Game, rather than a Prisoner's Dilemma, however. Even if the production function is relatively lumpy, the Prisoner's Dilemma logic will still hold so long as the individual does not internalize enough from the contribution to make it worthwhile. See HARDin, Collective ACTION, supra note 8, at 57-58 (making this point, and arguing that even a slight upward slope on the riser of what otherwise appears to be a "step good" may still yield a Prisoner's Dilemma).

198 See, e.g., Ostrom, supra note 7, at 46-47 (discussing possible game structures, including the Assurance Game); STEVEN J. BRAMS, THEORY OF MOVES 1 (1994) (noting that there are seventy-eight unique game structures generated by the possible different ordinal rankings of outcomes by two players faced with two strategies); id. app. at 215-19 (detailing the fifty-seven "conflict" games in which the two players disagree on the best outcome).

199 See GOETZ, supra note 138, at 15-16 (explaining that categorizing conflict situations can highlight distinctions between situations that might otherwise appear similar).

200 See, e.g., UlLMANN-MARGALIT, supra note 8, at 36-37 (discussing how factors such as shame and glory can impact payoffs). 
people do likewise. ${ }^{201}$ Where this is the case, players may behave as if they are engaged in an Assurance Game strategic interaction, ${ }^{202}$ even where the pecuniary payoffs are structured as a Prisoner's Dilemma. ${ }^{203}$

Sometimes perceptions cut against cooperation. Perceived unfairness has been shown in experimental studies to be a powerful motivator that often causes people to take actions that appear personally disadvantageous. ${ }^{204}$ I have suggested that attempts to agree on a division of surplus typically take on the character of a Chicken Game, where refusal to agree will destroy all of the surplus for everyone. However, negative emotions toward the other players that emerge in the course of attempting to agree on a division of surplus may be so strong as to fundamentally alter one's perception of the game. Perhaps one decides that the other parties' bargaining conduct is so reprehensible that one would rather walk away from the deal than let those parties enjoy an excessive surplus. In other words, universal defection might begin to look more attractive than the sucker's payoff, because accepting the sucker's payoff would be bundled with a great deal of emotional disutility associated with being bested by one's opponents. In such a case, one may decide one is better off defecting (that is, demanding a supernormal surplus) regardless of whether that means derailing the deal. ${ }^{205}$

It is also possible that a single resource-allocation setting could yield differently-patterned interactions within different ranges. For example, a resource-allocation problem that looks like a Prisoner's Dilemma through some range of resource depletion might turn into a Chicken Game when depletion becomes so severe that universal defection will generate a catastrophic result.

201 See, e.g., Michael TAYlor, The Possibility of CoOperation 84-85, 104-05 (1987); Urs Fischbacher et al., Are People Conditionally Cooperative? Evidence from a Public Goods Experiment, 71 ECON. LETTERS 397 (2001).

202 The Assurance Game differs from the Prisoner's Dilemma in that players who have achieved a joint strategy of mutual cooperation are not tempted to defect; each player in an Assurance Game does best by cooperating, as long as the other person cooperates. See Amartya K. Sen, Isolation, Assurance and the Social Rate of Discount, 81 Q.J. ECON. 112, 114-15 (1967) (formulating the "assurance problem"). The Assurance Game is similar to, and sometimes presented as identical with, the Stag Hunt, another game in which the best individual outcome can be realized by cooperating, as long as the other person also cooperates. The distinction sometimes drawn between the two games involves the rank ordering of the choices of universal noncooperation and individual noncooperation while the other player cooperates. Daphna Lewinsohn-Zamir, Consumer Preferences, Citizen Preferences, and the Provision of Public Goods, 108 YALE L.J. 377, 392-93 nn.39-40 and sources cited therein (describing the Assurance Game and noting variations of it); see ULLMANN-MARGALIT, supra note 8, at 121 \& n.5 (discussing the Stag Hunt game).

203 See Fischbacher et al., supra note 201, at 398 (explaining that the experimental design that elicited conditional cooperation among approximately 50 percent of the subjects was one that would have been predicted to result in "complete free riding by all subjects" on standard economic assumptions).

204 See, e.g., Jolls et al., supra note 103; THALER, supra note 103.

205 Needless to say, the ability to believably convey this attitude greatly enhances one's bargaining position. $C f$. Robert H. Frank, PAssions Within ReAson: The Strategic Role of the EMOtions 99-101 (1988) (presenting a fictional example that shows how convincing one's adversary of one's own irrationality can be useful). 
Alternatively, what begins as a Prisoner's Dilemma among individuals can turn into a Chicken Game interaction among sets of individuals. If we posit a minimum subgroup of people who, by cooperating, could generate a result better than universal defection, the stage is set for Chicken Games among all feasible subgroups of that minimum size. ${ }^{206}$ Moreover, as noted above, heterogeneous communities may lead to games that are not symmetrically structured; one person may confront the payoff structure of a Prisoner's Dilemma while another, perhaps due to a greater sensitivity to norms or a more active conscience, faces an Assurance Game or perhaps simply feels impelled to cooperate under all circumstances. ${ }^{207}$

An additional set of problems tends to fall temporally in between the two strategic interactions upon which I have been focusing. I have emphasized that an anticommons, usually characterized by the holdout or Chicken pattern of interaction, may sometimes follow closely on the heels of a tragedy of the commons, usually characterized by a Prisoner's Dilemma strategic interaction. But I have said little about the intervening steps that might take a group from a position in which the surplus from cooperation is a distant dream to one in which the surplus from consolidation of entitlements is real enough to be actively scrapping over. ${ }^{208}$ Someone must incur transaction costs in order to span this chasm. Who will do it?

The most likely candidate would be someone who expects to glean a larger-than-proportionate share of the surplus that will be generated. Yet there is no assurance that the surplus can be attained at all, and even less assurance that the party who takes the lead in bringing it about will enjoy much of it. Hence, the gains from assembling together property entitlements may be forgone, not because of people strategizing for larger shares of the surplus, but for lack of a willing assembler to get the process going. It is also possible that a would-be assembler will become discouraged in advance by the prospect of endless Chicken Games, or even by more mundane sorts of transaction costs, such as the costs of communication, that often plague large-number interactions. ${ }^{209}$

\footnotetext{
206 See ELSTER, supra note 157, at 28 (explaining that a point of "self-sustaining cooperation" is reached when a cooperating group exists of a size sufficient to achieve better results than in a world of universal defection, but going on to note that those who are not in such a cooperating group would do "even better"); Taylor \& Ward, supra note 18, at 355-57 (discussing the Chicken Game that results when a subgroup is capable of providing a "lumpy" public good); Fennell, supra note 76, at 44 (presenting an example showing this dynamic); see also Oliver et al., supra note 183, at 537 (discussing "willing subsets" capable of providing a collective good).

207 For a discussion of the impact of such heterogeneity, see Fennell, supra note 76, at 54-56.

208 These steps represent one piece of a well-noted puzzle about the origins of private property institutions. If individual selfishness explains the need for property, it is hard to explain how property institutions came about, given that setting them up requires a certain degree of unselfish cooperation. See, e.g., Krier, supra note 14, at 337-39 \& nn. 39, 44; Rose, supra note 103.

209 See Robert C. Ellickson, The Case for Coase and Against "Coaseanism”, 99 YALE L.J. 611, 615 (1989) (describing three "functional categories" of transaction costs: "get-together costs," which include "the burdens of arranging physical and electronic connections among transacting parties"; "deci-
} 
This middle ground between the blindered chaos of the commons and the bluffing standoffs of the anticommons is an important part of the puzzle that must be taken into account in formulating solutions. It can perhaps be best understood as bearing elements of both strategic interactions. It involves both the anticipatory costs of the Chicken Game, which may block assembly altogether, ${ }^{210}$ and the usual collective action problem associated with making investments that are socially beneficial but individually costly - in this case, investments in communication and coordination.

\section{THE TAXONOMY'S TRACTION}

The value of any taxonomy lies in its ability to enhance understanding. ${ }^{211}$ In this context, greater understanding brings with it the promise of innovative and creative approaches to difficult problems of resource use and community life. In this Part, I show how taking a functional approach to common interest tragedies can advance both an understanding of these tragedies and a search for better solutions to them. In subpart A, I explain how a focus on strategic patterns illuminates choices about the assignment and protection of entitlements. In subpart B, I explore this point further by demonstrating the inevitability - and, indeed, desirability - of fragmented interests in complex interdependent settings. Because solving one problem of fragmentation often creates another, different problem of fragmentation, a community sharing a common pool resource must choose the least harmful way of slicing up interests. In subpart $\mathrm{C}$, I show how the heterogeneity among production functions associated with the assembly of fragmentary interests provides a meaningful way of weighing these options. In subpart D, I draw together all of these lines of analysis with a stylized example involving entitlement protection within a residential neighborhood. ${ }^{212}$

\footnotetext{
sion and execution costs" incurred in "actualiz[ing] their agreement"; and "information costs" about the parties and goods under consideration).

210 See supra note 90 and accompanying text (discussing the anticipation of holdout problems).

211 See, e.g., Peter Birks, Equity, Conscience, and Unjust Enrichment, 23 MELB. U. L. REv. 1, $27-$ 28 (1999) (discussing the significance of taxonomy in the law and drawing analogies to biological classifications); Ugo Mattei, Three Patterns of Law: Taxonomy and Change in the World's Legal Systems, 45 AM. J. COMP. L. 5, 5-6 (1997) (discussing the importance of taxonomy in law and, in particular, its importance in "transferring knowledge from one area of the law to another"); see also Heller, supra note 12 , at 79-80 (observing that "static categories" and "familiar analytic tools" can be costly when they "render[] new forms of property invisible").

212 A neighborhood is, in an important sense, a "commons within a commons" insofar as its formation may involve strategic interactions. I have explored elsewhere some of the issues that are presented when the formation of a group, as well as its internal actions, are the product of strategic interactions, see generally Fennell, supra note 76, but will confine my analysis here to the internal workings of the neighborhood.
} 


\section{A. Approaching the Cathedral}

A key advantage of an approach that focuses on strategic patterns is that it connects the problems of the commons and the anticommons to the burgeoning literature on the allocation and enforcement of entitlements - an area of study launched by Guido Calabresi and Douglas Melamed in a pathbreaking article, Property Rules, Liability Rules, and Inalienability: One View of the Cathedral. ${ }^{213}$ The impressive analysis of entitlement protection has not been extensively applied to the commons and anticommons problems, even though entitlements and their protection lie at the heart of common interest tragedies. ${ }^{214}$ Unrecognized connections between the bodies of literature are much easier to see when common interest tragedies are catalogued according to whether they present a holdout problem (the bane of property rule protections) or a problem of improperly-priced conduct (the stumbling block of liability rules).

The chief complaint in a tragedy of the commons is a pricing flaw that makes socially costly acts or omissions personally beneficial. Because of inappropriate pricing, people act without regard for the full social cost (or benefit) of their actions. In many cases, this can yield a Prisoner's Dilemma. The chief complaint in a tragedy of the anticommons is blocked access to a unified entitlement - a blockage that stems from property rule protection over the fragments held by the other parties. Because property rule protection allows parties to stand on their rights and refuse transfers, it sets the stage for the bluffing behaviors associated with the game of Chicken. Liability rule protection would avoid the holdout problem just described, because a unilateral transfer would be possible. ${ }^{215}$ However, transfers might occur too cheaply (at less than the true social cost) if the price is set too low, or might be blocked unnecessarily if the price is set too high (at more than the true social cost). ${ }^{216}$

213 Calabresi \& Melamed, supra note 17.

214 See Krier \& Schwab, supra note 17, at 479 (describing the interdisciplinary work in the area of collective action as an "area of inquiry pretty much ignored to date in the property rule-liability rule literature"). There have been some notable exceptions. See, e.g., Robert C. Ellickson, Alternatives to Zoning: Nuisance Rules, and Fines as Land Use Controls, 40 U. CHI. L. REV. 681, 728-33 (1973) (discussing choice of entitlement protections in the neighborhood setting); Robert P. Merges, Contracting into Liability Rules: Intellectual Property Rights and Collective Rights Organizations, 84 CAL. L. REV. 1293 (1996) (discussing choice of entitlement protection in intellectual property realm where it may be necessary to assemble many entitlements together).

215 E.g., LeSSIG, supra note 48, at 260, 332 n.26 (discussing of the use of damage remedies in patent law to avoid holdouts, and providing citations to literature on this point); Dibadj, supra note 3, at 111315 (discussing potential of liability rules to preclude anticommons problems); Lewinsohn-Zamir, supra note 17 , at 226 (explaining that liability rules "remove the owner's holdout power").

216 The inverse relationship between externalities and holdout problems that is suggested by this discussion is developed at length in Epstein, supra note 13. As Epstein explains, "[t]he essential dilemma is that often the effort to counteract one problem will only aggravate the other, for where both are present, they stand in an inverse relationship with each other." Id. at 557. 
As parties react to a given entitlement regime, elements of the commons and anticommons tragedies surface. For example, the person whose interests are overridden too cheaply through a liability rule regime faces an anticommons situation. If the liability rule regime gives each person an option to engage in some obnoxious behavior (say, noisemaking) upon payment of a preset price, an individual particularly sensitive to noisemaking might wish to buy up all those options in order to enjoy silence. But assembling the noisemaking entitlements from everyone in the community is likely to be difficult, for standard anticommons reasons. A party who holds an option to engage in behavior typically enjoys property rule protection for that option, meaning that she does not have to give up her privilege to exercise it unless she is offered a deal that she finds attractive. This permits disingenuous statements of valuation, and can result in bluffing. The rights of the sensitive could be protected by granting everyone a property rule entitlement to stop annoying noise, but a person who highly values noisemaking would then have to assemble the right to engage in acoustic excesses by buying up rights from everyone else-again, a potential anticommons situation. $^{217}$

When viewed from this perspective, the choice between liability rules and property rules involves a choice between potential common interest tragedies. The potential for tragedy is an inherent result of the fragmentation of entitlements that accompanies common resource situations. No matter how entitlements are rearranged among the parties in a commons, fragmentation of some important interest is likely to remain. The next subpart explains.

\section{B. Fear of Fragmentation}

In recent years, property scholarship has emphasized the disadvantages associated with the fragmentation of entitlements - whether along physical or conceptual lines. ${ }^{218}$ Although the points that have been made in this connection are well taken, the implicit suggestion that we should avoid fragmentation qua fragmentation deserves closer scrutiny. ${ }^{219}$ It is easy to see why fragmentation attracts angst - we have already noted its association

217 See notes 117-19 and accompanying text (discussing both sides of this problem).

218 E.g., Freyfogle, supra note 75; Michael Heller, The Boundaries of Private Property, 108 YALE L.J. 1163 (1999); Heller \& Hills, supra note 90, at 1; Julia D. Mahoney, Perpetual Restrictions on Land and the Problem of the Future, 88 VA. L. REV. 739, 785 (2002); Thomas J. Miceli \& C.F. Sirmans, Partition of Real Estate; or, Breaking Up Is (Not) Hard to Do, 29 J. LEGAL STUD. 783 (2000); Francesco Parisi, Entropy in Property, 50 AM. J. CoMP. L. 595 (2002).

219 The fact that there are better and worse sorts of fragmentation has not gone unrecognized in the literature. See, e.g., Heller, supra note 218, at 1184 (noting, in the context of common interest communities, "the difficulty of distinguishing good from bad fragmentation"); Parisi, supra note 218, at 613 \& nn.62-63 (explaining that "dysfunctional fragmentation" is associated with forgone complementarities, and observing that some kinds of fragmentation may be functional under some social and economic conditions). 
with both the commons and anticommons tragedies. ${ }^{220}$ Indeed, a number of longstanding property doctrines can be understood as mechanisms to control the pernicious effects of fragmentation. ${ }^{221}$ Add to this the intuitive suggestion that smashing property into pieces is much easier than painstakingly piecing the shards back together, ${ }^{222}$ and the case against property fragmentation looks airtight. Or so it does, until one asks: "Compared to what?"

Consider a modern urban or suburban neighborhood comprising a grid of 100 lots, each occupied by a house, which is in turn occupied by a family. Viewed from above, this is the very picture of fragmentation. There are hundreds of separate lot boundaries, and one hundred separate owners. But it is not the sort of fragmentation that usually troubles commentators or judges. Why not? Well, one might say, each of these individual owners holds unified use privileges and exclusion rights as to her own parcel. ${ }^{223}$ But take a closer look and you will notice spillovers-visual, olfactory, auditory, even floral and faunal ${ }^{224}$-flowing freely across the property lines. This seems normal and natural. In most neighborhoods, homeowners receive a standardized bundle of property rights that includes the right to engage in many activities that will impose mild spillover effects on neighbors. ${ }^{225}$

Bundling certain spillover-causing use privileges together with each neighbor's fee simple, however, means that neighbors have no right to ex-

220 See supra Part II.A.

221 See, e.g., Heller, supra note 218, at 1170-74 (discussing antifragmentation mechanisms in real property); Parisi, supra note 218, at 603-13 (providing an historical overview of antifragmentation doctrines); Henry E. Smith, The Language of Property: Form, Context, and Audience, 55 STAN. L. ReV. $1105,1143 \& \mathrm{n} .137$ (2003) (explaining that "[a] wide variety of rules in property law can be regarded as preventing excessive fragmentation of several types").

222 See, e.g., Heller, supra note 218, at 1165-69 (noting the comparatively greater difficulty of assembling fragmented entitlements); Miceli \& Sirmans, supra note 218 (recognizing the costliness of reassembling excessively fragmented interests); Parisi, supra note 218, at 626-27 (observing that "the reunification of fragmented rights usually involves transaction and strategic costs of a greater magnitude than those incurred in the original act of fragmentation" and noting the "one-directional stickiness in the fragmentation process"). But see Smith, supra note 221, at 1143-44 (querying whether sunk costs might not provide another explanation for enduring fragmentation).

223 See Parisi, supra note 218, at 613 n.62 (arguing that "[u]se and exclusion rights are a paradigmatic example of strict complements in the bundle of property").

224 See FREYFOGLE, supra note 27, at 167 (observing that dividing land into privatized parcels does not, in itself, keep animals from crossing borders).

225 See Bernard E. Jacob, The Law of Definite Elements: Land in Exceptional Packages, 55 S. CAL. L. REV. 1369, 1385 (1982) (observing that land packages held by neighboring landowners include "mutual privileges to which no one has the right to object"). Control over uses of the land can be divided between the individual landowner and the community in any number of ways. See, e.g., William A. Fischel, Equity and Efficiency Aspects of Zoning Reform, 27 PUB. POL'Y 301, 304 fig.1 (1979) (presenting a "restriction index" that graphically represents the possible divisions of entitlements); WILLIAM A. Fischel, REgUlAtORY TAKINGS 343 fig.9.1 (1995) (same); Lee Anne Fennell, Hard Bargains and Real Steals: Land Use Exactions Revisited, 86 IowA L. REV. 1, 18-19 \& fig.1 (2000) (depicting and describing possible divisions of entitlements between the community and the landowner). 
clude the spillovers from their property. Hence, with regard to the spillovers, each neighbor has use privileges without exclusion rights. Moreover, we can understand this problem as one of fragmentation. Bundling the entitlements to certain spillover-causing activities along with each property owner's estate means splintering the converse entitlement to live in a neighborhood free of those spillovers. For example, if each of my neighbors can do as she pleases with regard to lawn care, then I cannot live in a uniformly landscaped neighborhood unless I buy up each neighbor's privilege to control lawn care and assemble in my own hands an entitlement to "uniform landscaping.",226

Transferring more property entitlements from the individual homeowners to the community resolves one fragmentation problem, but introduces a new one - the fragmentation of the entitlement to engage in certain spillover-producing behaviors among the many neighbors affected by those spillovers. ${ }^{227}$ We can see this by considering the implicit fragmentation wrought by those land use entitlements already firmly under the community's control. For example, in surveying this neighborhood, we are unlikely to see any pig farms. There is a simple reason for this: the residents of the neighborhood have an entitlement to keep out pigs. As a result, no person in the neighborhood can have a pig farm-even an efficient pig farm-without gaining the consent of the other members of the neighborhood. $^{228}$ In other words, as to the activity of pig-farming, the neighbors have exclusion rights without use privileges. ${ }^{229}$

If a would-be pig owner would get a tremendous amount of value from a pig farm and the neighbors care little about the aesthetic impact of pigs, the pig-farming potential of the land may well be underused. Again, we can blame fragmentation: I might complain that my Blackstonian prerogative

\footnotetext{
226 It is possible that norms could generate a uniform effect. See Ellickson, supra note 214, at 686 n.17 (noting the ability of some Vermont towns to maintain consistent aesthetic schemes through norms). In such a case, we might say that the community has de facto control over individual aesthetic choices.

227 See infra Part III. For an extended analysis of this point, see Lee Anne Fennell, Contracting Communities, 2004 U. ILL. L. REV. (forthcoming).

228 This is a simplification. If restrictive covenants constituted the only obstacle to the pig farm, universal releases would be both necessary and sufficient. Unanimous consent by neighbors might be neither necessary nor sufficient to undo the prohibition on a given land use worked by nuisance law or zoning. However, because neighbors generally have a great deal of say in what land uses get zoning approval, and because neighbors could also agree not to bring nuisance actions, we might understand the neighbors to have something approaching alienable veto rights. See FISCHEL, supra note 225, at 251 (describing the impact of a California Supreme Court decision that gave many parties the right to stop development); Heller, supra note 218, at 1186 (observing that "zoned communities can create a tragedy of the anticommons by giving too many neighbors veto rights over reasonable uses of land or by empowering too many overlapping jurisdictional bodies").

229 See Kennedy \& Michelman, supra note 114, at 768 (observing that when the law designates some activity as a nuisance, such as operating a casino or brothel, it means that no person has the privilege of engaging in the activity, while every person holds a right to not be exposed to the activity).
} 
to keep pigs has somehow, without my consent, been dispersed in the form of veto rights among my many neighbors within smelling range. The fragmented pig-farm entitlements could be brought back under each landowner's control, but only at the price of splintering another interest that homeowners hold dear: the right to breathe air untainted by pigs. Were homeowners given back their pig-farm entitlements, any homeowner that wished to breathe pig-free air would have to potentially buy up the pig farming rights from everyone else.

The point should be clear by now: Fragmentation of entitlements is a virtual inevitability in complex interdependent society. ${ }^{230}$ Fighting fragmentation in such a setting is a bit like fighting gravity. If the entitlements in the neighborhood I have described do not seem as fragmented as those that might be generated through reconfiguring the entitlements, this is only because cultural understandings and engrained expectations cause us to think of certain kinds of property entitlements as properly or naturally belonging together. ${ }^{231}$ As a result, the fragmentation of such "unified" entitlements may be more salient to observers, including legal scholars and judges. ${ }^{232}$ It is possible that the bundles (and corresponding fragments) that seem "natural" to us do so because they happen to embody certain economies of scale, so that they actually represent a more efficient way of dividing up the world of entitlements ${ }^{233}$ - or did at the time they gained

230 There is a tight connection between this point and the "Law of Reciprocity of Entitlements and Exposures," formulated by Kennedy and Michelman. This principle, distilled from Wesley Hohfeld's work on jural relations, holds that "[f]or every legal entitlement there is an equal and opposite legal exposure." Id. at 760. Because property rights are in rem, the correlative duties associated with them are necessarily fragmented among the multitudes. Likewise, any limitation on those rights spreads privileges to those same multitudes. See HoHFELD, supra note 129, at 36 (setting out system of jural opposites and correlatives); id. at 73 (discussing the meaning of rights in rem). Once we posit a somewhat densely populated and interdependent social setting, the reciprocal sets of rights, duties, privileges, and "no-rights," see id. at 36, create unavoidable coordination problems, regardless of the configuration chosen. As Kennedy and Michelman explain, "[e]xposures can be shifted but not changed in number. . . The books are double-entry and they have to balance." Kennedy \& Michelman, supra note 114, at 760.

231 Cf. Heller, supra note 2, at 671-72 n.228 (noting the difficulties in defining the "normal boundaries of an object"). But see Parisi, supra note 218, at 613 n.62 (suggesting that "we can easily think of other essential attributes of a property right [aside from use and exclusion rights] that are meant to be in the control of a single individual" (emphasis added)).

232 In addition, there can be advantages associated with recognizing a limited number of standardized forms of property and protecting those bundles from decomposition or reconfiguration into less readily recognizable bundles. See Kennedy \& Michelman, supra note 114, at 764 (discussing the limits our legal system places on decomposition of property interests); Thomas W. Merrill \& Henry E. Smith, Optimal Standardization in the Law of Property: The Numerus Clausus Principle, 110 YALE L.J. 1 (2000); see also Henry Hansmann \& Reinier Kraakman, Property, Contract, and Verification: The Numerus Clausus Problem and the Divisibility of Rights, 31 J. LEGAL STUD. S373 (2002) (arguing that limits on the division and variety of property rights are designed to facilitate verification by requiring appropriate levels of notice).

233 Cf. Otto A. Davis \& Andrew Whinston, Externalities, Welfare, and the Theory of Games, $70 \mathrm{~J}$. POL. ECON. 241, 243-44 \& n.8 (1962) (discussing the notion of "natural units" in industry that might be achieved through merger and citing George J. Stigler on this point). 
dominance. Nevertheless, these consolidated bundles of property rights often implicitly depend upon the fragmentation of some other entitlement. Fragmentation is neither as negative nor as avoidable a phenomenon as it might at first appear.

We can imagine efforts to make property in a neighborhood or village less fragmented across the board. One person (or the government) could buy up all the land and the residents could become tenants. Aside from questions about whether this consolidation of land ownership is desirable, ${ }^{234}$ this would still fragment the fee simple temporally by granting a term of years to tenants, and would create incentive problems along that dimension. Alternatively, the "neighborhood commons"- that is, the shared aspects of the environment that are subject to spillovers caused by the exercise of landowner privileges - could be brought under the control of a central decisionmaking body, such as a homeowners association. However, this would fragment decisionmaking powers into the individual voters' hands (or concentrate it into the hands of some of them) and potentially present new concerns. Fragmentation of one sort or another cannot be avoided, and efforts to avoid a particular kind of fragmentation may create another kind that is, on balance, worse.

Nor can we even say that all fragmentation that generates independently useless fragmentary entitlements is something we should necessarily avoid. Fragmentation is sometimes important for the very purpose of relinquishing power over a given resource without granting power over the resource to anyone else, perhaps as a form of precommitment. For example, when car ignitions are keyed separately from car doors, a partygoer who fears overindulgence might entrust the ignition key to a friend while retaining the door key herself; this would give the friend control over the driving of the partygoer, but would afford the friend no actual access to the car without the partygoer's consent. Fragmentation also works to temporally spread negotiations so that they encompass more generations or at least more "selves" who are exposed to more information. ${ }^{235}$ For example, granting a continuing veto power over use of a resource, such as a park, to a number of different people forces the parties to negotiate each use among their then-current selves, using then-current information, whenever an issue regarding the resource's use arises. ${ }^{236}$ For a variety of reasons, this may be

234 See Haw. Hous. Auth. v. Midkiff, 467 U.S. 229, 232 (1984) (relating the findings of the Hawaii legislature that "concentrated land ownership was responsible for skewing the State's residential fee simple market, inflating land prices, and injuring the public tranquility and welfare"); $c f$. Davis \& Whinston, supra note 233, at 261-62 (noting the ability of merger to internalize externalities, but observing that this may change the market structure in ways that generate a welfare loss).

235 The effect, and perhaps also the intention, is likely to be stability of the resource over time. See TONY HONORÉ, MAKING LAW BIND 187-88 (1987) (suggesting that many splits of property interests are "directed towards continuity by maintaining in being a physical thing, collection, or fund in order that it may serve a family, business, or association over a substantial period").

${ }^{236}$ Cf. Bell \& Parchomovsky, supra note 3 (manuscript at 5-6, 34-37). 
preferable to holding an auction today that would place full power over the park into a single individual's hands.

None of this is to deny that certain manifestations of fragmentation can yield suboptimal — even tragic — results. The trick is to distinguish the sorts of fragmentation that cause the most harm from their more benign counterparts. It is to this task that I now turn.

\section{Heterogeneous Tragedies}

While the preceding discussion suggests that something like an anticommons is lurking around the corner of every commons, and that fragmentation is both ubiquitous and unavoidable, it is important to recognize that not all problems involving fragmented interests are equivalent. What perhaps matters most is the shape of the production function for the surplus or deficit involved. ${ }^{237}$ Recognizing these heterogeneities points the way towards choosing wisely among possible tragedies.

In order for a fragmented entitlement situation to yield "tragedy" at all, there must be complementarities among fragments so that their assemblyin and of itself-generates surplus. Notwithstanding this complementarity requirement, it is not always the case that the value of a set of fragments is literally zero up until the point at which all the fragments are assembled. ${ }^{238}$ Differences in the production functions for the surplus associated with assembly yield differently-structured dilemmas.

In the walled park example presented above, the surplus associated with aggregation of property fragments was a step-level good featuring a single sharp and well-defined "step." ${ }^{339}$ However, it is not always essential that all of the fragments be assembled in order for any of the surplus to be enjoyed. Compare a jigsaw puzzle, which might be enjoyed (albeit suboptimally) by a group of children even if one piece is missing, with a machine that will absolutely not run without all of its parts. In both cases, complementarities are present, but the surplus associated with assembly does not follow the same curve in both cases. ${ }^{240}$ Vivid examples of development around holdouts (or holdins) suggest that something short of unanimous

237 See MARWELl \& OLIVER, supra note 18, at 25 (observing that in their analyses "the nature of the production function emerges as the most important determinant of the outcome of a potential collective action").

238 See Depoorter \& Vanneste, supra note 160, at 8-10, 18-19 (presenting and discussing the results of a study designed to test the impact of varying degrees of complementarity on reservation prices); Schulz et al., supra note 12, at 605 (discussing instances in which exclusion rights exhibit "less than perfect complementarity").

239 See supra fig.5 and accompanying text.

240 Parchomovsky and Siegelman allude to this point when they discuss differences between "[c]lassic holdout settings," in which all properties must be acquired, with pollution situations in which a polluter can block an injunction with something less than a unanimous buyout. Parchomovsky \& Siegelman, supra note 91, at 128; see Depoorter \& Vanneste, supra note 160, at 8-10, 18-19 (studying the effects of altering the degree of complementarity). 
consent is often sufficient to achieve at least a significant part of the available surplus associated with land assembly. ${ }^{241}$ Where the consolidator's need to obtain unanimous consent is not present, bluffing on the part of a fragment-holder becomes riskier and hence self-limiting.

Figures 6 and 7 provide two examples of different production functions associated with the surplus from assembling fragmented entitlements. In both cases, surplus is associated with the assembly of the entitlements, but unlike the situation depicted in Figure 5, it is not realized in one large jump when the last piece is added. Figure 6, "Golden Silence," shows the surplus that might result from one person's assembly of the rights of other group members to make annoying noises. ${ }^{242}$

\section{Figure 6: Golden Silence}

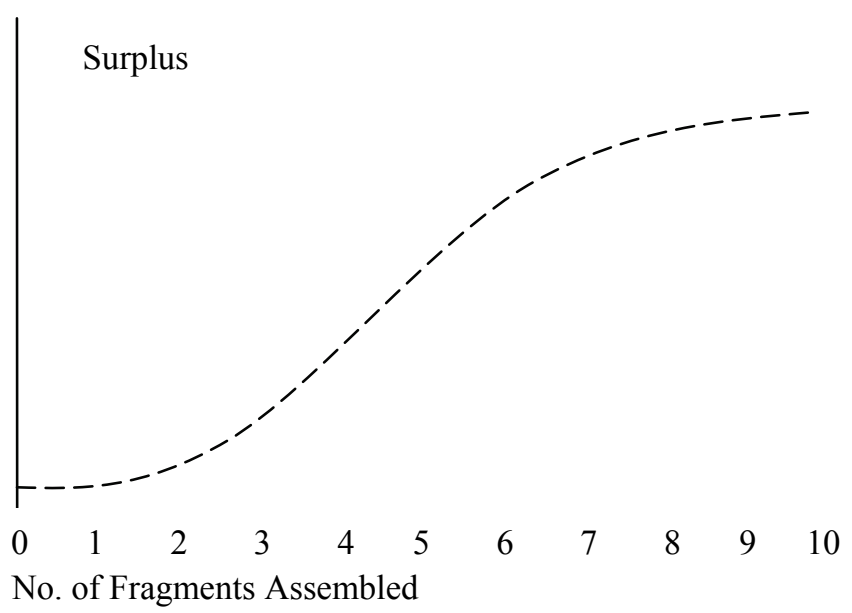

As the shape of the dotted line shows, buying up one group member's right to make noise would have little impact on the overall noise levels, but there would be a cumulative effect as more "doses" of silence were added to the mix, so that a significant surplus might result from putting together a half dozen such entitlements. Eventually (in this example) things become quiet

241 See ANDREW AlPERn \& SEYMOUR Durst, Holdouts! (1984) (illustrating this point through photographs and text); Cohen, supra note 76, at 358-59 (recounting the true story of a residential holdout in Atlantic City whose plan backfired when a casino-builder finally stopped making escalating offers and built his casino around the resident's home, lowering its value below the pre-negotiation point).

${ }^{242}$ I have depicted this as an S-curve, although the actual shape would depend on the specific preferences of the would-be assembler and the persons who presently hold the entitlements to make the annoying noises. In some cases, noisemaking could take on the character of a "step" bad. See HARDIN, COLLECTIVE ACTION, supra note 8 , at 51 (characterizing a neighbor operating a power mower on a Sunday morning as a step public bad). 
enough that there is a diminishing marginal surplus associated with adding each additional noise right to the set.

Figure 7 shows yet another possibility - a curve that might be associated with the assembly of a path between two public parks along private beachfront property.

\section{Figure 7: The Beach Path}

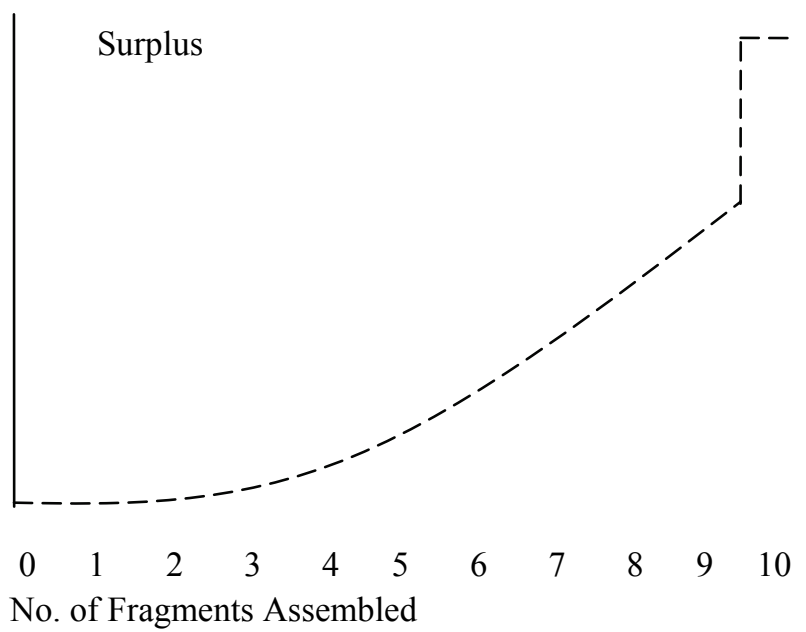

In this example, the complete path yields the largest surplus and is much better than a nearly-complete path. Therefore, we have a large jump in surplus when the last fragment is added. Similarly, there is little surplus associated with putting together just two or three fragments. However, as the incomplete path grows, it begins to generate larger surpluses. A partial path beginning at either park will let parkgoers stroll along the beach for some distance, and even a short assembled segment that connects to neither public park still generates (let us posit) some surplus for those with access to the private property.

There are obviously many other possibilities associated with the assembly of fragmented entitlements, and a full explication of the various implications of these configurations is beyond the scope of this paper. What is important for present purposes is to note that assembly problems take a variety of forms, and that the strategic interactions they present will vary. In short, not all problems of this genre are equally problematic. The kind of assembly problem presented in Figure 5 is probably the trickiest to solve because the stakes of getting all the pieces together is the highest (the total surplus), and the return from dealings falling short of that are the lowest 
(zero). As noted earlier, even parties who attest a joint interest in a "fair" division of the surplus may disagree vehemently about what that means, and the heterogeneity of preferences makes it difficult to tell greed from a mere desire to break even on the deal. ${ }^{243}$

This same difficulty is present in assembly problems that take a different shape, but there is less risk of bluffing in those instances. Because much of the surplus can be achieved without a particular individual's cooperation, those falsely attesting to higher valuations run a risk that they will be simply left out of the deal, at relatively little cost. For example, some land assembly problems might take the shape of Figure 6, as where a developer has significant latitude about exactly what portion of an existing neighborhood to use for a cluster of, say, new shops. In these cases, the surplus associated with one's contribution to the assembly shrinks rather than grows as more of one's neighbors accept offers; this could trigger a rush to sell within a certain range, rather than attempts to hold out and be the last seller. ${ }^{24}$ We should worry less about the risk of Chicken Game interactions leading to inefficient results in such cases, other things equal. Of course, other kinds of strategic problems may exist in such a case, perhaps stemming from a clamor to sell as quickly as possible.

A focus on the shape of production functions is also useful for sizing up and distinguishing among tragedies of the commons. As noted above, the stage is set for a tragic outcome when the actions of purely selfinterested parties yield a lower amount of social value overall than would be achievable if the parties took account of the externalities of their actions. But the increment by which private interest and group interest diverge is not a constant value in a given resource-allocation setting. Consider the case of overfishing. When the members of a commons are merely extracting fish for personal use from the pond, there may be no net social cost associated with the fishing because it does not deplete the fish population enough to reduce the overall amount available for someone in the group to enjoy. As fishing intensifies (perhaps in response to a developed market for fish), extractions begin to produce larger social costs by reducing the replenishment rate of the pool and causing fishers to have to spend more time getting fish out of the pond. ${ }^{245}$ As the replenishment rates drop dramatically, fishers reach a point at which they cannot depend on future generations of fish being present in the pond, and, unless the impulse is checked, race to extract all the existing fish they possibly can before someone else does. This ful-

\footnotetext{
243 See supra fig. 4 and accompanying text and notes.

$244 C f$. Cohen, supra note 76, at 361. Cohen observes that a holdout problem is unlikely to develop when only a majority of shares is required to change a corporate board; even if the raider's plan becomes known before the majority is acquired, the remaining stockholders' realization that the plan requires the participation of only a fraction of them is "more likely to induce a mad rush to sell" than efforts to hold out. Id.

245 See Demsetz, supra note 14, at 351-52 (positing that the emergence of markets for furs led to rapidly escalating rates of hunting and increasingly costly externalities).
} 
fills the fear that there will not be a continuing population of fish in the pond and leads to a tragic result.

The precise relationship between fishing behaviors and the sustainability of the fish population is ultimately an empirical question; mathematical models cannot provide answers without good inputs from those with specialized knowledge of the resource and the many factors impacting it. ${ }^{246}$ But assuming for the sake of argument that the facts are roughly as I have just posited them, the course of the tragedy might look something like Figure $8 .{ }^{247}$

246 There is a substantial literature on such questions. See, e.g., Thomas Dietz et al., The Drama of the Commons, in THE DRAMA OF THE COMMONS, supra note 8, at 3, 9-11 (summarizing the literature on modeling fishing); H. Scott Gordon, The Economic Theory of a Common-Property Resource: The Fishery, 62 J. POL. ECON. 124 (1954) (attempting to model impact of fishing on yields over time); Dean Lueck, The Extermination and Conservation of the American Bison, 31 J. LEGAL STUD. S609, S616-17 \& fig.2 (2002) (modeling bison population dynamics); Rose, supra note 34, at 241 (explaining how factors such as "weather patterns, shifts in water temperatures and currents, [and] alterations in food sources and predators," cast doubt on "the idea of a smoothly curved relationship between human activity (e.g., fishing or pollution) and resources stock levels (e.g., bountiful fish or clean air)"). In natural resource contexts, assumptions about the total size of various resources or about the impacts of human activity on those resources are constantly subject to revision. See, e.g., Gordon, supra, at 126-28 (discussing cyclical shifts in opinion among biologists about the impact of fishing on fish populations); Christopher Pala, Multiplication Problem Threatens Stock of Sturgeon, N.Y. TIMES, Jan. 6, 2004, at D3 (reporting controversies over data on the beluga sturgeon population in the Caspian Sea); José Ramirez, Revised Estimates of Whale Population, N.Y. TIMES, July 26, 2003, at A10 (reporting a study estimating that the population of humpback whales before commercial whaling began may have been as high as 1.5 million, not 100,000 as previously believed); Andrew C. Revkin, Ozone Layer Is Improving, According to Monitors, N.Y. TimES, July 30, 2003, at All (reporting that studies show "the first sign that the phasing out of chemicals that harm the ozone layer is having a restorative effect"). For an essay addressing the problem of uncertainty associated with natural systems, see James Wilson, Scientific Uncertainty, Complex Systems, and the Design of Common-Pool Institutions, in THE DRAMA OF THE Commons, supra note 8 , at 327.

247 See Taylor \& Ward, supra note 18, at 353 (presenting diagram showing two possible relationships between the use value of a fishery and its rate of exploitation). Although Figure 8 differs somewhat in format and shape from the graphs shown in the Taylor \& Ward diagram, it grows out of similar assumptions and has similar implications. 


\section{Figure 8: The Fish Pond}

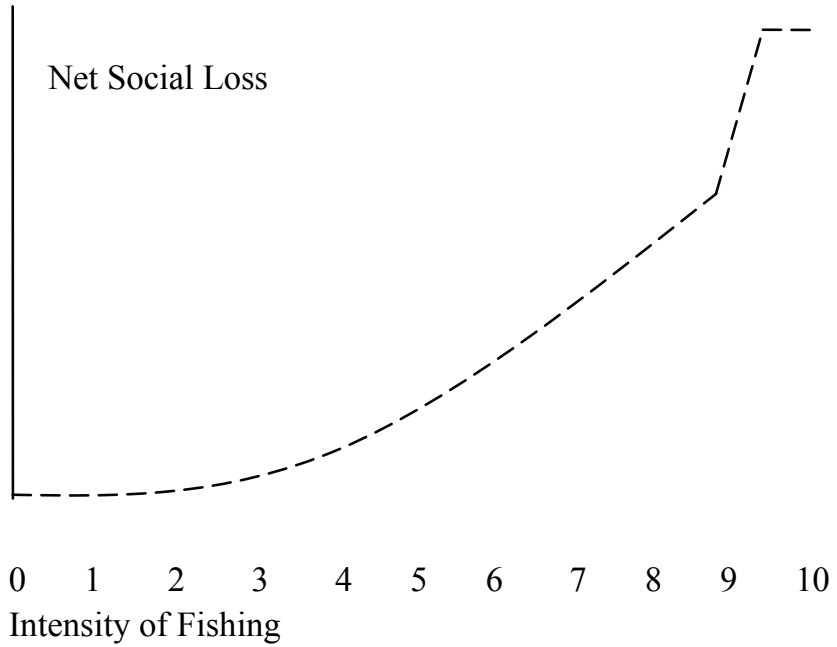

The horizontal axis tracks the intensity of extraction, and the vertical axis represents the deficit imposed on the group as a whole as a result (the difference between the private benefit achieved and the public cost it inflicts on the others). Over some range, there is no deficit produced. ${ }^{248}$ On the contrary, the benefits internalized by the extractor exceed the costs imposed on the whole group, so that extraction is beneficial on balance. This might be the case where fishing is done for personal consumption only. As fishing intensifies, costs rise slowly and then climb at an increasing rate until they sharply peak at the point where the pond loses viability. ${ }^{249}$ As we move to the right on the graph, each fisher suffers a larger and larger cost as a result of the deficit that is inflicted on the group, and each will intensify her own extraction efforts in an effort to defray that deficit by pulling out some benefits of her own. Of course, this exacerbates the situation.

On the other hand, heightened externality costs could create pressures towards changes in property rights capable of overcoming the collective action problem. ${ }^{250}$ One possible solution is suggested by the large "step" at

${ }^{248}$ See id. (observing that "[e]cological systems such as lakes, rivers, the atmosphere, fisheries and so on can normally be exploited up to some critical level while largely maintaining their integrity and retaining much of their use value").

249 See id. (suggesting there is often a point at which exploitation generates a catastrophic drop in use value for resources such as fisheries).

250 See Demsetz, supra note 14, at 351-52 (suggesting that property rights developed in response to changes in the fur trade that increased the costs associated with externalities). Such changes require collective action, however. See supra note 208 (noting the difficulty property theory has in explaining how selfish parties can cooperate to a sufficient degree to establish property rights that are designed to restrain selfishness). 
the end, just before the fish pond's demise. If increasing intensity (moving from left to right on the curve) raises the social cost sharply within that final range, this also means that decreasing intensity from the point of total disaster (moving from right to left on the curve) would generate a sharp drop in costs (or a gain, relative to the baseline of the pond's destruction). If each number on the intensity scale represented the all-out efforts of an individual fisher, then any one of the fishers would be able to unilaterally achieve a significant improvement (an intensity drop from 10 to 9) by abstaining from fishing. While it is unlikely that the internalized share of this improvement would be enough to motivate such an action, the other fishers might find it worthwhile to "buy out" the tenth fisher's fishing privileges, so as to preserve the viability of the pond. This would work if the other fishers were already operating at top capacity and could not expand their own operations. Otherwise, keeping Fisher 10 out of the pond would only enable intensified fishing efforts on the part of the other nine fishers, potentially leading to disaster once again. ${ }^{251}$

Not all tragedies are shaped like this one. To turn again to the example of noise pollution, it might be the case that a little bit of extra noise does little or no harm, but as noise levels increase, extra increments become additionally harmful to the overall ambience of an area. At some point, however, the noise is so great that extra increments add very little to the overall cacophony. This might be depicted by an S-curve, as shown in Figure 9.

Figure 9: Annoying Noise

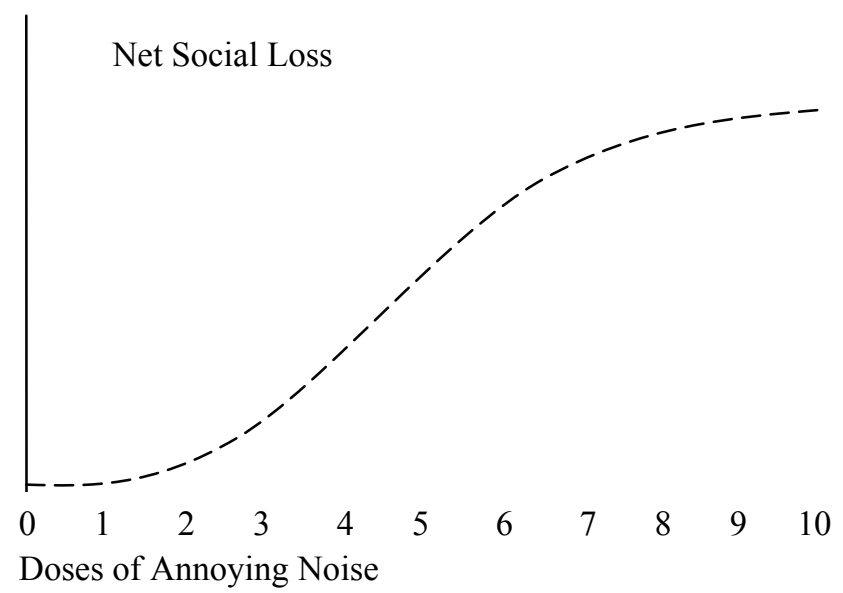

251 This distinguishes this example from the umbrella example given earlier. There, each student faced a discrete choice to take a single unit (one umbrella) and had no incentive to intensify extraction above that level in response to the sacrificial action of one of the students. 
Notice that this is exactly the converse of Figure 6, Golden Silence. ${ }^{252}$ If the community (or an individual) buys back the rights to each increment of annoying noise, the effects on the overall cost curve can be seen by moving down the curve from right to left (reducing from 10 increments to 9 increments of noise, and then from 9 to 8 , and so on). If the gains thereby achieved were plotted as "surplus," the result would look like Figure 6.

Finally, how might we map the tragedy of underinvestment? Here, we can draw on the literature assessing the production functions of public goods, which suggests an S-curve of the sort shown in Figure 9 is a possibility. ${ }^{253}$ The first few efforts to contribute to, say, the intellectual life of a group may generate relatively little surplus. As things begin to improve, however, each addition does more and more good. In these cases, the challenge is to get the investment off the ground in the first place. Once it gets going, the large visible gains associated with additional increments of investment may encourage those investments. ${ }^{254}$ Even a purely self-interested individual who takes no account of the externalities bestowed on others will receive a larger benefit when the total returns associated with her investment are larger, and will be somewhat more likely to make the investment, other things equal, than she was when her efforts generated smaller personal returns. Ultimately, however, a level is achieved at which additional inputs of intellectual investment generate only small positive externalities. Once the returns begin to diminish, so too will the incentive to contribute. ${ }^{255}$

Again, it becomes important to consider whether the good being produced through investment has the nonrival character of a public good (as would the intellectual climate example just mentioned) or is one from which units can be subtracted at will (as would be the case if one were investing - through restrained extraction-in a replenishing resource). In the latter case, one cannot be sure that larger returns from action will mean a larger share for oneself, at least insofar as the group members have the incentive and ability to increase their demands on the system. In the former case, however, an increasing benefit for the group will necessarily mean an increasing benefit for oneself. Successfully comparing tragedies therefore requires an awareness not only of the shape of the production function, but also the amounts at stake, and the characteristics of the underlying resource.

\footnotetext{
252 This reiterates the point made earlier, supra note 45 , that the same activity can be characterized either as producing a harm or failing to bestow a benefit.

253 See MARWELl \& OLIVER, supra note 18, at 58, 60-61 (quoting Anthony Oberschall and discussing his assumption that $\mathrm{S}$-curves are typical in collective action).

254 This pattern exists whenever a production function is accelerating (as the S-cuve is in its early phase). See Oliver et al., supra note 183, at 542 (noting that it is difficult to get initial contributions going where a collective good exhibits an accelerating production function, but that cooperation "tends to snowball" once it gets underway).

255 See id. at 547 (explaining that "once the later, flatter portion of the curve is reached, it is ruled by the dynamics of deceleration, and the less interested cease contributing").
} 


\section{Choosing the Lesser Tragedy}

In this last subpart, I will illustrate how the analysis developed in the subparts above might be used to make better decisions about entitlement assignment and protection in a common resource context. To do this, I use the example of a residential neighborhood, where homeowners must necessarily share overlapping environments. The overall neighborhood ambience can be understood as a common pool resource against which costly draws may be made through land uses that produce negative externalities, and to which valuable contributions may be made through land uses that produce positive externalities. ${ }^{256}$

1. Entitlement Options.-Figure 10 uses the schema developed by Calabresi and Melamed and their successors to lay out a menu of options for addressing matters of neighborhood ambience. ${ }^{257}$ I use two examples throughout the chart to show the practical implications of each rule in this context: one involves an activity-putting a plastic flamingo in the yard - often thought to generate negative externalities; the other involves an activity-landscaping - generally believed to generate positive externalities. The words "flamingo" and "landscaping" in each example could be replaced by anything that generates negative and positive spillovers, respectively, within a commons.

256 To be sure, not everyone will agree about the impact of certain uses, and views of a given use may change over time. The possibility of disputes about the sign (positive or negative) associated with externalities generated by particular activities introduce difficulties that are very important, although not unique to the realm of neighborhood aesthetics. Beliefs about the value of (and implicitly about the externalities generated by) many other land and resource use arrangements have changed over time. See, e.g., Robert Bruegmann, Urban Density and Sprawl: An Historical Perspective, in SMARTER Growth: MARKeT-BASEd StRATEgies For LAND-USE PlanNing IN THE 21st Century 155, 177 (Randall G. Holcombe \& Samuel R. Staley eds. 2001) (discussing past preference reversals regarding matters such as power generation, public housing, urban renewal, and zoning); Mahoney, supra note 218, at 759-63 (describing how cultural changes can transform aesthetic sensibilities and alter the desired patterns of land use).

257 This table is adapted from ones generated by other authors. See, e.g., Avraham, supra note 17, at 8 tbl.1; Ayres \& Goldbart, supra note 17, at 6 fig.2. The first four rules are those discussed by Calabresi and Melamed; the last two were added by later scholars. See Morris, supra note 17, at 854-56 (discussing "reverse liability" or "put" options); see also Avraham, supra note 17, at $7 \&$ nn.10-11 (describing history of Rules 5 and 6 and providing citations to work developing them). In some scholarly discussions of these rules, numbers 5 and 6 are reversed. See Ayres \& Goldbart, supra note 17, at 7 n.13. 
N O R TH W ES TER N UN IVERS I T L A W REVIE W

Figure 10: Neighborhood Ambience: A Menu of Choices

\begin{tabular}{|l|l|l|l|}
\hline RULE & $\begin{array}{l}\text { ENTITLEMENT } \\
\text { HELD BY }\end{array}$ & $\begin{array}{l}\text { HOW } \\
\text { PROTECTED? }\end{array}$ & EXAMPLES \\
\hline 1 & Community & Property Rule & $\begin{array}{l}\text { flamingos are forbidden; } \\
\text { landscaping is required }\end{array}$ \\
\hline 2 & Community & $\begin{array}{l}\text { Liability Rule } \\
\text { (Individual } \\
\text { Holds Call } \\
\text { Option) }\end{array}$ & $\begin{array}{l}\text { flamingos are taxed; } \\
\text { failure to landscape is taxed }\end{array}$ \\
\hline 3 & Individual & Property Rule & $\begin{array}{l}\text { flamingos are permitted; } \\
\text { landscaping is optional }\end{array}$ \\
\hline 4 & Individual & $\begin{array}{l}\text { Liability Rule } \\
\text { (Community } \\
\text { Holds Call } \\
\text { Option) }\end{array}$ & $\begin{array}{l}\text { the community can remove } \\
\text { the flamingo by paying the } \\
\text { individual a removal fee; the } \\
\text { community can require land- } \\
\text { scaping by paying the indi- } \\
\text { vidual a landscaping fee }\end{array}$ \\
\hline 5 & Individual & Put Option & $\begin{array}{l}\text { individual can keep the fla- } \\
\text { mingo or get rid of it and } \\
\text { collect a removal fee; } \\
\text { individual can go without } \\
\text { landscaping, or landscape } \\
\text { and collect a fee }\end{array}$ \\
\hline 6 & Community & $\begin{array}{l}\text { community can demand the } \\
\text { flamingo's removal or col- } \\
\text { lect a flamingo tax; } \\
\text { community can demand } \\
\text { landscaping or collect a tax } \\
\text { for failure to landscape }\end{array}$ \\
\hline
\end{tabular}

In the next section, I will discuss Rules 1 and 3, entitlements protected by property rules. These are entitlements that can only be transferred by mutual consent at a mutually agreeable price, and hence present one set of concerns. In section 3, I will take up liability rules (which can also be characterized as "call options") that enable unilateral transfers of an entitlement upon the payment of a specified fee or tax, and "put options" that offer parties a choice between keeping their entitlement or forcing the other party to buy it at a specified price.

2. Property Rule Options.--Rules 1 and 3 in Figure 10 represent two possible ways of handling a neighborhood's conflicts over ambience through entitlements protected by property rules. In Rule 1, the community holds the entitlement for flamingo display, and this entitlement is protected 
by a property rule. This means that the community can enjoin flamingo placement in front yards. The individual who wishes to place flamingos in her front yard must buy the right from the community at a price satisfactory to the community, and the community can refuse to accept any and all offers. Rule 1 could also be applied to an affirmative obligation like landscaping. If the community holds an entitlement to landscaping protected by a property rule, it could force the individual to landscape her yard. Under Rule 1, the community would be entitled not just to damages if the individual failed to landscape, but to specific performance.

Under Rule 3, the individual holds the entitlement to control flamingo display and may place flamingos in her yard if she pleases. If the community, or any members within it, want her to remove the flamingo (or if they want to prevent flamingo placement in advance) they must purchase the individual's flamingo placement entitlement at a price she finds satisfactory, and the individual can refuse to sell her flamingo privileges at any price if she so chooses. Likewise, the individual controls her own landscaping entitlement, and can landscape or not, as she chooses. If the community, or any members within it, want her to landscape (or want to make sure in advance that she can never stop landscaping) they would have to buy the individual's entitlement over her own landscaping at a price she finds satisfactory, and she can refuse to sell at any price.

Although private developments governed by restrictive covenants and areas zoned for historical preservation represent a growing class of exceptions, in most places the homeowner retains control over a significant set of draws from, and contributions to, neighborhood ambience. Thus, most neighborhoods in the United States represent Rule 3 regimes: People have an entitlement to put objects of their own choosing, such as plastic flamingos, in their front yards, and that entitlement is protected by a property rule. They cannot be compelled to give it up unless offered a price acceptable to them. The Rule 3 regime potentially represents a tragedy of the commons. Because people do not internalize the full cost associated with yard art, but do internalize the full benefit, they are likely to do too much of it from an allocative efficiency standpoint. In other words, they will be tempted to "overgraze" the visual or aesthetic field.

One possible response would be to shift to a Rule 1 world in which flamingos are banned. The shift itself would be very costly to achieve without a coordinated mechanism for bringing it about; it would require every member of the community to relinquish his or her own flamingoplacing privileges to every other member of the community, while simultaneously gaining rights over the flamingo placement of each other member. This would require hundreds or thousands of separate covenants. ${ }^{258}$ How-

258 See Richard A. Epstein, Covenants and Constitutions, 73 CORNELL L. REV. 906, 914-15 (1988) (observing that 4,950 pairwise covenants would be required in a 100-person community if it were not possible to handle covenants through a central party such as a developer). 
ever, homeowners in private communities can overcome this coordination problem by entering into covenants through the central figure of the developer. ${ }^{259}$ Each homebuyer automatically binds herself to each other neighbor and automatically receives the benefit of covenants with each other neighbor when she enters the community. Thus, a Rule 1 world (flamingos forbidden) can be readily established through the use of covenants. ${ }^{260}$

A Rule 1 regime avoids the tragedy of the commons just described, but introduces two new concerns. First, a collective action problem may arise around the enforcement of the community's entitlement. However, if the community can devise a collective enforcement mechanism (such as the managing board of a homeowners association), this problem can be obviated. ${ }^{261}$ Second, the flamingo ban may stop efficient flamingo placement. For example, it is possible that some people enjoy putting art in their yards to such a great degree that the benefits they enjoy as a result outweigh the associated costs, including those imposed on other members of the community. ${ }^{262}$ If so, that person will face an anticommons situation in attempting to gain permission to place her flamingo.

For example, consider Bella, who values flamingo placement at $\$ 700$, where the costs imposed on the entire community are only $\$ 500$. In a world free of transaction costs, ${ }^{263}$ she could buy her way out of the restriction. In the real world, however, things are more difficult. Bella could, for example, attempt to assemble permission from each and every neighbor in order to display her flamingo in violation of the ban. ${ }^{264}$ Given the surplus to be had, everyone is better off if she is successful in obtaining permission to place the flamingo. Moreover, let us assume that the community has an excellent online communication system to which every member is linked electronically in real-time, reducing nearly to zero the mundane costs of communicating and negotiating over entitlements. So far, the picture seems promising.

259 See id.

260 Although this is a very convenient way of establishing a massive network of reciprocally binding covenants, it also means that homebuyers do not consider covenants separately, but rather accept them as part of a bundled deal that includes a home on a particular parcel of land in a particular location. For a discussion of this point, as well as other potential disconnects between homebuyer choices in private communities and the maximization of value for those homebuyers, see Fennell, supra note 227.

261 Collection of uniform dues for purposes of undertaking enforcement will, however, introduce potential mismatches between individual valuations of the enforcement and the amount that each individual is required to pay.

${ }^{262}$ See supra Part II.B.1 (discussing possibility that activities with externalities may nevertheless be efficient).

263 This sort of world is often described as Coasean, although Coase himself recognized, and emphasized, that the real world features large transaction costs. See generally Ellickson, supra note 209.

264 If the ban were implemented through reciprocally binding covenants, then this would involve negotiating a release with each of her neighbors; a single holdout neighbor could block the deal and obtain injunctive relief against the breach of the covenant. See, e.g., Rick v. West, 228 N.Y.S.2d 195 (N.Y. App. Div. 1962) (refusing to override the interests of a single landowner who would not release nearby land from covenant restrictions that benefited her). 
However, conflict over the division of the surplus is likely to thwart Bella's quest to collect the necessary permissions. Even if Bella is prepared to pay $\$ 699$ to the other community members (she is willing to "swerve" in advance in the game of Chicken by gleaning only a $\$ 1$ surplus), the "community" is not a single person but rather an amalgamation of different interests. How should the remaining surplus be divided? An even division is unlikely to be satisfactory. Consider the case of Sneed. Not only does he find that the sight of flamingos interferes with his digestion, but his breakfast nook looks directly onto Bella's proposed flamingo placement site. Sneed is likely to have a reservation price that is quite high. Bella would be willing to pay Sneed's true valuation, as well as the true valuations of the other community members, so highly does she value her flamingo entitlement. Yet, other members of the community, seeing the price that Sneed is asking for his grant of flamingo permission, will be inclined to ask for similar amounts. Further, given the nature of subjective valuations, it is impossible for anyone to tell whether a given neighbor really has the reservation price of a Sneed, or is just pretending to have such a price. The result may well be that Bella cannot gain the privilege to place her flamingo. ${ }^{265}$ Hence, in attempting to address a tragedy of the commons associated with "overgrazing" of neighborhood ambience, the community has created an aesthetic anticommons into which even efficient incursions are impossible. ${ }^{266}$

The Rule 1 solution to the commons tragedy risks the creation of an anticommons tragedy by precluding efficient draws against neighborhood ambience. Because Rule 1 gives each person in the community the right to set her own price for putting up with Bella's flamingo, it protects people with unusually high subjective valuations. ${ }^{267}$ But the protection that it provides for people with genuinely high valuations also provides protective cover for people without abnormally high valuations, who are merely interested in capturing a larger surplus from the sale. This presents the wellknown difficulty of telling people with genuinely high valuations from those strategically holding out in the hopes of a better deal.

265 Can the community solve this problem by appointing a representative or body to deal with entitlement transactions, instead of leaving matters to be handled neighbor by neighbor? This is certainly possible, but one of two things will be true of any effort to solve the problem in this way. Either the representative or body will be empowered to make decisions on less than unanimous consent, in which case some interests will be overridden against individuals' wills, or the representative or body will be permitted to act only after gaining the unanimous consent of the group, in which case the problems already detailed will likely hamper transactions. See JAMES M. BuCHANAN \& GORDON Tullock, ThE CALCUluS of CONSENT: LOGICAL Foundations of CONSTITUTIONAL DEMOCRACY 65-73 (Liberty Fund 1999) (1962) (describing the tradeoffs between easier decisionmaking and protection of oneself from adverse decisions in choosing the level of consensus required for a decision).

${ }^{266}$ For application of the anticommons notion to covenants in common interest communities, see Heller, supra note 218 , at 1185.

267 See Ellickson, supra note 214, at 736 n.192 (observing that "[b]argaining permits subjective, idiosyncratic assessments of value"). 
However, it is important to recognize that a similar set of problems may exist even if the community were to adopt (or keep) Rule 3, in which individuals hold entitlements over flamingo use. Consider now the case of Nora. Nora highly values an environment free of yard art; indeed, she values that environment more than the aggregate amount of value that all of her neighbors derive from their various lawn items. She would like to have an entitlement to keep any yard art from assaulting her eyes when she is in her neighborhood, but under Rule 3 there is no single person from whom she can purchase that entitlement. Instead, the right to control yard art in Nora's visual field is presently fragmented among all of the neighbors within viewing distance of her home. The difficulties that Nora will face in obtaining the efficient result - a consolidation of the yard art rights in her own name-is similar conceptually to the anticommons problem faced by a person who must secure permission from everyone in the neighborhood before placing art in her own yard.

However, there are differences between the anticommons situations potentially faced by Bella and Nora that become apparent when we compare the production functions associated with the surplus available in the two cases. ${ }^{268}$ Nora may greatly value a flamingo-free neighborhood, but it is still likely that she derives some benefit from flamingo reduction, even if she is unable to accomplish complete flamingo eradication. In other words, the production function for the surplus she will glean from buying up flamingo entitlements probably does not look like Figure 5; it more likely resembles the s-curve shown in Figure 6, or some other curve in which significant surplus is available short of assembling all of the entitlements. In contrast, a person who desires to put a flamingo in the yard but is forbidden from doing so until she obtains permission from every neighbor (or a community acting on behalf of all neighbors) faces a situation more like the one shown in Figure 5, in which the surplus is a step good that requires assembly of all the entitlements.

Nora's anticommons problem looks easier to solve than Bella's, but this does not decide matters on its own. We still must consider the impacts of the various rules on the community members who have more run-of-themill preferences. A Rule 3 world allows not only Bella's (efficient) flamingo, but also the many flamingos that generate net social costs. We can learn something about the costs of allowing these inefficient flamingos by examining the shape of the production function of harm generated by them.

\footnotetext{
268 In theory, Bella and Nora could not logically coexist in the same community. If one person (such as Bella) so highly values flamingo placement that she could pay everyone else off and still come out ahead, there is by definition no person (such as Nora) in the community who so hates flamingos that she could pay off everyone to not place them and still come out ahead. However, it will often be unclear in setting entitlements whether a Bella or a Nora exists, and the possibility that a community member will acquire the preferences of either a Bella or a Nora over time complicates matters. In addition, the original assignment of entitlements may have wealth or cognitive impacts of its own that will determine whether a person with Nora's or Bella's preferences exists in the resulting regime.
} 
In this case, the harms are probably self-limiting; after a time, more flamingos stop hurting the community much, just as was the case with annoying noise in Figure 9. In other settings, inefficient behavior continues to escalate to a crisis point at which the resource is wholly destroyed, as was the hypothetical fishery shown in Figure 8. In the latter setting, the Rule 3 regime is not workable at all, and the Rule 1 regime, although still quite imperfect, represents some improvement.

Figure 11 summarizes the differences between Rules 1 and 3 in the neighborhood context, noting the potential for Prisoner's Dilemma (PD) and Chicken Game (CG) problems under each rule. We must consider the costs associated with strategic dilemmas created by the original assignment of the entitlement (which will be suffered if transfer cannot occur), as well as those that would be encountered in attempting to transfer the entitlement (which will determine whether transfer is likely to occur). In addition, to the extent a successful switch occurs from Rule 1 to Rule 3, or vice versa, it will potentially bring in its wake the problems associated with that rule. ${ }^{269}$ As noted above, some of these strategic problems could be ameliorated if a centralized figure, such as a homeowners' association or developer, coordinated a response to the problem.

Figure 11: Property Rule Options

\begin{tabular}{|l|l|l|l|l|}
\hline RULE & $\begin{array}{l}\text { ENTITLEMENT } \\
\text { HELD BY }\end{array}$ & EXAMPLES & $\begin{array}{l}\text { DILEMMA AS } \\
\text { ASSIGNED? } \\
\text { (TYPE OF } \\
\text { PROBLEM) }\end{array}$ & $\begin{array}{l}\text { DILEMMA IN } \\
\text { TRANSFERING? } \\
\text { (SHAPE OF } \\
\text { SURPLUS) }\end{array}$ \\
\hline 1 & Community & $\begin{array}{l}\text { flamingos are } \\
\text { forbidden; } \\
\text { landscaping } \\
\text { is required }\end{array}$ & $\begin{array}{l}\text { PD or CG } \\
\text { (underenforce- } \\
\text { ment) }\end{array}$ & $\begin{array}{l}\text { CG } \\
\text { (step) }\end{array}$ \\
\hline 3 & Individual & $\begin{array}{l}\text { flamingos are } \\
\text { permitted; } \\
\text { landscaping } \\
\text { is optional }\end{array}$ & $\begin{array}{l}\text { PD } \\
\text { (too many } \\
\text { flamingos; too } \\
\text { little landscap- } \\
\text { ing) }\end{array}$ & $\begin{array}{l}\text { CG } \\
\text { (non-step) }\end{array}$ \\
\hline
\end{tabular}

3. "Calls" and "Puts".-Of course, the community is not limited to property rule solutions. Liability rules can operate to appropriately "reprice" the use, taking into account external impacts. ${ }^{270}$ Entitlements vested

269 The fact that a transfer has occurred suggests that the entitlement lies with the party who values it most highly, at least at the time of transfer, so that the problems associated with further transfers would seem unimportant. But preferences can change over time, leading to new inefficiencies.

270 This approach is known as Pigouvian, after its pioneer, Arthur Pigou. See PIGOU, supra note 45, 
in one party and protected by a liability rule (Rules 2 and 4) effectively grant the other party a "call option" to unilaterally buy the entitlement at a specified price. ${ }^{271}$ A famous case law example of Rule 2 is Boomer v. Atlantic Cement Co. ${ }^{272}$ where the court held that the cement plant could continue to pollute (that is, it could obtain the entitlement over the air) by paying "permanent damages"- a court-determined amount- to the parties injured by the pollution. ${ }^{273} \mathrm{~A}$ call option can work in the opposite direction as well; the polluter might be given the entitlement to continue polluting, but the victim might be given an option to buy up that pollution right at a specified price. A close case law analog is Spur Industries v. Del E. $W e b b .{ }^{274}$ In that case, a developer who had constructed and sold residences uncomfortably close to a cattle feedlot was able to secure an injunction against the continued operation of the feedlot, but at the price of covering the cost of the feedlot's relocation. ${ }^{275}$ A regulatory regime that grants authorities the power to "buy back" fishing rights from fishers at a specified price constitutes another example of this rule. ${ }^{276}$

at 159-62, 168-70 (suggesting that "divergences between private and social net product" might be removed by the State through taxes or bounties). While Coase showed that such a system of public intervention into prices through the tax system was not necessary to achieve efficient results in the absence of transaction costs, Ronald H. Coase, The Problem of Social Cost, 3 J.L. \& ECON. 1 (1960), it remains a potentially useful option where transaction costs are positive- which of course, they always are.

271 See, e.g., Ayres \& Talley, supra note 17, at 1041 \& n.49 (observing that under a liability rule, the defendant holds a call option); Morris, supra note 17, at 852-54 (discussing liability rules as call options); Carol M. Rose, The Shadow of the Cathedral, 106 YALE L.J. 2175, 2178-79 (1997) (observing that a liability rule is the equivalent of a property rule combined with an option).

272257 N.E.2d 870 (N.Y. 1970).

273 Id. at 875.

274494 P.2d 700 (Ariz. 1972).

275 Id. at 707-08. It is not entirely clear that the developer, Del E. Webb, actually had an option to permit the pollution to continue, if the losses it caused him were less than the price of moving the feedlot. The court noted that this was a public nuisance affecting many individuals who were not parties to the lawsuit (i.e., the homeowners); hence, it does not appear that the feedlot could have continued its operations in such close proximity to housing in any event. See DUKEMINIER \& KRIER 5TH, supra note 6, at 776 (discussing this question); Krier \& Schwab, supra note 17, at 445 n.23 (observing that "the court's judgment implies that Del Webb must pay and that Spur Industries must move"). But see id. at 470 (suggesting that "[d] espite such an ultimatum, however, Spur Industries and Del Webb would presumably remain free to bargain after the liability-rule judgment was entered, just as they would have been free to do so after a property-rule judgment"). In any event, the remedy was a highly unusual one. See Douglas Laycock, Modern American Remedies: CASes And Materials 409-10 (3d ed. 2002) (discussing the Spur case and observing that the remedy it provided "appears to be unique, both unprecedented and never repeated").

276 See John L. McMullan \& David C. Perrier, Lobster Poaching and the Ironies of Law Enforcement, 36 LAW \& SoC. REV. 679, 685 (2002) (explaining that the regulatory regime governing lobster fishing in Nova Scotia included a proviso entitling the government to "buy back boats and to retire licenses" when a Class A licensed boat stopped lobster fishing) (citing A. SCOTT \& M. TUGWELL, PUBLIC REgulation of COMMERCIAL Fisheries IN CANADA-THE MARITIME LOBSTER Fishery (Economic Council of Canada, Technical Report No. 16, 1981)). 
Conversely, it is possible to vest in the same party both the entitlement itself and the option to make the other party buy the entitlement at a specified price (Rules 5 and 6). In both cases, the party holding the entitlement also holds a "put" option to force its sale at an established price. ${ }^{277}$ For example, a party harmed by another party's conduct can choose to stop the harmful conduct or to receive court-calculated damages in exchange for continuing to suffer from it. This was precisely the choice offered to the plaintiff in Pile v. Pedrick, ${ }^{278}$ a case involving a minute encroachment of a wall upon the land of another. Alternately, the party causing the harmful conduct could be given a "put" option. Under such a rule, a party like Spur (the feedlot operator) would be given a choice between continuing its operation unimpeded or accepting a judicially determined amount of money in exchange for moving away. Retirement incentive options offered to employees are a close analog if offered in situations where employees' continued employment generates costs for the organization, but the employees hold entitlements to stay on the job. ${ }^{279}$ Subsidies for behavior that produces positive externalities (or that reduces negative externalities) represent familiar incarnations of this entitlement regime. ${ }^{280}$

Figure 10 illustrates all four of these options (Rules 2, 4, 5, and 6) in the context of neighborhood aesthetics. All of these options permit unilateral transfers of entitlements, and hence avoid the anticommons or holdout problems often associated with property rule protection. If the exercise prices are set accurately, they also solve the tragedy of the commons problem by making each individual's personal payoff match up to the social payoff of her behavior. But setting the prices accurately will be difficult, especially if the community is heterogeneous and the impact of each successive draw or contribution is not uniform. Because the transfers can oc-

277 See Ian Ayres, Protecting Property with Puts, 32 VAL. U. L. REV. 793 (1998); Krier \& Schwab, supra note 17; Morris, supra note 17, at 854-56. A "put" can also be understood as a type of liability rule, because it permits a unilateral entitlement transfer. See Ayres \& Goldbart, supra note 17, at 6. However, the term "liability rule" has been traditionally associated with call options rather than puts, and I will retain that usage here.

27831 A. 646 (Pa. 1895); see Ayres, supra note 277, at 815-16. The plaintiff in Pile elected injunctive relief that required the defendant to tear down a wall in order to rectify a tiny incursion into the plaintiff's property. A possible concern is that spite might cause a party holding a "put" to choose the option most harmful to the other party, rather than the one most beneficial to the choosing party. Insistence upon injunctive relief could also constitute a bluff, a prelude to further negotiations in which the plaintiff hopes to capture a larger amount of damages than the court originally specified. See Ian Ayres \& Kristin Madison, Threatening Inefficient Performance of Injunctions and Contracts, 148 U. PA. L. REV. 45, 49-50 (1999) (noting that plaintiffs like the one in Pile would have an incentive to choose injunctive relief to enhance their bargaining position, when the damages expected from the court are significantly lower than the costs the injunction would inflict on the defendant).

279 See Samuel Issacharoff \& Erin Worth Harris, Is Age Discrimination Really Age Discrimination?: The ADEA's Unnatural Solution, 72 N.Y.U. L. REV. 780, 814-15 \& n.176 (1997) (describing the use of retirement incentive plans to remove costly older workers from the workforce).

280 See, e.g., Morris, supra note 17, at 854-55 (providing example of the St. Louis police department's gun buy-out program, which provided payment on a "no questions asked" basis for each gun turned in). 
cur over the objections of the other party to the transaction, the person exercising the option need only take account of the exercise price, not the other parties' true reservation prices. If we cannot tell how much the parties are really harmed or benefited by the exercise of an option, the possibility arises that a tax or subsidy may be either insufficient or excessive relative to the impact of the option's exercise on the other parties. In either case, the tax or subsidy replaces one set of flawed "prices" with another.

The results of these pricing flaws echo the commons and anticommons problems already discussed. Suppose a community adopts a flamingo tax (Rule 2). If the tax is set too low (for example, $\$ 100$ when the true social impact is $\$ 500$ ), then we can expect the same basic tendency towards overgrazing that existed in a Rule 3 world where flamingo placement was free. This is a standard commons dilemma. Of course, the tax reduces the divergence between personal payoffs and social payoffs and in that way improves matters over a Rule 3 regime. Another possibility is that someone in the community (such as hypersensitive Nora) values a flamingo-free environment highly enough that it would be efficient for her to buy up everyone's "call options" to engage in flamingo placement. Her effort to buy up those call options presents the same kind of anticommons situation described earlier. Of course, the existence of the tax reduces the value of the call option to the individuals, and also acts as a check on any tendency to strategically place flamingos in an effort to annoy Nora into buying up their rights at higher prices.

If the tax is set too high (say, $\$ 800$ when the true social cost is $\$ 500$ ) then an echo of the anticommons is produced: Some efficient incursions into the aesthetic space of the neighborhood may be blocked. Recall Bella, who values flamingo placement at $\$ 700$, an amount higher than the true social harm $(\$ 500)$ but lower than the tax. She could attempt to assemble permission from everyone in the community to proceed with flamingo placement without paying the tax, and in theory she should be able to do this at a price somewhere between $\$ 500$ and $\$ 700$. However, familiar holdout difficulties, as well as mundane transactions costs, render this result unlikely.

If setting the tax precisely is impossible, should the community err on the side of making it too high or setting it too low? Again, it is helpful to consult the production functions involved and consider the strategic interactions likely to follow from particular kinds of errors. We can see that the anticommons problem faced by Nora is easier to solve than the one faced by Bella, which has a step-level shape. This might seem to argue for setting the tax low. However, we must also examine the costs associated with the inefficient behaviors that a low tax would permit. If we imagine that we are within a range where each additional increment of activity causes increasing marginal harms, then a too-low tax may have quite bad consequences. Comparing the stakes associated with errors in different directions, the shape of the production functions involved, and the prospects for correcting errors through further trade yields insights into the advantages and disadvantages of different entitlement regimes. 
4. Some Qualifications. - There are many considerations that affect the choice of how entitlements should be assigned and protected, including the interplay of cognitive factors and wealth effects with entitlement choices ${ }^{281}$ the impact of entitlement regimes on preexisting and evolving norms, ${ }^{282}$ and the costs of administering the system. ${ }^{283}$ Common resource settings also present special considerations that are obscured in the usual "injurer-victim" examples that dominate the entitlement literature, ${ }^{284}$ and these considerations must be taken explicitly into account in choosing entitlement regimes. ${ }^{285}$

The example I have developed here sheds light on only one corner of the overall question of appropriate entitlement assignment and protection in a commons. However, it is a quite important corner, and the light that the analysis sheds demonstrates the payoff of this Article's taxonomy of common interest tragedies. That taxonomy prompts us to focus on the strategic dilemmas that various legal rules trigger and resolve, and to recognize the size and shape of the harms potentially associated with those dilemmas. Doing these things can ease the decisionmaking task and spur innovation in designing entitlement solutions.

281 See, e.g., Herbert Hovenkamp, Rationality in Law and Economics, 60 GEO. WASH. L. REV. 293, 305-06 (1992) (discussing the impact of wealth effects and the endowment effect on outcomes and efficiency); Christine Jolls et al., A Behavioral Approach to Law and Economics, 50 STAN. L. REV. 1471 (1998) (discussing experimental results showing endowment effects and other factors that affect the trading of entitlements); Stewart Schwab, Coase Defends Coase: Why Lawyers Listen and Economists Do Not, 87 MiCH. L. REV. 1171, 1178 (1989) (discussing the implications of wealth effects associated with assignment of legal entitlements).

282 See, e.g., Fennell, supra note 227 (discussing ways in which covenants and enforcement regimes might interact with the development and deployment of norms in private communities); Paula A. Franzese, Does It Take a Village? Privatization, Patterns of Restrictiveness and the Demise of Community, 47 VILL. L. REV. 553 (2002) (discussing the potential of private covenant arrangements within common interest communities to erode social capital); Krier \& Schwab, supra note 17, at 464 (suggesting that a legal regime that does not intervene to overcome bargaining difficulties is more likely to lead to better bargaining, over the long run, as the parties learn how to reduce transaction costs); Michelman, supra note 1, at 34 (recognizing the possibility that "particular private property arrangements sanction and reinforce trustlessness").

283 See, e.g., Kaplow \& Shavell, supra note 17, at 741-43 (comparing the administrative costs of property rules and liability rules).

284 See Krier \& Schwab, supra note 17, at 442, 479 (introducing stock example that pits a polluting factory against a resident and observing a relative lack of application of these ideas to questions of collective action).

285 For example, in a commons, group members are prospective injurers and victims at the same time. Although heterogeneity among group members complicates the picture, the overlap between the restrainers and the restrained has important implications for designing entitlement solutions. See Jennifer H. Arlen, Reconsidering Efficient Tort Rules for Personal Injury: The Case of Single-Activity Accidents, 32 WM. \& MARY L. REV. 41 (1990) (presenting a bilateral account of tort risks, in which individuals are simultaneously potential victims and potential injurers, and explaining how it yields results that differ from those produced by a conventional unilateral risk model that assumes each person is either a victim or an injurer). 


\section{CONCLUSION}

Common interest tragedies are enormously important and tremendously difficult to solve. A better classification system and streamlined vocabulary for discussing these problems cannot substitute for the painstaking, context-specific work of fashioning workable solutions to each resource-allocation problem as it exists in situated reality. ${ }^{286}$ Yet this difficult and important work is made lighter by a theoretical framework that lays bare, rather than obscures, the specific strategic tendencies likely to stand in the way of efficient solutions. This is particularly true in modern urban settings where law will, of necessity, play a central role in ordering the relationships between people with respect to resources.

The anticommons literature, despite having come a phenomenal distance in a very short time, is still evolving. I hope that this Article will help advance that literature by showing the anticommons tragedies' structural connections to the more familiar commons problems and to basic strategic templates. The schema that I have developed here should be viewed as a provisional one that takes its place in an ongoing dialogue about how best to think about this crucial set of problems. If this Article generates further interest in this important area, it will have fulfilled its purpose.

286 See, e.g., FREYFOGLE, supra note 27, at 163 (noting the complexity of land and suggesting that we might usefully turn for assistance to scientists who have long investigated "the land's mechanisms of production"). 